\title{
Stereospecific Olefin Polymerization with Chiral Metallocene Catalysts
}

\author{
Hans H. Brintzinger, * David Fischer, Rolf Mülhaupt, Bernhard Rieger, \\ and Robert M. Waymouth
}

Dedicated to all those excellent graduate students who are the true heroes of this story

\begin{abstract}
Current studies on novel, metallocenebased catalysts for the polymerization of $\alpha$-olefins have far-reaching implications for the development of new materials as well as for the understanding of basic reaction mechanisms responsible for the growth of a polymer chain at a catalyst center and the control of its stereoregularity. In contrast to heterogeneous Ziegler-Natta catalysts, polymerization by a homogeneous, metallocene-based catalyst occurs principally at a single
\end{abstract}

type of metal center with a defined coordination environment. This makes it possible to correlate metallocene structures with polymer properties such as molecular weight, stereochemical microstructure, crystallization behavior, and mechanical properties. Homogeneous catalyst systems now afford efficient control of regio- and stereoregularities, molecular weights and molecular weight distributions, and comonomer incorporation. By providing a means for the homo- and copolymerization of cyclic olefins, the cyclopolymerization of dienes, and access even to functionalized polyolefins, these catalysts greatly expand the range and versatility of technically feasible types of polyolefin materials.

Keywords: alkenes - catalysis - metallocenes $\cdot$ polymerizations

\section{Introduction}

Forty years after Karl Ziegler's invention of transition metal catalyzed polyinsertion and Giulio Natta's discovery of the stereoselective polymerization of $\alpha$-olefins, ${ }^{[1-4]}$ we are witnessing the evolution of new generations of catalysts and polyolefin materials, which originate from studies on homogeneous, metallocene-based polymerization catalysts. In the following, we will attempt to review some of these recent developments. ${ }^{[5-7]}$

Research on metallocene-catalyzed olefin polymerization has derived much of its impetus from the desire to model the reaction mechanisms of heterogeneous polymerization catalysts. In the evolution of Ziegler-Natta catalysis, an empirical approach has proven highly successful. Modern $\mathrm{MgCl}_{2}$-supported catalysts have tremendous activities for the production of polypropene and other polyolefins; at the same time, they are

${ }^{*}$ ] Prof. Dr. H. H. Brintzinger

Fakultät für Chemie der Universität

D-78434 Konstanz (Germany)

Telefax: Int. code + (7531) 883137

Dr. D. Fischer

BASF AG, Abteilung ZKP

Ludwigshaten (Germany)

Prof. Dr. R. Mülhaupt

Institut für Makromolekulare Chemie der Universität Freiburg (Germany)

Dr. B. Rieger

Institut für Anorganische Chemie der Universität Tübingen (Germany)

Prof. Dr. R. M. Waymouth

Department of Chemistry, Stanford University (USA)
Sawhorse projection:

Modified Fischer projection:
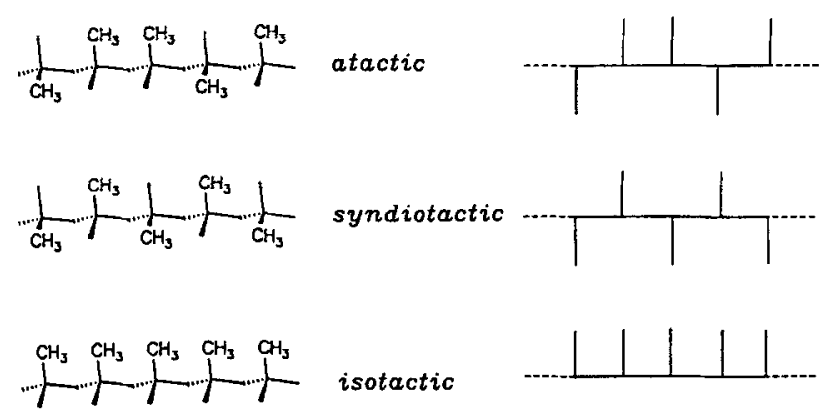

Conformation of chains in crystalline isotactic polypropene:
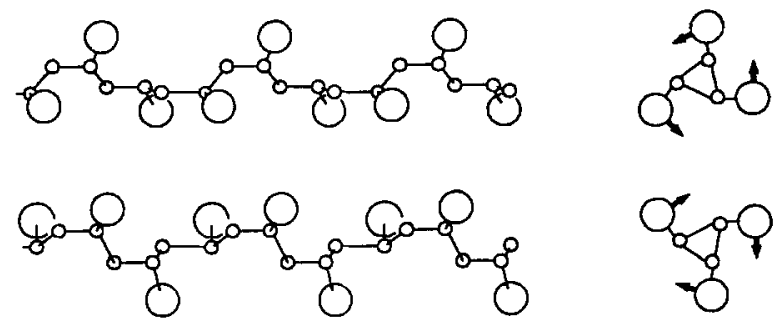

Scheme 1. Structure of isotactic, syndiotactic, and atactic polypropene in sawhorse and modified Fischer projections [107] (top), and conformation of the chains in crystaltine isotactic polypropene, determined by Natta and Corradini [2] (bottom). 
highly stereoselective, forming practically only the isotactic, most useful stereoisomer of the polymer ${ }^{[8]}$ (Scheme 1). Still unsatisfactory, however, is our understanding of the reaction mechanisms that are the basis of this advanced catalyst technology. Plausible hypotheses concerning these mechanisms have certainly been advanced, most notably Cossee's model of polymer chain growth by cis-insertion of $\alpha$-olefins into a $\mathrm{Ti}-\mathrm{C}$ bond on the surface of crystalline $\mathrm{TiCl}_{3} \cdot{ }^{[9,10]}$ Based on Natta's early ideas about the role of chiral surface sites in the formation of isotactic polyolefins, ${ }^{[6,11]}$ very adequate models were proposed to explain the induction of stereoregular polymer growth by the chiral environment of the catalyst centers $\left.{ }^{[9 b}, 12\right]$ (Scheme 2).
The relationship between the properties of a particular catalyst and the coordination geometry of its reaction centers, however, leaves many questions open, ${ }^{[8 \mathrm{~g}, \mathrm{~h}]}$ due to the notorious nonuniformity of active sites in these heterogeneous catalysts and the limited experimental access to their structural details. In a review written in 1980, Pino and Mülhaupt summarized this shortcoming: ${ }^{[4 \mathrm{~b}]}$ "Up to now, there is no direct proof for the structures proposed; most of them are the result of speculations or derived from indirect experimental indications."

In this situation, related developments in other fields of catalysis nourished the hope that homogeneous organometallic catalysts capable of stereoselective olefin polymerization might eventually allow more direct observations on the catalyst species

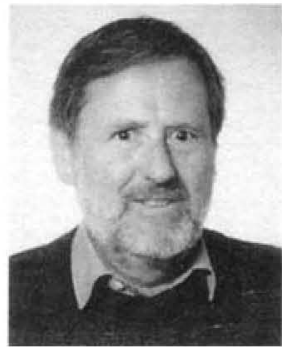

H.-H, Brintzinger

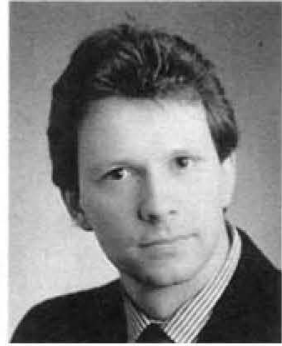

D. Fischer

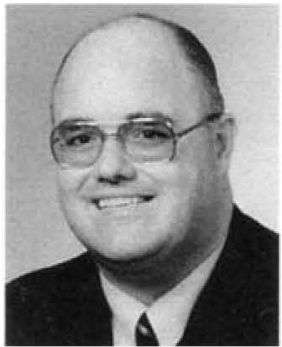

R. Mülhaupt

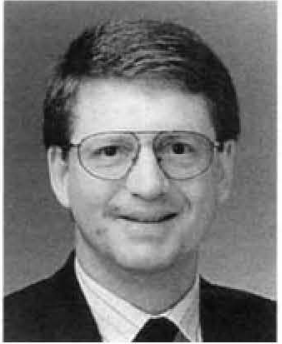

B. Rieger

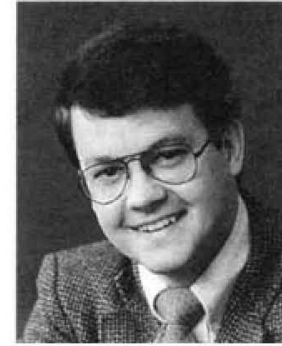

R. M. Waymouth

Hans-Herbert Brintzinger, born in Jena, Germany, in 1935, studied chemistry in Basel, where he received his Ph.D. in 1960 with Hans Erlenmeyer and his Habilitation in 1964. After teaching chemistry at the University of Michigan for several years, he moved to the University of Constance in 1972, where he holds a professorship for General Chemistry and Coordination Chemistry. His fields of interest are organometallic chemistry and reaction mechanisms in homogeneous catalysis.

David Fischer, born 1963 in Cologne, Germany, studied chemistry at the University of Cologne. After earning his diploma in physical chemistry, he joined Rolf Mülhaupt's group at the University of Freiburg as a graduate student. He received his Ph.D. in 1992 for studies on propene polymerization with homogeneous zirconocene catalysts. After a postdoctoral period with Robert Waymouth at Stanford, he joined the plastics laboratory of BASF AG in 1993, where he is still working on stereospecific propene polymerization with metallocene catalysts.

Rolf Mülhaupt was born in Waldshut-Tiengen, Germany, in 1954. From 1973 to 1978 he studied chemistry in Freiburg; he received his Ph.D. in 1981 with Professor Pino at the Laboratory for Technical Chemistry at the ETH in Zürich. Following industrial research positions at the Central Research and Development Experimental Station of Dupont in Wilmington, Delaware, from 1981 to 1985 and at Ciby-Geigy AG in Marly, Switzerland, from 1985 to 1989, he was appointed professor of Macromolecular Chemistry at the University of Freiburg in 1989. Since 1992 he has been director of the Material Research Center in Freiburg. His research interests include, besides transition metal catalyzed polymerization, new polymer structural materials, material compounds, dispersions and specialty polymers.

Bernhard Rieger was born in Augsburg, Germany, in 1959. He studied chemistry at the University of Munich and received his Ph.D. in 1988 for studies on enantioselective hydrogenations with rhodium-phosphane catalysts. After research appointments at the Institute for Polymer Science and Engineering of the University of Massachuset ts at Amherst and in the plastics laboratory of $B A S F A G$, he received his Habilitation in 1995 at the University of Tübingen, where he presently holds a faculty position in chemistry.

Robert M. Waymouth was born in Warner Robins, Georgia (USA), in 1960. He received bachelor's degrees in mathematics and chemistry at Washington and Lee University and his Ph.D. from California Institute of Technology in 1987, where he worked with Professor R. Grubbs. Following a year's postdoctoral appointment at the ETH in Switzerland with Professor Pino, he joined the faculty at Stanford in 1988, where he is now an Associate Professor of Chemistry. His research interests are in stereoselective catalysis. 


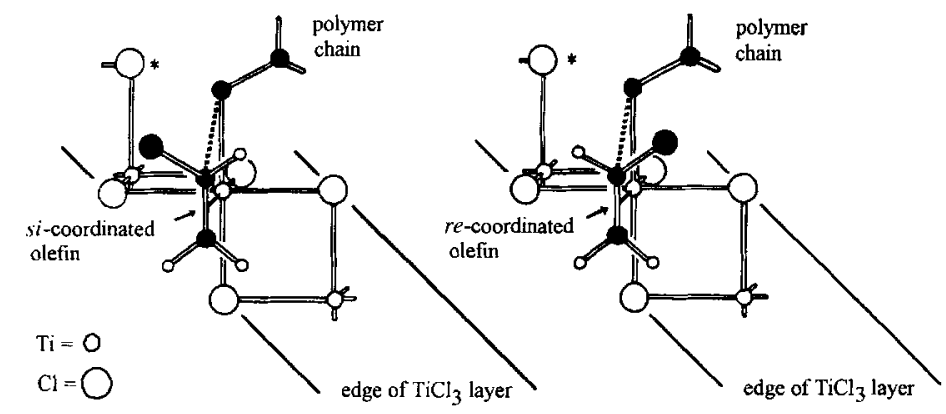

Scheme 2. Model for the stereospecific polymerization of propene at a chiral $\mathrm{Ti}$ center on the edge of a $\mathrm{TiCl}_{3}$ crystal, as proposed by Corradini and co-workers [12b]. The growing polymer chain occupies the open sector of the chiral coordination sphere: the olefin adopts that enantiofacial orientation which places the olefin substituent irans to the polymer chain at the incipient $\mathrm{C}-\mathrm{C}$ bond (left); a cis orientation of olefin substituent and polymer chain is disfavored (right).

involved and, hence, on the mechanisms of polymer growth and its stereochemical control. ${ }^{[13]}$ This sentiment was expressed, for example, by Boor in the concluding chapter of his book on Ziegler-Natta catalysts. ${ }^{[3 c]}$

Particularly attractive as model systems of this kind appeared alkylaluminum-activated metallocene complexes of the Group 4 transition metals, which have been known since 1955 to catalyze the polymerization of ethene $e^{[14,15]}$ and have since been the topic of many studies. The simple coordination geometry of Group 4 metallocene complexes-only two reactive, cispositioned ligand sites - promised opportunities for identifying and characterizing essential intermediates of homogeneous polymerization catalysts and providing more direct experimental verification for some of the hypotheses in the field of Ziegler-Natta catalysis.

\section{Activation of Metallocene Halides for $\alpha$-Olefin Polymerization}

In 1957, patents and publications by Breslow and Newburg ${ }^{[14]}$ at the Hercules Research Center and by Natta, Pino, and their co-workers ${ }^{[15]}$ reported that homogeneous reaction mixtures of dicyclopentadienyltitanium dichoride $\left(\mathrm{Cp}_{2} \mathrm{TiCl}_{2}\right)$ and diethylaluminum chloride $\left(\mathrm{Et}_{2} \mathrm{AlCl}\right)$ catalyze the formation of polyethene under conditions similar to those used with heterogeneous Ziegler catalysts. Numerous subsequent studies were aimed at the identification of reaction intermediates and reaction mechanisms of this homogeneous catalysis. The results obtained have been summarized previously; [4a, b, 16] $^{\text {some are }}$ particularly noteworthy in the context of the following discussion.

Formation of (alkyl)titanocene complexes $\mathrm{Cp}_{2} \mathrm{TiRCl}$ $(\mathrm{R}=\mathrm{Me}$ or $\mathrm{Et}$ ) by ligand exchange with the alkylaluminum cocatalyst, polarization of the $\mathrm{Cp}_{2} \mathrm{Ti}-\mathrm{Cl}$ bond by Lewis-acidic aluminum centers in an adduct of the type $C p_{2} \mathrm{Ti}(\mathrm{R})-$ $\mathrm{Cl} \cdot \mathrm{AlRCl}_{2}$, and insertion of the olefin into the $\mathrm{Cp}_{2} \mathrm{Ti}-\mathrm{R}$ bond of this (or some closely related) electron-deficient species, had been deduced by 1960 from spectroscopic, kinetic, and isotope labeling studies done at the Hercules laboratories by Breslow, Newburg, and Long and by Chien ${ }^{[17,18]}$ (Scheme 3). These ear-

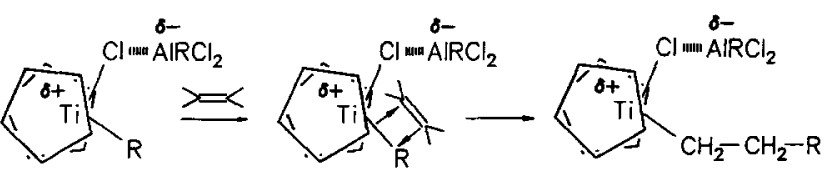

Scheme 3. Polymerization of ethene by cis-insertion into the Ti-C bond of an alkylaluminum halide activated titanocene complex, as proposed by Breslow, Newburg, and Long [17].

ly metallocene studies contributed to the ideas put forth by Cossee $^{[9 a]}$ with regard to the mechanisms of heterogeneous Ziegler-Natta catalysis.

\subsection{Metallocene Cations in the Polymerization of Ethene}

An interesting question remained unresolved by this early research: does olefin insertion occur in a bimetallic species, in which an alkyl group or a halogen bridges the titanium and aluminum centers, as advocated by Natta and his group, ${ }^{[19]}$ by Patat and Sinn, ${ }^{[20]}$ by Reichert and co-workers, ${ }^{[21]}$ and by Henrici-Olivé and Olivé? ${ }^{[2]}$ Or does it require the formation of a truly ionic species $\left[\mathrm{Cp}_{2} \mathrm{TiR}\right]^{+}$by abstraction of a halide anion and its incorporation into an anion $\mathrm{R}_{x} \mathrm{Cl}_{4-x} \mathrm{Al}^{-}$, as proposed by Shilov, Dyachkovskii, and Shilova $?^{[23]}$

Crystal structures of complexes that were occasionally isolated from reaction mixtures containing $\mathrm{Cp}_{2} \mathrm{TiCl}_{2}$ and an alkylaluminum chloride ${ }^{[24,25]}$ were not conclusive in this regard, as they represented degradation products, which require either reoxidation ${ }^{[17]}$ or renewed alkyl exchange with alkylaluminum cocatalysts ${ }^{[4 a]}$ for reactivation. In 1986, however, Jordan and co-workers isolated the tetraphenylborate salts of cations such as $\left[\mathrm{Cp}_{2} \mathrm{ZrCH}_{3} \cdot \mathrm{THF}\right]^{+}$and $\left[\mathrm{Cp}_{2} \mathrm{ZrCH}_{2} \mathrm{Ph} \cdot \mathrm{THF}\right]^{+}$and demonstrated their capability to polymerize ethene without addition of any activator ${ }^{[26]}$ These and related findings in the groups of Bochmann, ${ }^{[27]}$ Teuben, ${ }^{[28]}$ and Taube ${ }^{[29]}$ and by Hlatky and Turner at Exxon ${ }^{[30]}$ lent general credence to the proposal that (alkyl)metallocene cations are crucial intermediates in homogeneous polymerization catalysis.

A useful concept for the description of alkylaluminum-activated metallocene catalyst systems goes back to kinetic studies in Reichert's group. ${ }^{[1]}$ During the growth of a polymer chain, each metal-polymer species appears to alternate between a "dormant" state and a state in which it actively grows. This "intermittent-growth" model was further elaborated by Fink $^{[31]}$ and by Eisch ${ }^{[32]}$ and their co-workers in extensive kinetic and reactivity studies. Consecutive equilibria appear to convert alkylaluminum and (alkyl)metallocene halides first into Lewis acid-base adducts equivalent to inner (or contact) ion pairs and then into dissociated (or separated) ion pairs. In these highly dynamic equilibria, only the cation of a separated ion pair appears to be capable of interacting with an olefin substrate and, hence, of contributing to polymer growth. ${ }^{[3]}$ Contact ion pairs, which appear to dominate in these equilibria, can then be termed "dormant" in this regard ${ }^{[34,35]}$ (Scheme 4).

This model would explain the inability of metallocenes activated by alkylaluminum halides to catalyze the polymerization of propene and higher olefins ${ }^{[4 a, 36]}$ by the insufficient capability of the more weakly coordinating, substituted $\alpha$-olefins to form 


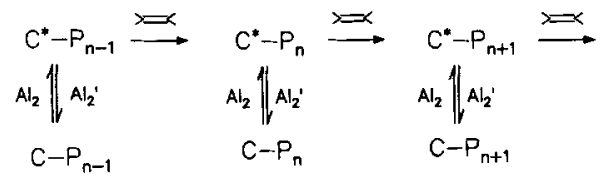

Scheme 4. "Intermittent-growth" model involving equilibria between polymerbearing, but inactive primary complexes $\left(C-P_{n}\right)$ and active catalyst species $\left(C^{*}-P_{n}\right)$, generated by excess alkylaluminum halide, as proposed by Fink and co-workers [31]. $\mathrm{Al}_{2}=\left(\mathrm{AlEtCl}_{2}\right)_{2}, \mathrm{Al}_{2}^{\prime}=$ unknown, $\mathrm{P}_{n}=$ polymer chain with $n$ monomer units; $\mathrm{C}-\mathrm{P}_{n}$ here $\mathrm{Cp}_{2} \mathrm{TiP}_{n} \mathrm{Cl} \cdots \mathrm{AlCl}_{2} \mathrm{Et}$.

reactive, olefin-separated ion pairs by displacement of an aluminate anion from the metal center. At any rate, the limitation of homogeneous catalyst systems to the polymerization of only ethene was a crucial obstacle for progress in this field for many years. Fortunately, this impediment was overcome by a series of serendipitous observations, ${ }^{[37-39]}$ which led, around 1980, to the discovery by Kaminsky, Sinn, and co-workers that metallocenes are activated for the catalytic polymerization of propene and higher olefins by methyl aluminoxanes. ${ }^{[4 a, 39]}$

\subsection{Polymerization of Propene and Higher Olefins}

Water, which had long been considered to be a "poison" for Ziegler-Natta catalysts, was first reported by Reichert and Meyer to cause a surprising increase in the rate of ethene polymerization by the catalyst system $\mathrm{Cp}_{2} \mathrm{TiEtCl} / \mathrm{AlEtCl}_{2} \cdot{ }^{[3]} \mathrm{Sub}-$ sequent studies by Long and Breslow on the effects of water in the otherwise inactive system $\mathrm{Cp}_{2} \mathrm{TiCl}_{2} / \mathrm{Me}_{2} \mathrm{AlCl}$ led to the notion that formation of a dimeric aluminoxane, $\mathrm{ClMeAl}-\mathrm{O}-\mathrm{Al}$ ClMe, by partial hydrolysis of $\mathrm{Me}_{2} \mathrm{AlCl}$ might generate an exceptionally strong Lewis acid and, hence, a potent activator for $\mathrm{Cp}_{2}$ TiMeCl toward ethene polymerization. ${ }^{[38]}$

While studying halogen-free systems such as $\mathrm{Cp}_{2} \mathrm{ZrMe}_{2} /$ $\mathrm{AlMe}_{3}$, Sinn and Kaminsky noticed that addition of water imparts to this otherwise inactive reaction system a surprisingly high activity for ethene polymerization which was, furthermore, unprecedentedly constant over extended reaction times. ${ }^{[39 a, b]}$ Sinn and Kaminsky observed that an interaction between $\mathrm{Cp}_{2} \mathrm{ZrMe}_{2}$ and $\mathrm{AlMe}_{3}$ occurred only when water had been added. The suspected formation of methyl aluminoxane (MAO) by partial hydrolysis of $\mathrm{AlMe}_{3}$ was subsequently supported by its direct synthesis and characterization as a mixture of oligomers of approximate composition (MeAlO) . Activation $^{2}$ of $\mathrm{Cp}_{2} \mathrm{ZrMe}_{2}$ and $\mathrm{Cp}_{2} \mathrm{ZrCl}_{2}$ with preformed $\mathrm{MAO}$ did indeed yield exceedingly active catalysts for the polymerization of ethene. ${ }^{[396]}$ Similar activities were obtained with $\mathrm{MAO}$-activated $\mathrm{Cp}_{2} \mathrm{TiCl}_{2}$; however, at temperatures above $0^{\circ} \mathrm{C}$ this catalyst system is rapidly deactivated, most likely by reduction to the Tilll stage. ${ }^{[40]}$

Sinn, Kaminsky, and co-workers noticed furthermore that MAO-activated homogeneous metallocene catalysts were-in contrast to previously studied metallocene catalysts activated by aluminum halides capable of polymerizing propene and higher olefins..$^{[4 a, 39 c-g]}$ Although the achiral metallocene catalysts were still lacking the stereoselectivity of heterogeneous Ziegler-Natta systems, aluminoxane-activated metallocene catalysts now came to be most promising as model systems.
While oligomeric alkyl aluminoxanes have been known for more than 30 years, for example as initiators for the polymerization of oxiranes, ${ }^{[41]}$ their exact composition and structure are still not entirely clear. When the hydrolysis of $\mathrm{AlMe}_{3}$, which is highly exothermic (and indeed potentially dangerous ${ }^{[39 j, 42 b]}$ ), is conducted under controlled conditions, it appears to generate mostly oligomers $\mathrm{Me}_{2} \mathrm{Al}-[\mathrm{O}-\mathrm{AlMe}]_{n}-\mathrm{OAlMe}_{2}$ with $n \approx 5-$ $20 .^{[39 j]}$

Investigations in quite a number of research groups by cryoscopy, UV, vibrational and NMR spectroscopy, chromatography, and other means ${ }^{[38,39 j, 42-50 \mathrm{c}]}$ yield the following picture for aluminoxane solutions. Residual $\mathrm{AlMe}_{3}$ in $\mathrm{MAO}$ solutions ${ }^{[42 b, 43]}$ seems to participate in equilibria that interconvert different $\mathrm{MAO}$ oligomers ${ }^{[42 b .43-46]}$ and possibly also cyclic and branched oligomers. ${ }^{[39 e-\mathrm{j}, 46]}$ Cross-linking by methyl-free oxoaluminum centers has been proposed to generate a microphase with an $\mathrm{Al}_{x} \mathrm{O}_{y}$ core ${ }^{[47]}$ Aluminoxane clusters $\left[\mathrm{RAl}\left(\mu_{3}-\mathrm{O}\right]\right)_{n}$, with $\mathrm{R}=$ tert-butyl and $n=4,6$, or 9 , have been isolated and structurally characterized by Barron and his group. ${ }^{[48]}$ Complexes with four-coordinate $\mathrm{Al}$ centers seem to predominate in MAO solutions ${ }^{[48,49]}$ and might contain intramolecular $\mathrm{Al}_{2} \mathrm{O} \rightarrow \mathrm{Al}$ or $\mathrm{Al}-\mathrm{CH}_{3} \rightarrow \mathrm{Al}$ bridges. ${ }^{[42 \mathrm{~b}]}$ The presence of three-coordinate $\mathrm{Al}$ centers in $\mathrm{MAO}$ solutions has been deduced by Siedle and co-workers from ${ }^{27} \mathrm{Al}$ NMR data. ${ }^{[50 \mathrm{~b}, \mathrm{c}]}$ While species of exceptional Lewis acidity are certainly present in MAO solutions, their exact composition and structure is still not adequately understood..$^{[51]}$

When toluene solutions of $\mathrm{Cp}_{2} \mathrm{ZrCl}_{2}$ are treated with $\mathrm{MAO}$, a fast, initial ligand exchange reaction generates primarily the monomethyl complex $\mathrm{Cp}_{2} \mathrm{ZrMeCl} ;{ }^{[39 i, 44 b]}$ excess MAO leads to $\mathrm{Cp}_{2} \mathrm{ZrMe}_{2} \cdot{ }^{\left[{ }^{[3 i]}\right.}$ These systems become catalytically active when the concentration of excess MAO is raised to $\mathrm{Al}: \mathrm{Zr}$ ratios of about $200: 1$ or higher. ${ }^{[39]}$ The ways in which excess MAO induces this activity have been investigated largely by spectroscopic methods. ${ }^{[39 i, 50-52.53 a]}$ It is generally assumed that some of the Al centers in MAO have an exceptionally high propensity to abstract a $\mathrm{CH}_{3}^{-}$ion from $\mathrm{Cp}_{2} \mathrm{ZrMe}_{2}$ and to sequester it in a weakly coordinating ion $\mathrm{CH}_{3}-\mathrm{MAO}^{-}$. A fast, reversible transfer of ${ }^{13} \mathrm{CH}_{3}$ groups from $\mathrm{Cp}_{2} \mathrm{ZrMe}_{2}$ to the Al centers of a MAO activator was observed by Siedle et al. ${ }^{[50 \mathrm{~b}, \mathrm{c}]}$ Barron and coworkers ${ }^{[48 b]}$ obtained NMR spectroscopic evidence that $\mathrm{Cp}_{2} \mathrm{ZrMe}_{2}$ and alumoxane clusters like $\left(\mu_{3}-\mathrm{O}\right)_{6} \mathrm{Al}_{6} t \mathrm{Bu}_{6}$ form complexes of the type $\left[\mathrm{Cp}_{2} \mathrm{ZrMe}^{+} \cdots\left(\mu_{3}-\mathrm{O}\right)_{6} \mathrm{Al}_{6}(t \mathrm{Bu})_{6} \mathrm{Me}^{-}\right]$in $\left[\mathrm{D}_{8}\right]$ toluene solution, which polymerize ethene. The tendency of four-coordinate Al centers in these aluminoxane clusters to abstract a methyl anion is ascribed by these authors to the relief of ring strain upon formation of the methyl complex.

${ }^{91} \mathrm{Zr}$ and ${ }^{13} \mathrm{CNMR}$ spectra of $\mathrm{Cp}_{2} \mathrm{ZrMe}_{2} / \mathrm{MAO}$ solutions ${ }^{[50 b, c]}$ and solid-state XPS ${ }^{[52]}$ and ${ }^{13} \mathrm{CNMR}^{[53 a]}$ studies indicate formation of a cation $\left[\mathrm{Cp}_{2} \mathrm{ZrR}\right]^{+}$, which is most likely stabilized by coordinative contact with its $\mathrm{CH}_{3}-\mathrm{MAO}^{-}$counterion, for example through bonding like that in $\mathrm{Al}_{2} \mathrm{O} \rightarrow \mathrm{Zr}$ or $\mathrm{Al}-\mathrm{CH}_{3} \rightarrow \mathrm{Zr}$. These contacts appear to give way, in the presence even of substituted olefins, to olefin-separated ion pairs $\left[\mathrm{Cp}_{2} \mathrm{ZrR} \text { (olefin) }\right]^{+} \mathrm{CH}_{3}-\mathrm{MAO}^{-}$, the presumed prerequisite for olefin insertion into the $\mathrm{Zr}-\mathrm{R}$ bond. This hypothesis - that the unusually low coordinating capability of the anion $\mathrm{A}^{-}$in the ion pair $\left[\mathrm{Cp}_{2} \mathrm{ZrMe}\right]^{+} \mathrm{A}^{-}$is crucial for catalytic activity ${ }^{[50 \mathrm{e}]}$-led to the discovery of a series of highly active cationic metallocene 
catalysts for the polymerization of propene and higher $\alpha$-olefins.

Even for large, weakly coordinating anions such as $\left(\mathrm{C}_{6} \mathrm{H}_{5}\right)_{4} \mathrm{~B}^{-}$and $\mathrm{C}_{2} \mathrm{~B}_{9} \mathrm{H}_{12}^{-}$fairly strong interactions have been observed with cationic (alkyl)zirconocene species. ${ }^{[30,53 \mathrm{~b}, 58 \mathrm{a}]}$ Reaction systems containing $\left[\mathrm{Cp}_{2} \mathrm{ZrMe}\right]^{+}$together with $\left(\mathrm{C}_{6} \mathrm{H}_{5}\right)_{4} \mathrm{~B}^{-}, \mathrm{C}_{2} \mathrm{~B}_{9} \mathrm{H}_{12}^{-}$, or other carborane anions thus polymerize propene only at low rates, if at all. $[26 f, g, j .27-30]$

A breakthrough in this regard was the introduction of perfluorinated tetraphenylborate as a counterion by Hlatky and Turner $^{[54]}$ and by Marks and co-workers. ${ }^{[53 b]}$ An ion pair $\left[\mathrm{Cp}_{2}^{x} \mathrm{ZrMe}\right]^{+}\left(\mathrm{C}_{6} \mathrm{~F}_{5}\right)_{4} \mathrm{~B}^{-}$(where $\mathrm{Cp}^{\mathrm{x}}$ is some substituted $\mathrm{Cp}$ or indenyl ligand) is formed by reaction of $\mathrm{Cp}_{2}^{\mathrm{x}} \mathrm{ZrMe}_{2}$ with dimethylanilinium tetrakis(perfluorophenyl)borate or by $a b$ straction of $\mathrm{CH}_{3}^{-}$from a (dimethyl)zirconocene complex by trityl tetrakis(perfluorophenyl)borate ${ }^{[55,56]}$ (Scheme 5). These

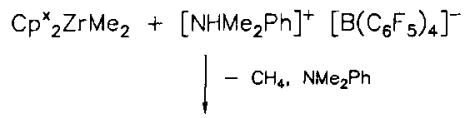
$-\mathrm{Ph}_{3} \mathrm{CMe}$

$\mathrm{Cp}_{2}{ }_{2} \mathrm{ZrMe}_{2}+\left[\mathrm{Ph} \mathrm{h}_{3} \mathrm{C}\right]^{+}\left[\mathrm{B}\left(\mathrm{C}_{6} \mathrm{~F}_{5}\right)_{4}\right]^{-}$

Scheme 5. Alternative ways to generate a propene-polymerizing (alkyl)zirconocene cation (associated with the weakly coordinating $B\left(C_{6} F_{5}\right)_{4}^{-2}$ anion) as reported by Hlatky. Upton, and Turner [54], by Marks and co-workers [53b]. by Ewen and Elder [55], and by Chien and co-workers [56]. $\mathrm{Cp}^{\mathrm{x}}$ represents a variety of substituted and/or bridged cyclopentadienyl and indenyl ligands (see Section 3.1).

were the first well-defined zirconocene catalysts capable of polymerizing propene and higher olefins at high rates without addition of a further activator. Similar activities for propene polymerization were subsequently observed also with other base-free or weakly stabilized ${ }^{[53,57,58]}$ (alkyl)metallocene cations. Cations obtained by abstraction of $\mathrm{CH}_{3}^{-}$from a (dimethyl)zirconocene complex by the powerful Lewis acid $B\left(\mathrm{C}_{6} \mathrm{~F}_{5}\right)_{3}$ were likewise found to be highly active catalysts for $\alpha$-olefin polymerization. ${ }^{[59,60]}$

Crystal structures obtained by Marks and co-workers, ${ }^{[60]}$ for example that of $\left[\left(\mathrm{Me}_{2} \mathrm{C}_{5} \mathrm{H}_{3}\right)_{2} \mathrm{ZrCH}_{3}^{+} \cdots \mathrm{H}_{3} \mathrm{C}-\mathrm{B}\left(\mathrm{C}_{6} \mathrm{~F}_{5}\right)_{3}^{-}\right]$, reveal residual coordinative contacts between the cationic $Z_{r}$ center and its counterion (Fig. 1). This contact appears to resemble those yet unidentified interactions that stabilize an (alkyl)metallocene cation in contact with a $\mathrm{H}_{3} \mathrm{C}-\mathrm{MAO}^{-}$counterion.

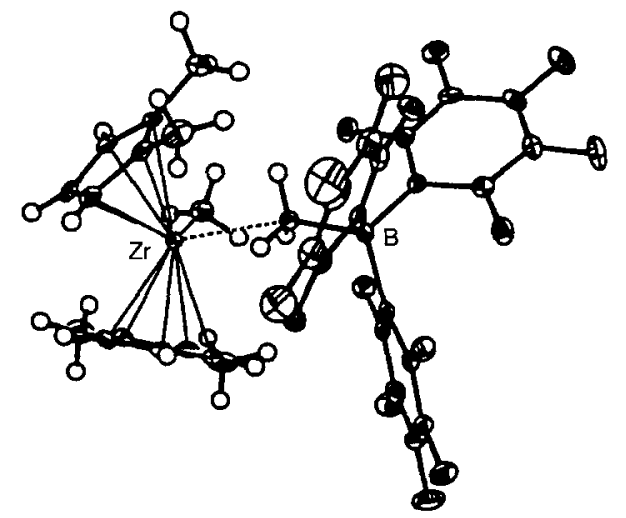

Fig. 1. Crystal structure of the zirconocene catalyst $\left[\left(\mathrm{Me}_{2} \mathrm{C}_{5} \mathrm{H}_{3}\right)_{2} \mathrm{ZrCH}_{3} \mathrm{WH}_{3} \mathrm{C}\right.$ $\left.\mathrm{B}\left(\mathrm{C}_{6} \mathrm{~F}_{5}\right)_{3}^{-}\right]$, as determined by Marks and co-workers [60]. The bridging $\mathrm{Zr} \cdots \mathrm{CH}_{3} \mathrm{~B}$ bond is substantially longer $(255 \mathrm{pm})$ than the terminal $\mathrm{Zr}-\mathrm{CH}_{3}$ bond $(225 \mathrm{pm})$.
In both cases, a fast methyl exchange occurs between the cationic and anionic complex moieties; ${ }^{[50,60]}$ most importantly, both types of contacts appear to be weak enough to allow an $x$-olefin to displace the anion from its coordination site at the $\mathrm{Zr}$ center.

Cationic metallocene complexes, particularly those that arise by in situ activation of a stable zirconocene precursor, ${ }^{[56]}$ yield catalysts with very high activities. They are easily deactivated, however, probably by minute traces of impurities. Addition of $\mathrm{AlMe}_{3}$ or $\mathrm{AlEt}_{3}$ has been shown to stabilize these cationic metallocene catalysts ${ }^{155.56 \mathrm{~b}]}$ by formation of $\mathrm{AlR}_{3}$ adducts. ${ }^{[57 \mathrm{~d}]}$

Of even greater simplicity, at least conceptionally, are catalysts based on an (alkyl)metallocene complex containing a Sc ${ }^{\mathrm{III}}$, $Y^{\text {III }}$, or a trivalent lanthanide center. As shown by Ballard et al. ${ }^{[61]}$ and by Watson et al., ${ }^{[621}$ neutral complexes of the type $\mathrm{Cp}_{2} \mathrm{M}^{\mathrm{III}} \mathrm{R}$ act as single-component catalysts for the oligomerization of $\alpha$-olefins. ${ }^{[63,64]}$ While generally more difficult to prepare and to handle than the Group 4 metallocene catalyst systems described above, catalysts such as $\left(\mathrm{C}_{5} \mathrm{Me}_{5}\right)_{2} \mathrm{ScR}(\mathrm{R}=\mathrm{Me}, \mathrm{Et})$ provided Bercaw and his co-workers detailed information on the rates and mechanisms of individual olefin insertion steps. ${ }^{[63]}$ The results of these studies lent additional support to the concept that an analogous olefin insertion into the isoelectronic species $\left[\mathrm{Cp}_{2} \mathrm{ZrR}\right]^{+}$is responsible for the growth of polymer chains in zirconocene-based catalyst systems.

\subsection{Kinetics and Mechanisms of $\alpha$-Olefin Polymerization}

Because of many practical advantages, activation of zirconocene dichloride derivatives by methyl aluminoxane still appears to be the generally favored route to homogeneous polymerization catalysts. Substantial efforts have been made, therefore, to identify intermediates arising in the resulting, relatively complex reaction systems and to clarify the kinetics of the polymer chain growth they induce.

At propene pressures of $1-2$ bar and ambient temperatures these reaction systems produce roughly $100-1000 \mathrm{~kg}$ polypropene per hour and mol of $\mathrm{Cp}_{2} \mathrm{ZrCl}_{2}$. This corresponds to about $2000-10000$ olefin insertions per hour at each $\mathrm{Zr}$ center. $\mathrm{T}$ is equivalent to the production of $500-5000$ polymer chains with average molecular weights on the order of $M_{\mathrm{n}}=200-2000$. Ethene is polymerized by these catalyst systems with still higher turnover numbers of $10-100$ insertions per second, which approach those of $\mathrm{C}-\mathrm{C}$ bond forming enzymes. ${ }^{[39 b, c, g]}$

Attempts to identify the species involved in the rate-determining step of the polymerization process by kinetic methods (i.e. by determining the rate of polymer formation as a function of the concentrations of zirconocene, MAO, and olefin reagents) have been hampered by the complex time-dependence of the catalytic reaction. Relatively high initial values, reached shortly after the components are mixed, decrease to much lower steadystate values. ${ }^{[65-69]}$ This decrease occurs within minutes at temperatures of $40-60^{\circ} \mathrm{C}$; at lower temperatures, it can take hours until the steady-state rate is reached.

In kinetic studies, Fischer and Mülhaupt ${ }^{[69 \mathrm{a} \cdot \mathrm{b}]}$ describe the steady-state activity of a $\mathrm{Cp}_{2} \mathrm{ZrCl}_{2} / \mathrm{MAO}$ catalyst system as a sequence of reversible and irreversible processes. A reactive species $C^{*}$ appears to be generated in a fast equilibrium reaction 
involving excess $\mathrm{MAO}$ and an (alkyl)zirconocene complex C (Scheme 6) ${ }^{[70]}$ Another, slower reaction, which shows a second-order dependence on the concentration of the active species $\mathrm{C}^{*}$, converts $\mathrm{C}^{*}$ to some inactive species $\mathrm{I}^{1}$. This inactive species $\mathrm{I}^{1}$ is constantly reconverted to the catalyst species $\mathrm{C}$ and $\mathrm{C}^{*}$ by reaction with excess $\mathrm{MAO}$; this was demonstrated by the effects of MAO additions on the catalytic activity of a system that had already reached steady-state conditions. ${ }^{[69 c]}$ A further, still slower reaction converts $I^{1}$ to another inactive species $I^{2}$ from which $\mathrm{C}^{*}$ is not regenerated in these reaction systems. Since the transformation of $\mathrm{C}^{*}$ to $\mathrm{I}^{1}$ is bimolecular, the steady-state fraction of the inactive species $I^{1}$ decreases at low concentrations of $C^{*}$. Accordingly, specific activities are observed to increase at lower zirconocene concentrations. ${ }^{[39,69]}$

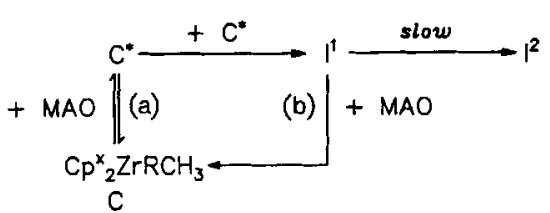

Scheme 6. Dual effect of MAO on the steady-state activity of a zirconocene-based polymerization catalyst, derived from kinetic studies by Mülhaupt and Fischer [69a, b]. (a) Generation of active species $C^{*}$ in a fast equilibrium with a (dialkyl)zirconocene complex and (b) reactivation of an inactive intermediate $I^{1}$ arising from a second-order deactivation reaction of $\mathrm{C}^{*} ; \mathrm{I}^{1}$ slowly decays to another inactive species $\mathrm{I}^{2}$. from which the active catalyst is not regenerated.

The reaction that converts $\mathrm{C}^{*}$ to $\mathrm{I}^{1}$ is undoubtedly connected with the known propensity of (methyl)zirconocene cations to react with a wide variety of $\mathrm{C}-\mathrm{H}$ units by means of $\sigma$-bond metathesis and release of $\mathrm{CH}_{4} \cdot{ }^{[26 \mathrm{~d}-\mathrm{f}, 28,30,50,71]} \mathrm{Kaminsky}$ and co-workers have indeed observed a steady liberation of $\mathrm{CH}_{4}$ from MAO-activated zirconocene catalysts, which reached up to 50 molecules of $\mathrm{CH}_{4}$ per $\mathrm{Zr}$ center. ${ }^{[39 \mathrm{i}]}$ The inactive, dominant steady-state species is proposed to be a binuclear complex with $\mathrm{CH}_{2}$ bridges between a $\mathrm{Zr}$ and an $\mathrm{Al}$ center. Binuclear species with $\mathrm{C}_{2} \mathrm{H}_{4}$ bridges between two $\mathrm{Zr}$ centers were isolated by the same authors from ethene-polymerizing catalyst systems. ${ }^{[4 a, 39]}$ Regeneration of active polymerization catalysts from these binuclear, $\mathrm{C}_{x} \mathrm{H}_{y}$-bridged deactivation products by MAO is proposed to occur by alkyl exchange reactions, for instance between a $\mathrm{Zr}-\mathrm{CH}_{2}-\mathrm{Al}$ species and the alkylaluminum activator $;{ }^{[72]}$ the latter will thus be consumed gradually under formation of $\mathrm{Al}-\mathrm{CH}_{2}-\mathrm{Al}$ units. Evidence for the formation of binuclear cations of the type $\left[\mathrm{Cp}_{2} \mathrm{ZrMe}\left(\mu-\mathrm{CH}_{3}\right) \mathrm{MeZrCp}\right]^{+}$is now firmly established. ${ }^{[53 a, 57 d, 60 a, 73,120 e, 132 b]}$ Further insights with regard to their identity and their involvement in deactivation processes ${ }^{[74]}$ can be expected from studies on MAO-free, cationic zirconocene catalysts.

The question of why such a huge excess of MAO is required to induce catalytic activity for $\alpha$-olefin polymerization is still unanswered. Catalytic activities are found to decline dramatically for MAO concentrations below an $\mathrm{Al}: \mathrm{Zr}$ ratio of roughly 200-300:1. Even at $\mathrm{Al}: \mathrm{Zr}$ ratios greater than 1000:1, steadystate activities increase with rising MAO concentrations, ${ }^{[75]}$ approximately as the cube root of the MAO concentration. ${ }^{[39 d, 69 b]} \mathrm{MAO}$ appears to be involved in a fast equilibrium $\mathrm{C}+\mathrm{MAO} \rightleftharpoons \mathrm{C}^{*+}+\mathrm{CH}_{3}-\mathrm{MAO}^{-}$as well as in the slower re- activation process $I^{1}+M A O \rightarrow C^{*}$. The concentration of the most Lewis-acidic Al centers must be related, furthermore, to the total MAO concentration through complicated equilibria. To date, it has not been possible to model the overall effects of MAO concentrations on catalytic reaction rates by a plausible, comprehensive system of kinetic equations.

The effect of olefin concentration on the reaction rates is likewise complicated by catalyst deactivation. Since the reactive species appears to be stabilized by excess olefin, rates of polymer production under steady-state conditions are not proportional to propene concentrations, but approximately to $c$ (olefin) ${ }^{1.3}$ [69b] Related observations (see for example refs. $[50 \mathrm{~b}, \mathrm{c}])$ that polymerization rates depend on olefin concentration to a fractional order between 1 and 2 have led to the proposal that two olefin molecules are involved in the insertion transition state. ${ }^{[76]}$ While initial rates of polymer production, determined before the onset of catalyst deactivation, have been reported in two instances to increase in proportion to ethene ${ }^{[65 \mathrm{c}]}$ or propene concentration ${ }^{[69 \mathrm{~b}]}$ (i.e. as $c$ (olefin) ${ }^{1.0}$ ), this point requires further clarification (see Section 3.3).

For the present we will assume, in accord with general opinion, that the productive reaction complex in MAO-activated zirconocene catalysts is a cationic alkyl(olefin)zirconocene complex of the type $\left[\mathrm{Cp}_{2} \mathrm{ZrR} \text { (olefin) }\right]^{+} \mathrm{H}_{3} \mathrm{C}-\mathrm{MAO}^{-}$, which is generated by displacement of an anion $\mathrm{H}_{3} \mathrm{C}-\mathrm{MAO}^{-}$from its $\left[\mathrm{Cp}_{2} \mathrm{ZrR}\right]^{+}$counterion by an olefin molecule.

The reaction step by which such an alkyl(olefin)zirconocene cation is finally converted to the olefin-insertion product has been further characterized by kinetic isotope effects. Laverty and Rooney, ${ }^{[7]}$ and Brookhart and Green ${ }^{[78]}$ had proposed that an agostic interaction of one of the $\alpha-H$ atoms of the metalbound alkyl chain with the metal center of a Ziegler-Natta catalyst ${ }^{[79]}$ facilitates the insertion of an olefin into the metal-alkyl bond. To test this hypothesis, Krauledat and Brintzinger ${ }^{[80]}$ investigated the catalytic hydrodimerization of $\alpha$-deuterated hexenes to the threo and erythro diastereomers of 5-CH $\mathrm{CH}_{2} \mathrm{D}-6-[\mathrm{D}]-$ undecane by $\mathrm{MAO}$-activated $\mathrm{Cp}_{2} \mathrm{ZrCl}_{2}$. Diastereomer ratios in accord with a value of $k_{\mathrm{H}} / k_{\mathrm{D}} \approx 1.3$ were observed with cis and trans $\alpha$-deuterated 1 -hexene. This indicates-along a line of reasoning developed earlier by Grubbs and co-workers ${ }^{[811}$ _that the transition state for the insertion of hexene into the $\mathrm{Zr}-\mathrm{C}$ bond of the initially formed $\mathrm{Zr}-\mathrm{CHD}-$ $\left(\mathrm{CH}_{2}\right)_{4} \mathrm{CH}_{3}$ unit involves considerable weakening either of its $\alpha-\mathrm{C}-\mathrm{H}$ or of its $\alpha-\mathrm{C}-\mathrm{D}$ bond. In other reaction systems agostic interactions with $\mathrm{H}$ atoms have been shown to be preferred over those with $\mathrm{D}$ atoms by a factor of about $1.2-1.5 .^{[79 \mathrm{a}]}$ The stereokinetic isotope effect $k_{\mathrm{H}} / k_{\mathrm{D}} \approx 1.3$ associated with the insertion of an $\alpha$-olefin into the metal-CHD-R unit of a MAOactivated zirconocene catalyst can thus be regarded as evidence that this reaction requires the agostic interaction of one of the $\alpha-\mathrm{H}$ atoms with the metal center (Scheme 7).

Similar results were obtained by Piers and Bercaw ${ }^{[82]}$ in studies on hydrocyclizations and hydrodimerizations induced by single-component scandocene catalysts. It remains to be tested whether this notion can be generalized or whether olefin insertions into metal-alkyl species might occasionally occur without agostic assistance. ${ }^{[83]}$

Olefin insertion into the metal-alkyl bond of a cationic metallocene complex of the type $\left[\mathrm{Cp}_{2} \mathrm{MMe}(\text { olefin })\right]^{+}(\mathrm{M}=\mathrm{Ti}$, 


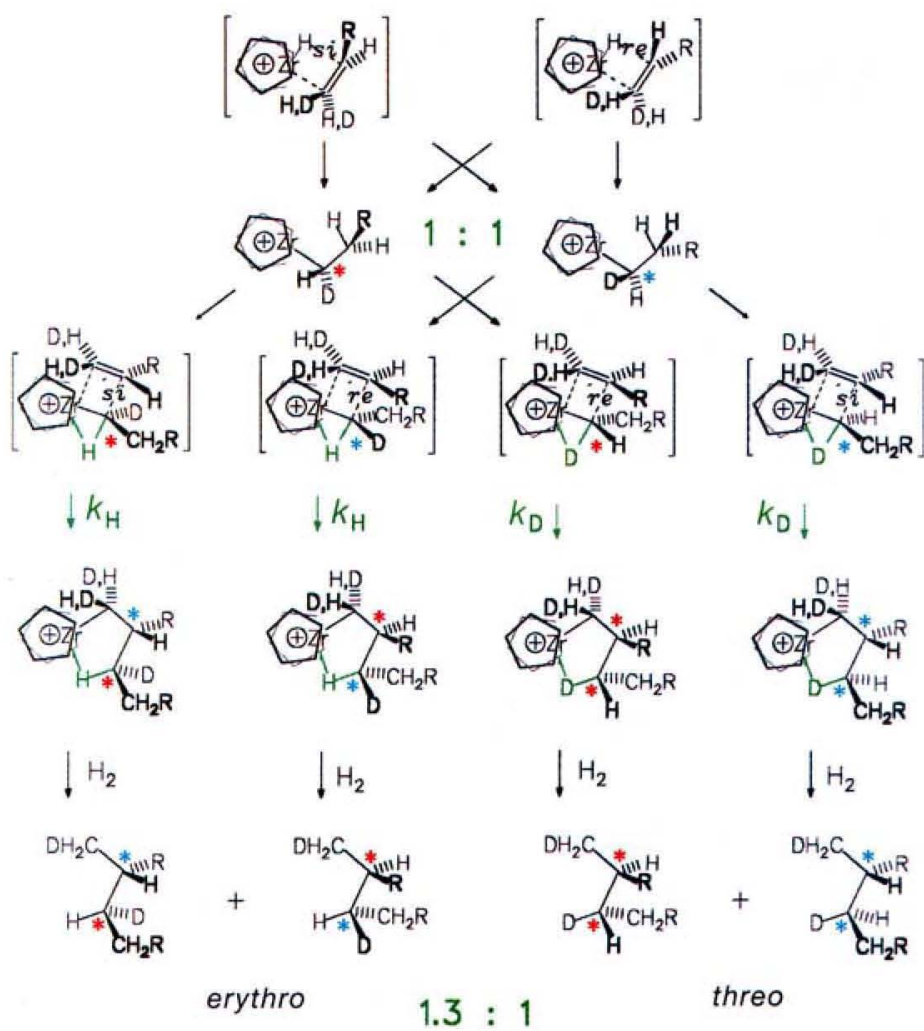

Scheme 7. Stereokinetic isotope effects in the $\left(\mathrm{C}_{5} \mathrm{H}_{5}\right)_{2} \mathrm{ZrCl}_{2} / \mathrm{MAO}$-catalyzed hydrodimerization of $(E)$ - and $(Z)-1-[D]-1$-hexene $\left(\mathrm{R}=n-\mathrm{C}_{4} \mathrm{H}_{9}\right)$ favor the erythro over the threo products in a ratio of $1.3: 1$ [80]. While the achiral starting compounds must give the $\mathrm{Zr}-\mathrm{CHD}-\mathrm{CH}_{2} \mathrm{R}$ enantiomers in a 1:1 ratio, the second olefin insertion is influenced by $\alpha$-agostic interactions. A $\mathbf{H}-\mathrm{C}(\alpha)$ bond is weakened in the formation of the erythro isomers, a D-C(x) bond in the formation of the threo isomers of the hydrodimer product.

$\mathrm{Zr}$ ) has been the subject of numerous theoretical studies. ${ }^{[84-89]}$ Calculations with $a b$ initio and density functional methods depict the transition state as a planar ${ }^{[84 \mathrm{e}, \mathrm{g}, 85,87,88]}$ or slightly puckered $^{[84 f, 86]}$ four-membered ring with $\mathrm{Ti}-\mathrm{C}$ and $\mathrm{Zr}-\mathrm{C}$ distances of $2.1-2.3$ and $2.3-2.5 \AA$, respectively, an incipient alkyl-olefin C $\cdots \mathrm{C}$ distance of $2.1-2.3 \AA$, and a slightly increased olefin $\mathrm{C}=\mathrm{C}$ bond length of roughly $1.4 \AA^{[84 \mathrm{e}-\mathrm{g}, 85-88]}$ (Fig. 2).

Most of these studies concur with the view that in the insertion transition state one $\alpha-\mathrm{H}$ atom of the migrating $\mathrm{Zr}-\mathrm{CH}_{2}-\mathrm{R}$
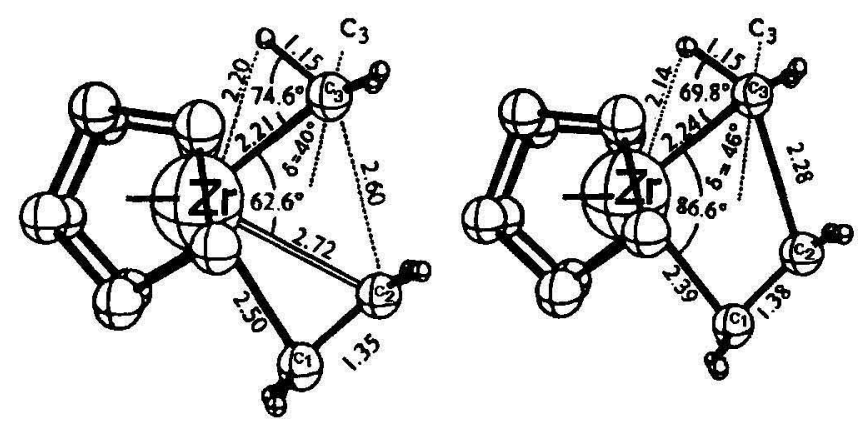

Fig. 2. Structures of a cation $\left[\left(\mathrm{C}_{5} \mathrm{H}_{5}\right)_{2} \mathrm{ZrMe}\left(\mathrm{C}_{2} \mathrm{H}_{4}\right)\right]^{+}$(left) and of the transition state for insertion of the ethene ligand into the $\mathrm{Zr}-\mathrm{Me}$ bond (right), as determined by Ziegler and co-workers by density functional methods [87]. A shortening of the agostic $\mathrm{Zr}-\mathrm{H}(x)$ contact helps align the $C_{3}$ axis of the $\mathrm{CH}_{3}$ group for interaction with the ethene $\pi^{*}$ orbital group is in close proximity to the metal center and that this $\mathrm{Zr}-\mathrm{H}$ interaction is due to an $\alpha$-agostic bond. ${ }^{[86-88]}$ An Extended-Hückel MO study ${ }^{[89]}$ indicates that the $\alpha$-agostic interaction of a $\mathrm{Zr}-\mathrm{CH}_{2}-\mathrm{R}$ unit with the $\mathrm{Zr}$ center is linked to the increasing electron deficiency of the reaction complex as it progresses along the olefin-insertion coordinate from a 16-electron to a 14-electron species. The size of the contribution of the agostic interaction to the stabilization of the olefin-insertion transition state is still a matter of debate. ${ }^{[89]}$

These studies also indicate that the $\mathrm{Zr}-n$-propyl unit at the end of the insertion path is stabilized by the agostic interaction of one of its $\gamma-\mathrm{C}-\mathrm{H}$ bonds with the $\mathrm{Zr}$ center ${ }^{[84 \mathrm{~g} .}{ }^{85-89]} \mathrm{A}$ yet more stable structure appears to be a product in which one of the $\beta$-C- $\mathrm{H}$ bonds of the $\mathrm{Zr}-n$-propyl unit interacts with the electron-deficient $\mathrm{Zr}$ center. ${ }^{\left[{ }^{[5-88]}\right.}$ The $\gamma$-agostic species initially arising from the insertion process is thus likely to rearrange into a structure with a $\beta$-agostic bond; ${ }^{[79]}$ the latter probably represents something like a resting state for a $\left[\mathrm{Cp}_{2} \mathrm{Zr}-\right.$ alkyl] ${ }^{+}$ion (see ref. [63]). Theoretical studies indicate that the $\gamma \rightarrow \beta$ rearrangement might be relatively slow. ${ }^{[85 \mathrm{~b}, 87 \mathrm{~b}]}$

Effects of the solvent and counterions, neglected so far in these theoretical studies, might be of more than peripheral concern. In an ion-cyclotron resonance study, Richardson and co-workers ${ }^{[74]}$ showed that $\left[\mathrm{Cp}_{2} \mathrm{TiCH}_{3}\right]^{+}$and $\mathrm{C}_{2} \mathrm{H}_{4}$ react in vacuo to form the allyl complex $\left[\mathrm{Cp}_{2} \mathrm{TiC}_{3} \mathrm{H}_{5}\right]^{+}$and $\mathrm{H}_{2}$, rather than the insertion product $\left[\mathrm{Cp}_{2} \mathrm{TiC}_{3} \mathrm{H}_{7}\right]^{+}$. It remains to be clarified which interactions induce the more useful course to polymers in the analogous condensed-phase reaction systems.

\subsection{Molecular Weights and Chain Termination Reactions}

An important aspect in which homogeneous olefin polymerization by metallocene catalysts differs from heterogeneous Ziegler-Natta catalysis is the narrow molecular weight distribution of homogeneously produced polymers. While polyolefins obtained with heterogeneous catalysts have broad molecular weight distributions with large polydispersities of $M_{\mathrm{w}} / M_{\mathrm{n}} \approx 5-10,{ }^{[8]}$ homogeneous catalysts produce polymers with polydispersities $M_{\mathrm{w}} / M_{\mathrm{n}}$ close to $2 .^{[39 f]} \mathrm{A}$ polydispersity of 2 is predicted by Schulz-Flory statistics ${ }^{[90]}$ for polymers arising from identical catalyst centers with fixed rates of chain propagation and chain termination, $v_{\mathrm{P}}$ and $v_{\mathrm{T}}$. A polydispersity of 2 is thus regarded as evidence that only a single catalyst species contributes to polymer growth in a homogeneous catalyst system. Even though the deactivation and reactivation reactions discussed above are likely to generate a diversity of complex species in these catalyst systems under steady-state conditions, only one of these species, presumably the cation $\left[\mathrm{Cp}_{2} \mathrm{Zr}-\right.$ alkyl(olefin) ${ }^{+}$, appears to contribute to polymer growth.

While ethene is polymerized by MAO-activated or cationtype $\mathrm{Cp}_{2} \mathrm{Zr}$-based catalysts to give polymers with high molecular weights in the range of 100000 to $1000000,{ }^{[39]}$ propene polymers obtained at room temperature with these catalysts have rather low degrees of polymerization, with molecular weights in the range of $200-1000{ }^{[39 e, g, 69 b]}$ The relatively low molecular weights of the polymer products must be due either to an increased rate of chain termination or to a decreased rate of olefin insertion (or both), since the average degree of polymerization 
$P_{\mathrm{N}}$ is determined by the ratio of the rates of chain propagation and chain termination, $P_{\mathrm{N}} \approx v_{\mathrm{P}} / v_{\mathrm{T}} \cdot{ }^{[90]}$

${ }^{1} \mathrm{H}$ and ${ }^{13} \mathrm{C} \mathrm{NMR}$ analyses show that polypropene chains produced with zirconocene-based catalysts bear $n$-propyl and 2-propenyl end groups. ${ }^{[91]}$ The 2-propenyl end groups could arise by transfer of a $\beta-\mathrm{H}$ atom from the polymer chain to the metal center (Scheme 8 ). The $\mathrm{Zr}-\mathrm{H}$ unit generated by this process can then react with propene to form a $\mathrm{Zr}-n$-propyl unit, from which a new polymer chain can start to grow. ${ }^{[96]}$ Another conceivable chain termination mechanism is the transfer of a $\beta$ - $\mathrm{H}$ atom from the $\mathrm{Zr}$-bound polymer chain directly to the $\beta$-C atom of a coordinated olefin molecule. In this case, the 2propenyl-terminated polymer chain and a new $\mathrm{Zr}$-n-propyl unit are generated without the intermediacy of a $\mathrm{Zr}-\mathrm{H}$ species (Scheme 8).

$\beta-H$ transfer to metal:
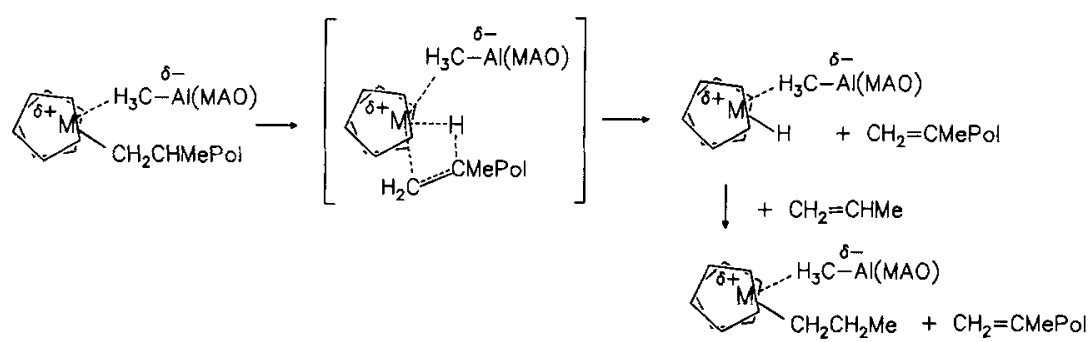

$\beta-H$ transfer to olefin:

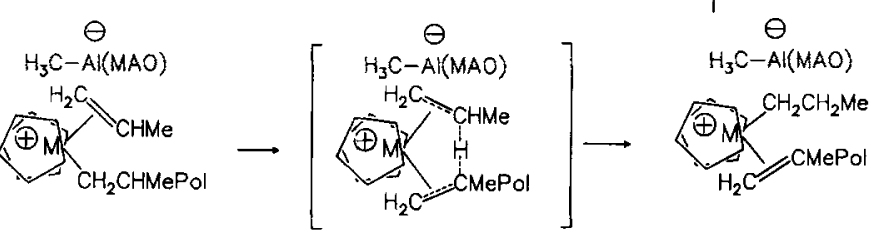

Scheme 8. Chain termination by $\beta-\mathrm{H}$ transfer to the metal (top) and to a coordinated olefin (bottom). A polymer chain with a 2-propenyl end and a metallocene complex with a $n$-propyl chain result from both of these processes, but the rate of the latter increases with olefin concentration in parallel to that of olefin insertion, while the rate of the former is olefin-independent. Molecular weights of the polymers will thus increase with olefin concentration in the case of $\beta$ - $\mathrm{H}$ transfer to the metal, while molecular weights independent of olefin concentration indicate $\beta-\mathrm{H}$ transfer to an olefin ligand.

Evidence for direct $\beta$-H transfer to a coordinated olefin was obtained by Kashiwa and co-workers ${ }^{[97]}$ from studies on ethene-propene copolymers. A $\mathrm{Zr}-\mathrm{H}$ intermediate would be expected to react at least as fast with ethene to give a $\mathrm{Zr}$-ethyl unit as with propene to give a $\mathrm{Zr}$-propyl unit; ethyl end groups should thus be found at the head of a polymer chain with the same frequency as $n$-propyl ends. In fact, very few ethyl ends were formed at comparable concentrations of ethene and propene. The most plausible explanation for this observation is that $\beta-\mathrm{H}$ transfer to a coordinated propene molecule occurs more often than that to a coordinated ethene molecule, since the rate of insertion of propene into a $\mathrm{Zr}$-polymer bond is lower than that of ethene. ${ }^{[97]}$

This mechanism does not appear compatible, on the other hand, with observations that polymer molecular weights increase linearly with ethene ${ }^{[65 c]}$ or propene ${ }^{[69 b]}$ concentrations. For chain termination by $\beta-\mathrm{H}$ transfer to a coordinated monomer one would expect $v_{\mathrm{T}}$ like $v_{\mathrm{P}}$ to depend linearly on monomer concentration. In this case, the mean degree of polymerization, $P_{\mathrm{N}} \approx v_{\mathrm{P}} / v_{\mathrm{T}}$, is expected to be independent of the monomer concentration. This discrepancy obviously needs to be readdressed; we will return to it in the discussion of stereoselective polymerization catalysis in Section 3.3.

Molecular weights of polyolefins obtained with MAO-activated zirconocene systems generally increase with the concentration of the MAO cocatalyst, ${ }^{[39,69 b, 98]}$ in parallel with increased rates of chain growth. Effects of zirconocene concentrations on polymer molecular weights again parallel those on catalytic activities: molecular weights increase substantially as zirconocene concentrations are decreased. ${ }^{[39.69 b, 98]}$ This might be due to dilution effects favoring the dissociated or olefin-separated ion pairs $C^{*}$ relative to their associated precursors $C$, and hence the rate of chain propagation over that of chain termination. ${ }^{[99]}$ As an alternative, Kaminsky and co-workers ${ }^{[39,98\}}$ advocate that a bimolecular reaction of the active complex with a second zirconocene species terminates growth of the polymer chain in a manner possibly related to the second-order deactivation process discussed in Section 2.3. Further clarification of these questions can be expected from future studies on MAO-free, cationic metallocene polymerization catalysts.

\section{Stereoregular Polymers from Chiral Metallocene Catalysts}

The discovery of homogeneous catalysts capable of polymerizing propene and higher $\alpha$-olefins around 1980 revived a long-standing question: ${ }^{[13]}$ Would it be possible to induce these homogeneous polymerizations in a stereoregular fashion, so as to produce isotactic polymers, by using suitably designed chiral metallocenes as catalysts?

Chiral metallocenes suitable for this purpose ${ }^{[100]}$ became available, not quite accidentally ${ }^{[101]}$ just at that time. Using ethylene-bridged ligands, ${ }^{[102]}$ Wild and Brintzinger ${ }^{[103]}$ obtained ethylenebis(indenyl)- and ethylenebis(tetrahydroindenyl)titanium complexes, $r a c$-(en)(ind) ${ }_{2} \mathrm{TiCl}_{2}$ and $\mathrm{rac}$-(en)(thind) $\mathrm{TiCl}_{2}$, and their zirconium analogues. The conformationally constrained indenyl and tetrahydroindenyl ligands give these complexes chiral structures (Fig. 3) which

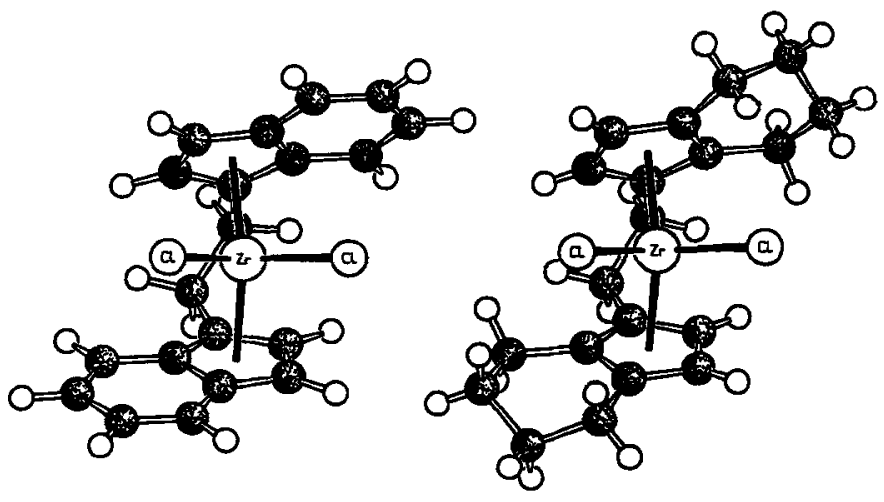

Fig. 3. Prototypical ansa-zirconocene complexes prepared by Wild et al. [103]: rac(en)(ind) $\mathrm{ZrCl}_{2}$ (left) and $\mathrm{rac}^{\prime}$-(en)(thind) ${ }_{2} \mathrm{ZrCl}_{2}$ (right). 
could be expected to be retained even under catalysis conditions. When activated with MAO in the manner described above, these ansa-metallocenes ${ }^{[104]}$ were indeed found, in independent studies by Ewen with (en)(thind) $\mathrm{TiCl}_{2} / \mathrm{MAO}^{[105]}$ and by Kaminsky and $\mathrm{Külper}$ with $\mathrm{rac}$-(en)(thind) $\mathrm{ZrCl}_{2} / \mathrm{MAO}^{\left[{ }^{[06]}\right.}$ to polymerize propene and other $\alpha$-olefins to give highly isotactic polymers. These findings led to extensive exploration of the mechanisms by which these catalysts control the stereochemistry of polymer growth and the effects of different metallocene structures on the tacticities and other properties of the polymers produced.

\subsection{Catalyst Structures and Stereoselectivities}

Polypropene produced by $\mathrm{MAO}$-activated chiral ansa-zirconocenes such as $\mathrm{rac}$-(en)(ind) ${ }_{2} \mathrm{ZrCl}_{2}$ or $\operatorname{rac}(\mathrm{en})$ (thind) ${ }_{2} \mathrm{ZrCl}_{2}$ has similar isotacticity to polymers produced with heterogeneous Ziegler - Natta catalysts. For a more quantitative discussion of these relations, we consider briefly the ${ }^{13} \mathrm{C}$ NMR spectroscopic methods ${ }^{[107]}$ currently used to characterize the stereoregularity of poly( $\alpha$-olefins).

The ${ }^{13} \mathrm{C}$ NMR signals of a polymer are most conveniently related to its microstructure by a stereochemical notation developed by Bovey. ${ }^{[107 a]}$ Relative configurations of neighboring units (or "dyads") are designated as $m$ (meso) for equally and $r$ (racemo) for unequally positioned substituents in a Fischer-type projection of the polymer chain. In polypropene, the ${ }^{13} \mathrm{C} N \mathrm{NM}$ shift of each $\mathrm{CH}_{3}$ group is determined by the configurations of two neighboring repeat units on either side; ${ }^{[108]}$ each $\mathrm{CH}_{3}$ signal is thus assignable to a particular "pentad" pattern, represented by the four consecutive $m$ or $r$ designators framing the $\mathrm{CH}_{3}$ group under consideration (Scheme 9). All ten possible

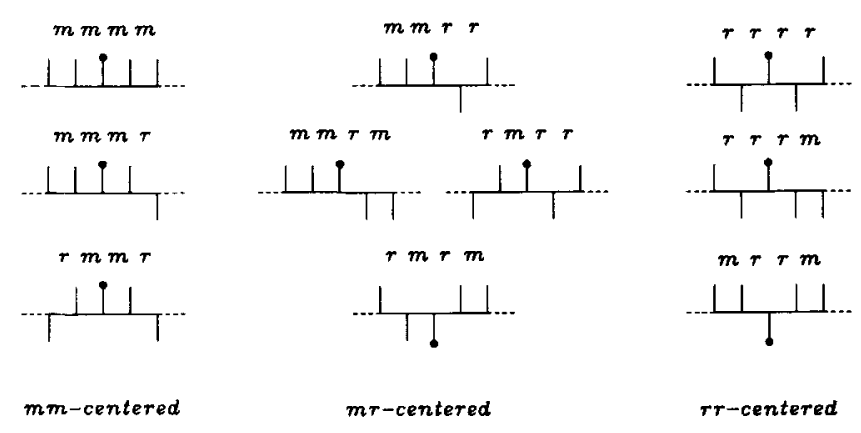

Scheme 9. The ten possible stereochemical pentads of a polyolefin [107].

pentad signals ( $m m m m, m m m r, r m m r, m m r r, m m r m, r m r r, r m-$ $r m$, rrrr, rrrm, and $m r r m)^{[109]}$ are observed for the randomly configurated repeat units of atactic polypropene ${ }^{[110]}$ (Fig. 4). Isotactic polypropene, on the other hand, is ideally characterized by a single ${ }^{13} \mathrm{C}$ NMR signal for $m m m m$ pentads, since its repeat units have identical configuration over long segments of the polymer chain.

The degree of isotacticity of such a polymer is usually expressed as the ratio of the $m m m m$ pentad integral to the integral sum of all pentad signals observed; it will be designated in the following as $[\mathrm{mmmm}] .^{[111]}$ Isotactic polypropene produced by modern heterogeneous Ziegler-Natta catalysts ${ }^{[8]}$ is highly

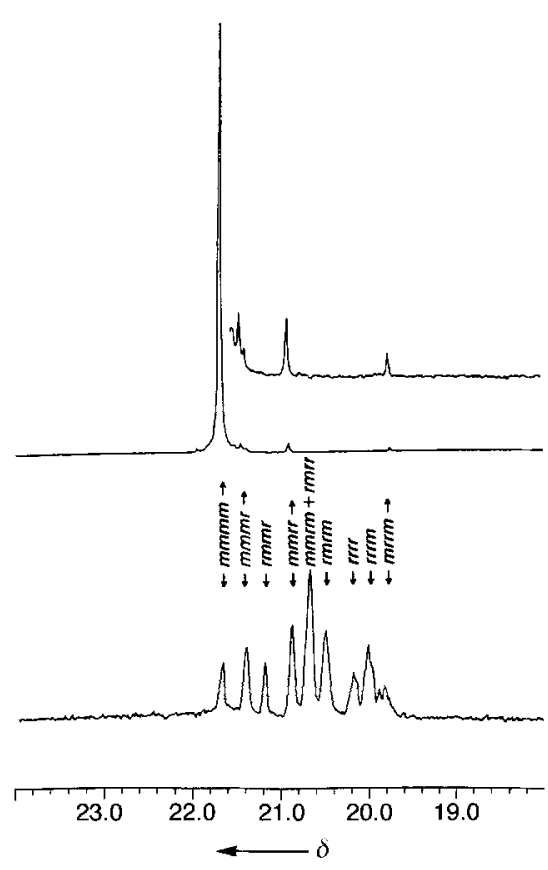

Fig. 4. ${ }^{13} \mathrm{C}$ NMR spectra of isotactic polypropene $\left(\mathrm{CH}_{3}\right.$ region) with $[\mathrm{mmmm}]>$ $90 \%$ obtained with rac $-\mathrm{Me}_{2} \mathrm{Si}\left(1-\right.$ benz $[e]$ indenyl) ${ }_{2} \mathrm{ZrCl}_{2} / \mathrm{MAO}[117 \mathrm{~h}, 120 \mathrm{~d}]$ (top). and of atactic polypropene with random pentad distribution obtained with the meso isomer of the same catalyst (bottom).

stereoregular with $[\mathrm{mmmm}]>0.95$. At ambient temperatures, typical MAO-activated chiral ansa-metallocene catalysts yield polypropene with stereoregularities of $[\mathrm{mmmm}] \approx 0.8-$ $0.9 .^{[106,112,113]}$ At increased polymerization temperatures, however, most of these homogeneous catalysts are distinctly less stereoselective than typical heterogeneous Ziegler-Natta catalysts. ${ }^{[14 a]}$

The ${ }^{13} \mathrm{C}$ NMR signals associated with occasional stereoerrors in the isotactic polymers produced by metallocene catalysts indicate that stereoregularity is controlled by the chirality of the metallocene catalyst and not by the asymmetry of the last inserted unit: Such "chain-end" control would give rise to the singleinversion pentad mmrm as a main error signal, since an occasionally inverted chain-end configuration would generally be followed by units of the same configuration. For this chain-end control one would expect an error pentad ratio close to $m m m r: m m r: m m r m: m r m=1: 0: 1: 0$. In fact, an error pentad distribution close to $m m m r: m m r: m m r m: m r r m=2: 2: 0: 1$ is observed for these polymers (Scheme 10). As previously established for heterogeneous catalysts, ${ }^{[12]}$ this pentad pattern is expected when olefin insertion is indeed under "catalytic-site" control. ${ }^{[105,115]}$ In this case, $r$ dyads due to stereoinversions will occur in pairs, since a catalyst center of fixed chirality forces the enantiofacial orientation of subsequent olefin insertions to return to the previous preference immediately after an occasional mistake (Scheme 10).

How the stereoselectivities of chiral catalysts depend on the structure of the complex, in particular on different bridging units and substituent patterns, has been the subject of comparative studies in several research groups.$^{[116-120]}$ In investigations of this kind, it is crucial to take into account the polymerization temperature $T_{\mathbf{P}} \cdot{ }^{[121]}$ Even an unbridged metallocene catalyst with unsubstituted ring ligands, $\mathrm{Cp}_{2} \mathrm{TiPh}_{2} / \mathrm{MAO}$, has been 
Catolytic-site control

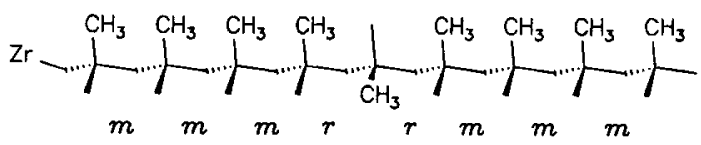

$m m m r: m m r r: m m r m: \underline{m r r m}=2: 2: 0: 1$

Chain-end control

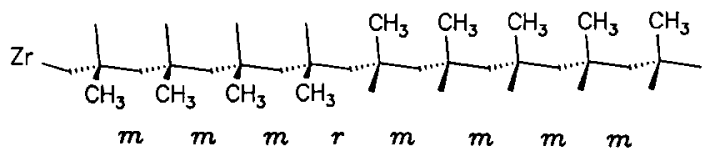

mmmr: $m$ mrr : $\underline{m m r m}: \operatorname{mrrm}=1: 0: 1: 0$

Scheme 10. Pentad distributions of stereoerrors in isotactic polypropene characteristic for catalytic-site stereocontrol (top; see also insert in Fig. 4) and for chain-end stereocontrol (bottom)

shown by Ewen ${ }^{[105]}$ to yield partially isotactic polypropene with $[m m m m] \approx 0.5$ at temperatures below $-40^{\circ} \mathrm{C}$. In this case, the nearly equal intensities of the $\mathrm{mmmr}$ and $\mathrm{mmrm}$ pentad signals indicate a chain-end control mechanism. ${ }^{[105.122]}$

Similar observations were reported by Erker and co-workers ${ }^{[123]}$ for unbridged zirconocenes with substituents containing an asymmetric $\mathrm{C}$ atom; these were found to give isotactic polymers with $[\mathrm{mmmm}] \approx 0.4-0.8$ at polymerization temperatures of $-50^{\circ} \mathrm{C}$ or lower. This partial control by the configuration of the last inserted unit over the stereochemistry of the next olefin insertion is almost completely lost at ambient temperatures. Apparently, insufficiently restricted rotations of the $\mathrm{C}_{5}$ ring ligands and their substituents and the increasing conformational mobility of the growing polymer chain abolish this stereocontrol mechanism at ambient temperatures.

An unbridged, chiral zirconocene that produces an isotactic polymer even at $T_{\mathrm{P}}=60^{\circ} \mathrm{C}$ was described by Razavi and Atwood. ${ }^{[124]} \mathrm{MAO}$-activated (1-methylfluorenyl) ${ }_{2} \mathrm{ZrCl}_{2}$ generates polypropene with $[\mathrm{mmmm}]=0.83$ and a catalytic site controlled pentad distribution. The fluorenyl ligands of this complex are chirally disposed, due to their methyl substituents, and apparently so strongly hindered in their mutual rotation that the enantiomers of this complex are not interconverted during the growth of a polymer chain.

Waymouth and co-workers recently reported on an unbridged metallocene catalyst, (2-phenylindenyl) ${ }_{2} \mathrm{ZrCl}_{2} / \mathrm{MAO}$, which appears to isomerize, by restricted rotation of its indenyl ligands, between chiral and achiral coordination geometries during chain growth; this catalyst yields a highly stretchable atactic-isotactic stereoblock polypropene with elastomeric properties (Scheme 11). ${ }^{[125]}$

A short interannular bridge will necessarily restrict rotation of the $\mathrm{C}_{5}$ ring ligands. Accordingly, high stereoselectivities are found for all chirally substituted ansa-metallocene catalysts with one-atom or two-atom bridges, ${ }^{[116-120]}$ at least at lower polymerization temperatures. At temperatures of $50-70^{\circ} \mathrm{C}$, typical for technical polymerizations, stereoselectivities are of-

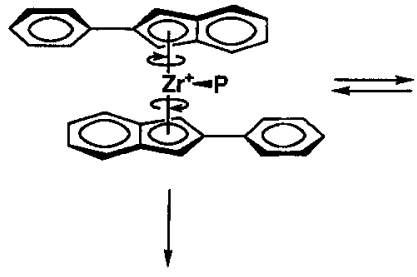

isotactic block

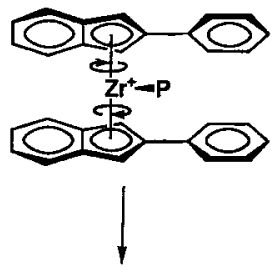

atactic block
Scheme 11. Reversible isomerization of an unbridged zirconocene catalyst between chiral and achiral geometries found by Waymouth and co-workers [125] to yieid isotactic and atactic blocks alternating along each polymer chain. The resulting polypropene is an elastomer.

ten substantially decreased. Incorporation of the ethylene bridge of (en)(ind) ${ }_{2} \mathrm{ZrCl}_{2}$ (which can fluctuate between $\delta$ and $\lambda$ chelate ring conformers $\left.{ }^{[126 a]}\right)$ into a carbocyclic system ${ }^{[127]}$ or its replacement by a one-atom silanediyl or germanediyl bridge ${ }^{[114 \mathrm{~b}, 116 \mathrm{c} .117 \mathrm{~b}]}$ increases stereoselectivities, but only to a limited extent. ${ }^{[117 \mathrm{~g}]}$ Even in metallocenes with a short $\mathrm{Me}_{2} \mathrm{Si}$ bridge, the $\mathrm{ZrX}_{2}$ and ligand framework moieties appear to retain substantial degrees of mobility. ${ }^{[126 b]}$ Molecular mechanics studies indicate that much of this mobility is restricted by substituents placed in $\alpha$-position to the bridgehead atom. ${ }^{[126 \mathrm{~b}]} \mathrm{Chi}$ rally substituted ansa-zirconocene catalysts with $\alpha-\mathrm{CH}_{3}$ groups at each $\mathrm{C}_{5}$ ring do indeed show increased stereoselectivities. ${ }^{[118-120]}$

Most interesting with respect to their effects on polymer stereoregularities, however, are the substituents in $\beta$-position to the bridgehead atom of an ansa-zirconocene. These $\beta$-substituents are in close proximity to the coordination sites at which the growing polymer chain and the $\alpha$-olefin substrate are bound. In the chiral complexes (en)(ind) ${ }_{2} \mathrm{ZrCl}_{2}$, (en)(thind) ${ }_{2} \mathrm{ZrCl}_{2}$, and $\mathrm{Me}_{2} \mathrm{Si}$ (ind) ${ }_{2} \mathrm{ZrCl}_{2}, \mathrm{CH}$ or $\mathrm{CH}_{2}$ groups of the annelated $\mathrm{C}_{6}$ ring function as $\beta$-substituents and flank each of the adjacent coordination sites. If the $\beta$-substituents are very bulky, as in $\mathrm{Me}_{2} \mathrm{Si}(2-$ Me-4- $\left.t \mathrm{Bu}-\mathrm{C}_{5} \mathrm{H}_{2}\right)_{2} \mathrm{ZrCl}_{2}{ }^{[120 \mathrm{a} \text {. b] }}$ or in Bercaw's [ $\mathrm{Me}_{2} \mathrm{Si}\left(2-\mathrm{SiMe}_{3}\right.$ 4-tert-butyl- $\left.\left.\mathrm{C}_{5} \mathrm{H}_{2}\right)_{2} \mathrm{YH}\right]_{2},{ }^{[144]}$ or particularly protruding, as in Spaleck's $\mathrm{Me}_{2} \mathrm{Si}$ (2-methyl-4-aryl-1-indenyl) ${ }_{2} \mathrm{ZrCl}_{2},{ }^{[117 \mathrm{~b}]}$ polypropenes with stereoregularities of $[\mathrm{mmmm}]>0.95$ are generated even at polymerization temperatures of $70-80^{\circ} \mathrm{C}$.

Chiral ansa-zirconocene complexes with two identical ligand moieties have $C_{2}$ symmetry. Both coordination sites of such a $C_{2}$-symmetric complex are thus equivalent; each is framed by the $\beta$-substituents in such a manner that olefin insertions at the $\mathrm{Zr}$ center occur with equal enantiofacial preference at both sites. Unilateral coverage of each coordination site is essential for this stereoselectivity; this is documented by the observation that atactic polypropene is produced if both coordination sites are flanked by two $\beta$-substituents, as in $\mathrm{C}_{2} \mathrm{H}_{4}$ (3-methyl-1-indenyl) ${ }_{2} \mathrm{ZrCl}_{2} / \mathrm{MAO}$ or in its silyl-bridged analogue $\mathrm{Me}_{2} \mathrm{Si}$ (3-methyl-1-indenyl) ${ }_{2} \mathrm{ZrCl}_{2} / \mathrm{MAO}^{[116 \mathrm{c}, 117 \mathrm{~h}]}$ The bilateral coverage of each coordination site in these complexes, by a $\mathrm{CH}$ and a $\mathrm{CH}_{3}$ group, appears to render them indifferent with respect to the enantiofacial orientation of an entering olefin. The same result, production of essentially atactic polymers, was also observed for the meso isomers of each ansa-metallocene catalyst. [105]

The relationship between the stereoselectivity of ansa-metallocene catalysts and the spatial disposition of their $\beta$-sub- 

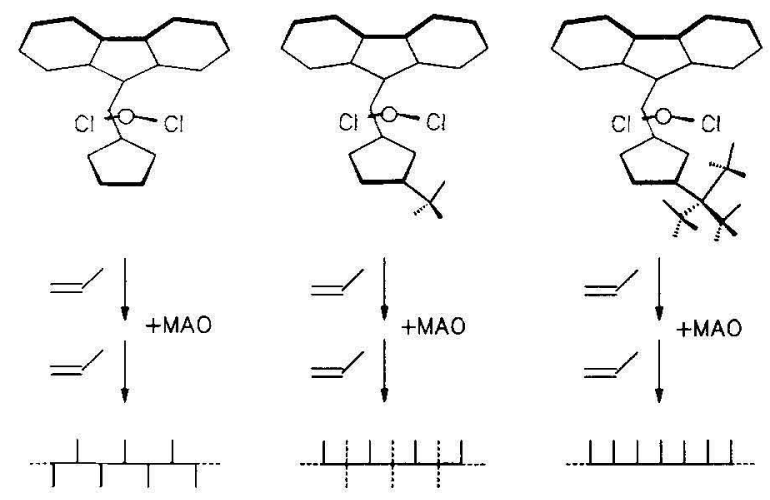

hemiisotactic

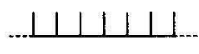

isotactic

Scheme 12. Relationship between catalyst structure and stereoselectivity discovered by Ewen and co-workers [116 d-h]. Syndiotactic polypropene is produced by $\mathrm{Me}_{2} \mathrm{C}\left(\mathrm{C}_{5} \mathrm{H}_{4}\right)\left(9\right.$-fluorenyl) $\mathrm{ZrCl}_{2} / \mathrm{MAO}$; introduction of a $\beta-\mathrm{CH}_{3}$ group on the $\mathrm{C}_{5}$ ring results in formation of hemiisotactic polymer in which every other repeat unit is randomly configurated; introduction of a $\beta$-tert-butyl group gives highly isotactic polypropene.

stituents has been most elegantly utilized by Ewen and co-workers in a series of studies on $\mathrm{Me}_{2} \mathrm{C}$-bridged fluorenyl complexes (Scheme 12). ${ }^{[16 d-h]}$ The complex $\mathrm{Me}_{2} \mathrm{C}(\mathrm{Cp})(9-f$ fluorenyl)$\mathrm{ZrCl}_{2}$, for example, is not a $C_{2}$-symmetric but a $C_{\mathrm{s}}$-symmetric structure with one unsubstituted $C_{5}$ ring ligand and, in its fluorenyl ligand, one $\mathrm{C}_{5}$ ring ligand with two $\beta$-substituents. ${ }^{[124 \mathrm{~b}, \mathrm{c}]}$ In the presence of MAO or cationic activators this complex produces highly syndiotactic polypropene..$^{[116 d-g, 117 d]}$

Syndiotactic polypropene is ideally characterized by a ${ }^{13} \mathrm{C}$ NMR spectrum with a single rrr pentad signal, as configurations alternate here from one repeat unit to the next. ${ }^{[128]}$ Ewen's syndiospecific catalyst provided this polypropene isomer for the first time in substantial quantities, with stereoregularities of $[\mathrm{rrr}]>0.9$ and with a pentad intensity distribution in accord with catalytic-site control. ${ }^{[16 \mathrm{~d}]}$ The alternating enantiofacial orientation of subsequent olefin insertions, which gives rise to this particular tacticity, is undoubtedly due to the fact that the two coordination sites in this $C_{\mathrm{s}}$-symmetric complex are no longer homotopic, as in a complex with $C_{2}$ symmetry, but enantiotopic. ${ }^{[129 \mathrm{c}]}$

The correlation between the substituent pattern of a metallocene and the stereoregularity of its polymer products is further extended by Ewen's finding that still another polypropene stereoisomer is formed with $\mathrm{MAO}$-activated $\mathrm{Me}_{2} \mathrm{C}\left(3-\mathrm{MeC}_{5} \mathrm{H}_{3}\right)$ (9-fluorenyl) $\mathrm{ZrCl}_{2} \cdot{ }^{[116 \mathrm{e}-\mathrm{g}, 117 \mathrm{~d}]} \mathrm{This}$ catalyst, with one coordination site framed by one $\beta$-substituent and one by two $\beta$-substituents (Scheme 12), produces hemiisotactic polypropene ${ }^{[129]}$ in which every other repeat unit is of identical configuration while the remaining units are randomly configurated. By totally blocking one of the coordination sites in the catalyst $\mathrm{Me}_{2} \mathrm{C}\left(3-t \mathrm{BuC}_{5} \mathrm{H}_{3}\right)\left(9\right.$-fluorenyl) $\mathrm{ZrCl}_{2} / \mathrm{MAO}$ with a tert-butyl group and a fluorenyl $\mathrm{C}_{6}$ ring, while keeping the other site unilaterally framed by the other fluorenyl $\mathrm{C}_{6}$ ring, Ewen and Elder finally obtained isotactic polypropene again. ${ }^{[116 \mathrm{~h}]}$

The stereoselectivity of a $C_{2}$-symmetric isotactic polymerization catalyst such as $\mathrm{Me}_{2} \mathrm{Si}$ (ind) ${ }_{2} \mathrm{ZrCl}_{2}$ is practically independent of zirconocene and MAO concentrations ${ }^{[131]}$ and essentially unaffected even by the replacement of MAO by a borane or borate activator. ${ }^{[116 f, 8,132 a, b]}$ The $C_{\mathrm{s}}$-symmetric syndiospecific catalyst $\mathrm{Me}_{2} \mathrm{C}(\mathrm{Cp})$ (9-fluorenyl) $\mathrm{ZrCl}_{2} / \mathrm{MAO}$, how-

ever, behaves differently in this regard: its syndiotactic polymers show more frequent rmrr errors when either MAO or olefin concentrations are decreased, ${ }^{[116 e, f, 132 a]}$

Ewen et al ${ }^{[116 f]}$ and Herfert and Fink ${ }^{[132 a]}$ showed that this dependence must indeed result from a crucial requirement for syndiotactic polymerization: each olefin insertion has to occur at the coordination site opposite to the previous one. This requirement can only be met when the polymer chain remains at the coordination site of the previous olefin unit until the next olefin insertion occurs. Stereoerrors with single- $m$ dyads must result whenever the polymer chain moves to the opposite coordination site before the next olefin inserts. Such an event ${ }^{[133]}$ will become more likely when the rate of olefin insertion is decreased by low olefin or MAO concentrations. Similar changes in the stereoregularity of hemiisotactic polypropene, recently reported by Herfert and Fink ${ }^{[132 c]}$ and by Farina and co-workers, ${ }^{[129 b]}$ and of partly isotactic polypropene obtained with several asymmetric catalysts, ${ }^{[130]}$ underscore the importance of the relative rates of olefin insertion and chain migration between coordination sites for these non- $C_{2}$-symmetric metallocene catalysts.

While olefin insertion in metallocene-based homogeneous catalysts, as in heterogeneous Ziegler-Natta systems, ${ }^{[10,12]}$ generally occurs with 1,2-regioselectivity so as to generate primary $\mathrm{Zr}$-alkyl units, polyolefins produced with metallocenebased catalysts contain varying fractions of regioinverted units. ${ }^{[114 a, 135,136]}$ Depending on the polymerization temperature and on the metallocene catalyst used, one finds either headto-head concatenations resulting from primary olefin insertion into regioinverted secondary $\mathrm{Zr}$-alkyl units, or tetramethylene units (1,3-insertions). The latter arise from an isomerization of a secondary $\mathrm{Zr}$-alkyl unit to one with a terminal $\mathrm{Zr}$-alkyl bond prior to insertion of the next olefin ${ }^{[114 a, 136]}$ (Scheme 13).

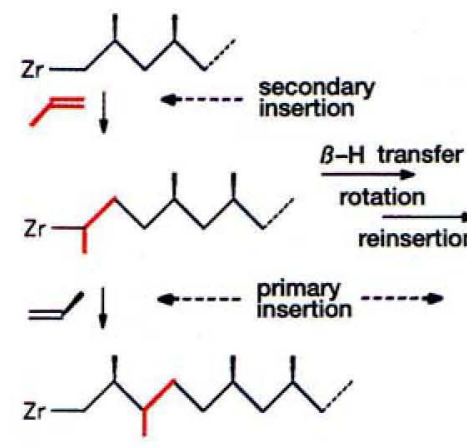

"2,1-insertion"
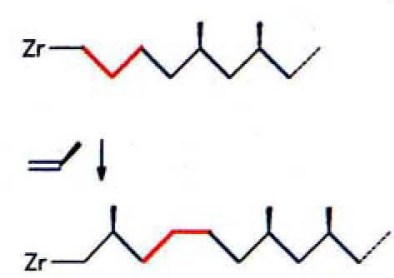

"1,3-insertion"
Scheme 13. Alternative sequences arising from a secondary olefin insertion [114a, 136]. A (relatively slow) primary insertion gives the tail-to-tail and head-to-head pattern typical of a 2,1-insertion; rearrangement of the secondary $\mathrm{Zr}$-alkyl unit into its terminal isomer, followed by a primary insertion, yields a tetramethylene or 1,3-insertion unit.

Different zirconocene catalysts produce the regioirregularities in different ratios: ${ }^{[69 \mathrm{~b}]}$ only 1,3 -misinsertions (ca. 1\%) are found in polymers made with (en)(thind) ${ }_{2} \mathrm{ZrCl}_{2} / \mathrm{MAO}$; with (en)(ind) $\mathrm{ZrCl}_{2} / \mathrm{MAO}$ both types of misinsertions are present; and $\mathrm{Me}_{2} \mathrm{Si}$ (ind) $\mathrm{ZrCl}_{2} / \mathrm{MAO}$ forms polymers with only 2,1misinsertions (ca. $0.6 \%$ ) at $40^{\circ} \mathrm{C}$. With "fast" catalysts, misin- 
sertions are generally of the 2,1-type; slower catalysts produce mainly 1,3-misinsertions. ${ }^{[117 \mathrm{~h}, 120 \mathrm{~d}]}$ Effects of these misinsertions on catalyst activities will be considered in Section 3.3.

The irregularities introduced into a polypropene chain by 2,1 or 1,3-misinsertions decrease its melting point considerably (see Section 3.4); these misinsertions are thus of practical concern. Their frequency seems to depend mainly on the steric demands of the substituents on the $C_{5}$ ring. Rather frequent misinsertions are found for metallocenes with bulky $\beta$-substituents, while $\alpha$ methyl substituents appear to suppress these regioirregularities. ${ }^{[120 a-c]}$

Steric relationships in a metallocene complex can be described by its "coordination-gap aperture", the largest possible angle spanned by two planes through the metal center which touch the van der Waals surfaces of the $\beta$-substituents at the $C_{5}$ ring ligands, and by its "lateral extension angle", which is limited by the two $\alpha$-substituents protruding into the coordination gap (Fig. 5). ${ }^{[137 a]}$
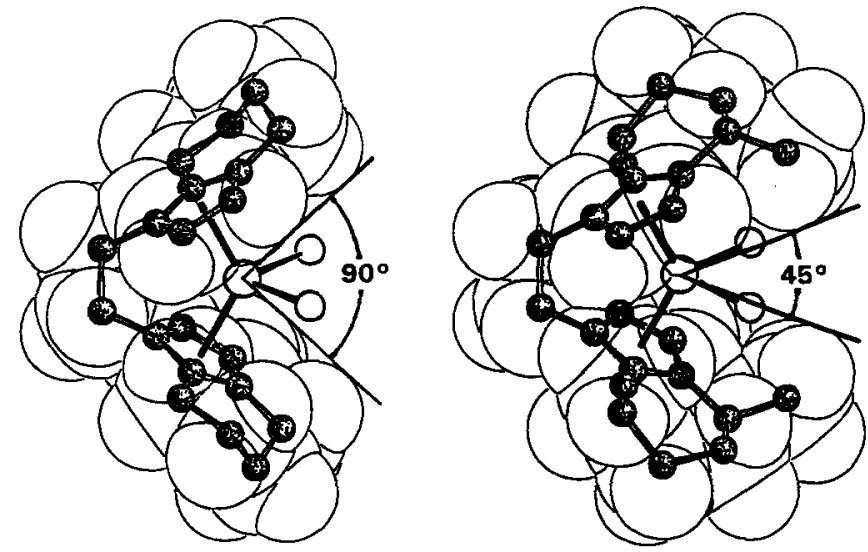

Fig. 5. Right: Narrow coordination gap aperture [137] of rac- $\mathrm{C}_{2} \mathrm{H}_{4}(4,7$-dimethyltetrahydroindenyl ${ }_{2} \mathrm{ZrCl}_{2}$ was found by Spaleck and co-workers [117i] to produce unusually large fractions (ca. $24 \%$ ) of 1,3 -misinsertions (molecular model). Left: Crystal structure of unsubstituted $r a c-\mathrm{C}_{2} \mathrm{H}_{4}$ (tetrahydroindenyl) ${ }_{2} \mathrm{ZrCl}_{2}$ [103] for comparison (see Fig. 3)

A secondary olefin insertion (2,1-insertion) is expected-due to the lateral orientation of the olefin substituent-to require less space in the aperture direction but more space in the lateral direction than a regular 1,2-insertion. Regioinversions are thus favored by those zirconocene catalysts whose $\beta$-substituents strongly limit the gap aperture, provided that the lateral extension angle is not restricted also by $\alpha$-substituents protruding into the coordination gap. ${ }^{[137 b, c]}$ Polypropene with an unusually high fraction of 1,3-misinsertions has been reported by Spaleck and co-workers ${ }^{[117]}$ to arise from the catalyst $\mathrm{C}_{2} \mathrm{H}_{4}(4,7-$ dimethyl-thind) ${ }_{2} \mathrm{ZrCl}_{2} / \mathrm{MAO}$, whose endo-oriented 4-methyl groups severely restrict the coordination gap aperture (Fig. 5).

\subsection{Mechanisms of Stereochemical Control}

The mechanisms by which chiral ansa-metallocenes control the stereochemistry of polymer growth are reasonably well-understood today. As usual, stereochemical analysis affords more reliable information on a reaction mechanism than most other methods. This analysis is simplified, furthermore, by the observation that the stereoregularity of isotactic polymers is rather insensitive to MAO or zirconocene concentrations ${ }^{[120 \mathrm{c}, 132 \mathrm{a}]}$ (see, however, ref. [131]) and even to the type of activator used to generate the reactive cationic species. ${ }^{[116 f, g, 132 b, 151 b]}$

First important clues as to the factors governing the stereoselectivity of $C_{2}$-symmetric, chiral metallocene catalysts came from ${ }^{13} \mathrm{C}$ NMR studies of Zambelli and co-workers. These authors followed the course of propene and 1-butene insertions into ${ }^{13} \mathrm{C}$-enriched $\mathrm{CH}_{3}$ and $\mathrm{CH}_{2} \mathrm{CH}_{3}$ end groups, which were introduced into a MAO-activated (en)(ind) ${ }_{2} \mathrm{TiMe}_{2}$ catalyst by alkyl exchange with $\mathrm{Al}\left({ }^{13} \mathrm{CH}_{3}\right)_{3}$ or $\mathrm{Al}\left({ }^{13} \mathrm{CH}_{2} \mathrm{CH}_{3}\right)_{3} \cdot{ }^{[138]}$ The results of these studies can be summarized as follows:

1. Propene inserts into (en)(ind) ${ }_{2} \mathrm{Ti}-{ }^{13} \mathrm{CH}_{3}$ bonds without significant stereoselectivity, as shown by signals of diastereomeric end groups with almost equal intensity.

2. Butene insertion into (en)(ind) ${ }_{2} \mathrm{Ti}-{ }^{13} \mathrm{CH}_{3}$ bonds occurs with slight $(2: 1)$ selectivity.

3. Complete stereoselectivity prevails when either propene or butene inserts into (en)(ind) ${ }_{2} \mathrm{Ti}-{ }^{13} \mathrm{CH}_{2} \mathrm{CH}_{3}$ bonds.

4. All these results resemble those obtained before with analogously activated heterogeneous polymerization catalyst systems, ${ }^{[1}$ 2]

Efficient control of the chiral catalyst over the enantiofacial orientation of the entering olefin is thus clearly contingent on the presence of a metal-alkyl segment with at least two $\mathrm{C}$ atoms. This segment appears to act as a sort of lever in transmitting the effects of the $\beta$-substituents on the orientation of the prochiral $\alpha$-olefin.

The nature of this stereocontrol mechanism was clarified by molecular mechanics calculations by Corradini, Guerra, and co-workers. ${ }^{[139]}$ As previously proposed for heterogeneous Ziegler-Natta catalysis, ${ }^{[12 \mathrm{~b}]}$ repulsive interactions were shown to force an olefin into that enantiofacial approach to the metalalkyl unit which places the olefin substituent trans to (i.e. away from) the $\beta$-C atom of the metal-bound alkyl chain. The metalalkyl chain, in turn, was proposed to favor an orientation in which its $\mathrm{C}(\alpha)-\mathrm{C}(\beta)$ segment is in the most open sector of the chiral ansa-metallocene ligand framework (Scheme 14). Subsequent model studies in other groups by means of more elaborate force field and $a b$ initio methods ${ }^{[85,86]}$ support this proposal.

Analogous considerations hold for stereocontrol mechanisms for ansa-metallocene derivatives that produce syndiotactic and hemiisotactic polymers. ${ }^{[116 e-g, 139 e, g-i, 140]}$ In each case, the $\mathrm{C}(\alpha)-\mathrm{C}(\beta)$ segment of the polymer chain appears to orient itself so as to avoid interaction with the $\mathrm{C}_{5}$ ring substituents in $\beta$-position adjacent to its coordination site (Scheme 15); an entering olefin is then forced into that orientation in which the two alkyl substituents at the incipient $\mathrm{C} \cdots \mathrm{C}$ bond are trans to each other. ${ }^{[141]}$

Experimental proof for this catalytic-site control by means of chain-segment orientation was provided by Pino and co-workers. ${ }^{[142]}$ Chiral hydrotrimers and hydrotetramers with the predicted absolute configurations were obtained when propene was hydrooligomerized ${ }^{[143 a]}$ with enantiomerically pure ${ }^{[103.125]}$ (en)(thind) ${ }_{2} \mathrm{ZrMe}_{2}$ activated by $\mathrm{MAO}$ in the presence of $\mathrm{H}_{2}$. Formation of asymmetric oligomers with olefinic end groups in similar reaction systems without $\mathrm{H}_{2}$ were studied by Kaminsky and co-workers ${ }^{[143 \mathrm{~b}]}$ and found to follow the same rules. 

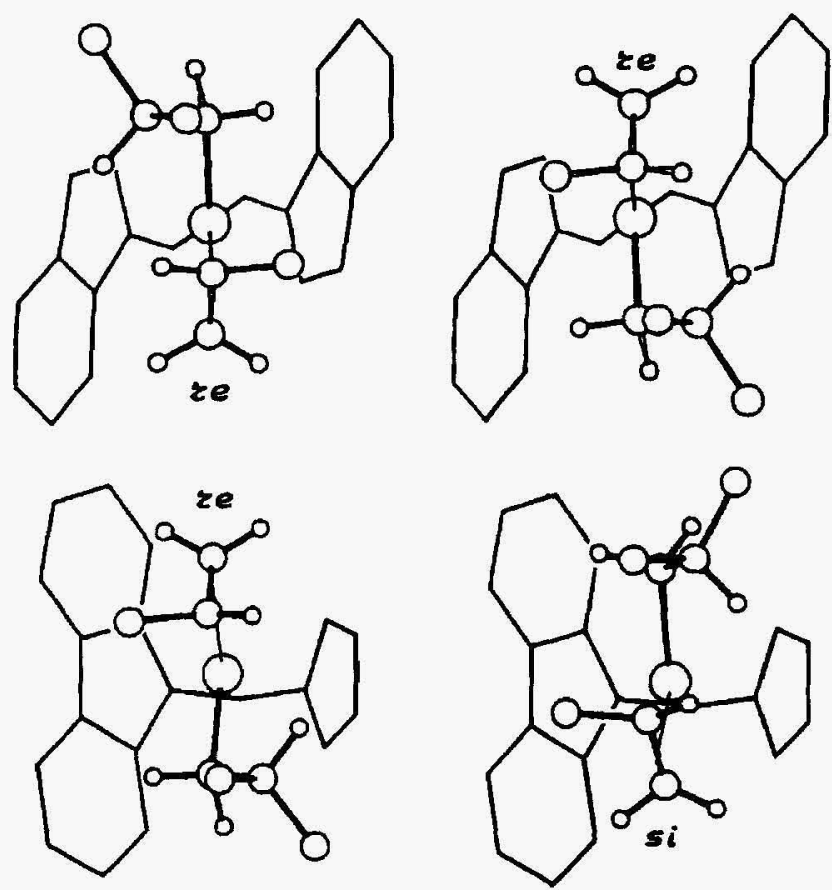

Scheme 14. Models for the stereocontrol of olefin insertions in ansa-zirconocene catalysts, proposed by Corradini, Guerra, and co-workers [139]. The growing alkyl chain occupies an open sector of the ligand framework; the olefin enters the reaction complex with its substituent trans to the $\mathrm{C}(\alpha)-\mathrm{C}(\beta)$ chain segment. For $C_{2}$-symmetric complexes identical enantiofacial olefin orientation at both coordination sites results in isotactic polymer formation (top); for $C_{\mathrm{s}}$-symmetric complexes the enantiofacial orientation alternates between coordination sites and leads to syndiotactic polymers (bottom)

The origin of stereoselectivity in ansa-metallocene catalysts was further examined by use of $\alpha$-deuterated olefins. In studies similar to those previously reported for achiral zirconocene and scandocene catalyst systems, ${ }^{[80,82]}$ stereokinetic isotope effects of $k_{\mathrm{H}} / k_{\mathrm{D}} \approx 1.4$ were observed for hydrodimerization of $(E)$ - and (Z)-1-[D $\left.\mathrm{D}_{1}\right]-1$-hexene by chiral ansa-zirconocene and scandocene catalyst systems. ${ }^{[144-146]}$ This indicates that the insertion reaction favors a transition state in which the $\alpha-H$ and not the $\alpha-D$ atom of initially formed $\mathrm{Zr}-\mathrm{CHD}-\mathrm{R}$ unit is in a position suitable for $\alpha$-agostic interaction with the metal center. Recently stereokinetic isotope effects of $k_{\mathrm{H}} / k_{\mathrm{D}} \approx 1.3$ were determined directly for isotactic propene polymerizations catalyzed by (en)(thind) ${ }_{2} \mathrm{ZrCl}_{2} / \mathrm{MAO}$ and other chiral ansa-zirconocene catalysts from the mean chain lengths of polymers produced from either $(E)$ - or $(Z)-1-\left[\mathrm{D}_{1}\right]$-propene (Scheme 15).$^{[145 \mathrm{~b}]}$ These results indicate that $\alpha$-agostic interactions control the stability of alternative transition states for the insertion of an olefin into a metal-alkyl bond.

These $\alpha$-agostic interactions can thus be considered to be the origin of the stereoselectivity of chiral ansa-metallocene catalysts. Of the two alternative $\mathrm{Zr}-\mathrm{C}(\alpha)-\mathrm{C}(\beta)$ orientations resulting from binding one of the $\alpha-\mathrm{H}$ atoms to the metal center, one orientation is sterically inaccessible since it would cause the growing chain to collide with a $\beta$-substituent of the chiral ligand framework; the other one is sterically unencumbered and in fact practically indistinguishable from that proposed by Corradini and co-workers ${ }^{[139]}$ on the basis of nonbonding van der Waals repulsions alone (see Scheme 14). The $\alpha$-agostic model would thus describe the re or si orientation of an inserting olefin as

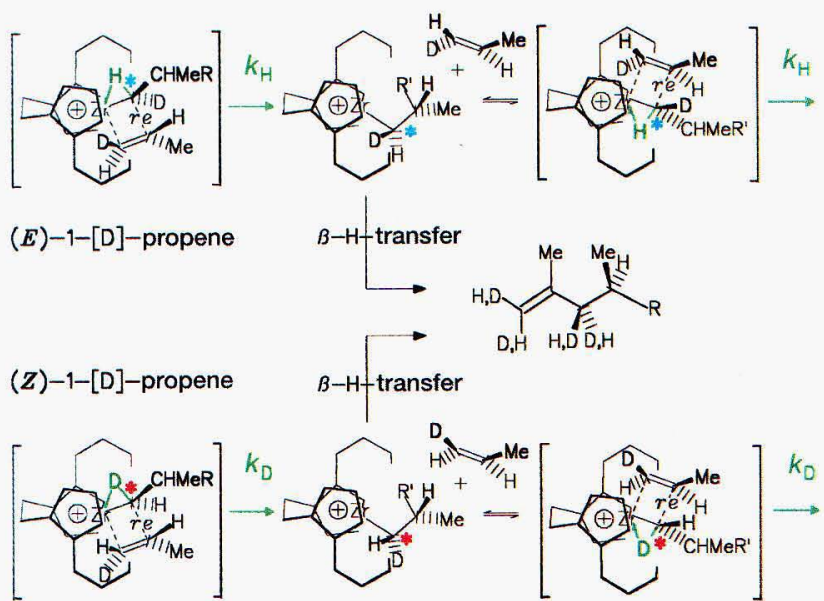

Scheme 15. Stereokinetic isotope effects in isotactic polypropene formation indicate $\alpha$-agostic interactions in the olefin insertion transition state [145]. Chain growth with $(E)-1-[D]$-propene proceeds faster, due to its $\mathrm{Zr} \leftarrow \mathrm{H}-\mathrm{C}(x)$-stabilized transition state, than that with $(Z)-1$-[D]-propene, which proceeds via a transition state with a $\mathrm{Zr}-\mathrm{D}-\mathrm{C}(x)$ interaction; this is manifested in polymer chain lengths that are ca. 1.3 times longer for $(E)$ - than for $(Z)$-1-[D]-propene.

being controlled by the required placement of the $\beta$-C atom of the growing chain in the more open of the two possible positions at a rigid three-membered $\mathrm{Zr}-\mathrm{H}(\alpha)-\mathrm{C}(\alpha)$ ring.

The exclusion of one of the possible $\mathrm{Zr}-\mathrm{H}(\alpha)$ interactions implied by this model raises questions as to the origin of the stereoerrors produced by homogeneous catalysts especially at higher reaction temperatures. Increased stereoerror frequencies at decreased olefin concentrations, recently observed by Cipullo and Busico, and by Resconi and co-workers, ${ }^{[131]}$ were ascribed to an epimerization of the last inserted unit, which competes with olefin insertion. Direct evidence for stereoerror formation by chain-end isomerization was obtained by Leclerc and Brintzinger from a study of D-label distributions in isotactic polypropene obtained from $(E)$ - or $(Z)-\left[\mathrm{D}_{1}\right]$-propene with chiral ansa-zirconocene catalysts. ${ }^{[145 b]}$ The appearance of $\mathrm{CH}_{2} \mathrm{D}$ instead of $\mathrm{CH}_{3}$ groups in the mrrm stereoerror positions indicates that most of these errors arise from the isomerization represented in Scheme 16. ansa-Zirconocene catalysts with par-
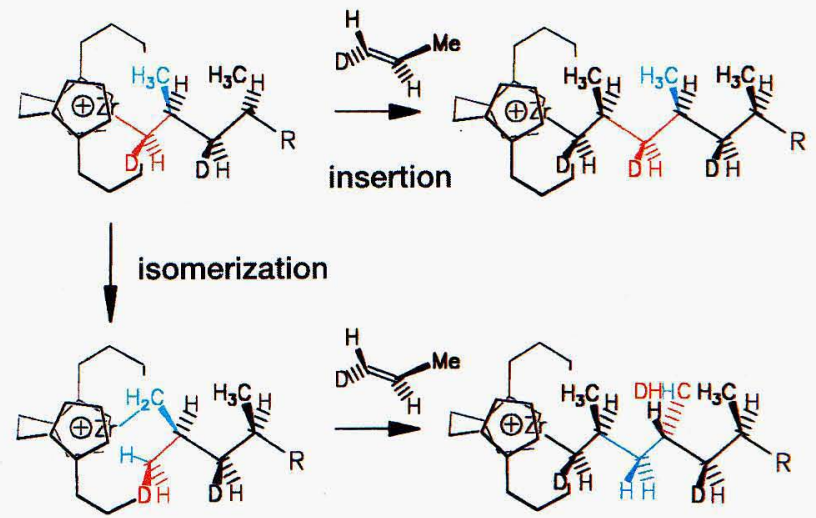

Scheme 16. Formation of stereoerrors by chain-end isomerization [145]. Isolated (mrrm-framed) stereoerrors are associated with $\mathrm{CH}_{2} \mathrm{D}$ instead of $\mathrm{CH}_{3}$ groups in isotactic polypropene made from $(E)$ - or (Z)-1-[D]-propene with (en)(thind) $\mathrm{ZrCl}_{2}$ / $\mathrm{MAO}$. The stereoinverted $\mathrm{CH}_{2} \mathrm{D}$ groups must originate from the $\alpha-\mathrm{CHD}$ olefin terminus by an isomerization process, the exact mechanism of which is still being debated [131 a, b] 
ticularly high stereoselectivity ${ }^{[117 h, i, 120 b, d]}$ thus appear to owe this property to their suppression of chain-end isomerization relative to olefin insertion.

\subsection{Activities of ansa-Zirconocene Catalysts}

The rate of a reaction is normally expected to decrease when it is made stereoselective by imposing steric restrictions on some of its possible reaction modes. Yet even the first studies on propene polymerization with the chiral ansa-zirconocene catalyst rac-(en)(thin) $\mathrm{ZrCl}_{2} / \mathrm{MAO}$ showed its catalytic activity to be substantially higher than that of the stereochemically unselective, unsubstituted catalyst $\mathrm{Cp}_{2} \mathrm{ZrCl}_{2} / \mathrm{MAO}{ }^{[106,107 \mathrm{~g}]}$ Even the sterically strongly congested chiral catalyst $\mathrm{rac}-\mathrm{Me}_{2} \mathrm{Si}(2-\mathrm{Me}-$ 4- $\left.t \mathrm{Bu}-\mathrm{C}_{5} \mathrm{H}_{2}\right)_{2} \mathrm{ZrCl}_{2} / \mathrm{MAO}$ produces polypropene at higher rates than $\mathrm{Cp}_{2} \mathrm{ZrCl}_{2} / \mathrm{MAO}$ system. [120c]

Apparently, some favorable effects compensate for the steric congestion of a $\beta$-substituted ansa-metallocene. $\beta$-Substituents might favor formation of active, olefin-separated ion pairs at the expense of the presumably dormant contact ion pairs or, alternatively, facilitate access to an $\alpha$-agostic insertion transition state by destabilizing the $\beta$-agostic interactions that otherwise compete.

With regard to the effects of different bridging units linking the $\mathrm{C}_{5}$ ring ligands, one finds that zirconocenes with the oneatom bridge $\mathrm{Me}_{2} \mathrm{Si}$ yield somewhat more active catalysts than otherwise comparable complexes with the two-atom bridge $\mathrm{C}_{2} \mathrm{H}_{4}$, ${ }^{[16 \mathrm{f}, 117 \mathrm{gI}}$ most likely because such a short bridge widens the coordination-gap aperture. ${ }^{[137]}$ Zirconocenes with threeatom or four-atom bridges have so far all been found to be practically inactive for propene polymerization in the presence of MAO. ${ }^{[117 b, 148-150 a]}$ The same is true for chiral zirconocenes containing two $\mathrm{Me}_{2} \mathrm{Si}$ bridges. ${ }^{[150 \mathrm{~b}]}$ Structural studies on these inactive complexes reveal that the geometrical constraints of their interannular bridges place at least one and, in some cases, two of the substituents on the $C_{5}$ ring in a central position close to the meridional centroid $-\mathrm{Zr}$-centroid plane (Fig. 6). Substituents in this position appear to interfere with the course of the otherwise facile insertion of an $\alpha$-olefin into the $\mathrm{Zr}$-bound alkyl chain, most probably by colliding with the alkyl substituent of the olefin substrate, which has to be close to this meridional position in the insertion transition state. In accord with this view, these propene-inactive catalysts are generally found to be active in the polymerization of ethene, which is unobstructed by a substituent. ${ }^{[117 b, 150,151 a]}$

Different ring substituents also affect catalyst activities to a substantial degree. Low activities in MAO-activated propene polymerization are obtained with the tert-alkyl-substituted ansa-zirconocenes $\mathrm{Me}_{2} \mathrm{Si}\left(2-\mathrm{Me}-4-\mathrm{R}-\mathrm{C}_{5} \mathrm{H}_{2}\right)_{2} \mathrm{ZrCl}_{2}$ with $\mathrm{R}=$ tert-butyl or 1-methyl-cyclohexyl. ${ }^{[120 \mathrm{c}]} \mathrm{A}$ kinetic study by Fischer and Mülhaupt revealed, however, that these catalyst systems show even higher initial activities than some of the most productive bis(benzindenyl) catalysts, but differ from these by a very fast deactivation to rather low levels of residual steadystate activity. ${ }^{[69 \mathrm{~d}]}$

Annelation of further six-membered rings as in $\mathrm{Me}_{2} \mathrm{Si}$ (benz $[e]$ indenyl $)_{2} \mathrm{ZrCl}_{2}$ results in three- to fourfold increases in productivity. ${ }^{[117 \mathrm{~h}, \mathrm{i}, 12 \mathrm{~d}]}$ These high activities are likely to stem
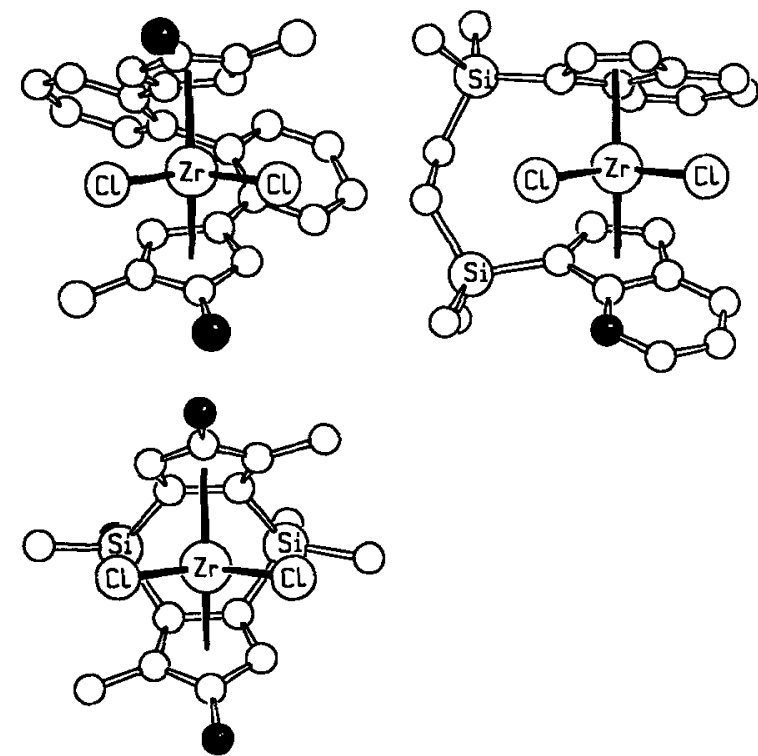

Fig, 6. Crystal structures of ansa-zirconocene complexes that are inactive for propene polymerization in the presence of MAO $[117 \mathrm{~b}, 150]$. A substituent on the $\mathrm{C}_{5}$ ring close to the meridionat centroid $-\mathrm{Zr}$-centroid plane appears to block the insertion of propene (but not that of ethene).

from steric or electronic shielding of the cationic reaction center against coordination of MAO-bound anions or other metallocene units by the extended annelated ring systems. Overall, little is known about the effects of electronic factors on catalyst activities. ${ }^{[119 b, 152]}$

Isospecific metallocene catalysts usually polymerize propene at rates four to five times slower than those for ethene. ${ }^{[132 a]}$ This preference for ethene is less pronounced, however, than that observed with the unsubstituted system $\mathrm{Cp}_{2} \mathrm{ZrCl}_{2} / \mathrm{MAO}^{[39 e, f]}$ Ewen's $C_{\mathrm{s}}$-symmetric, syndiospecific catalyst is unique in that it polymerizes propene with higher activity than ethene. ${ }^{[132 a]}$ Higher $\alpha$-olefins such as 1 -butene ${ }^{[106]}$ and 1 -hexene, ${ }^{[50 c]}$ and even $\alpha$-olefins branched at their 4-position such as 4-methyl-1hexene ${ }^{[152]}$ are polymerized by ansa-metallocene catalysts at rates only moderately lower than those for propene. The rather low degree of chemoselectivity of these catalysts is essential for their properties as copolymerization catalysts (cf. Section 4.1).

Studies with chiral olefins such as 4-methyl-1-hexene have shown that an enantiomeric catalyst center-both in homogeneous ${ }^{\left[{ }^{[52]}\right.}$ and in heterogeneous catalyst systems ${ }^{[153 a]}$--tends to incorporate preferentially one of the olefin enantiomers into the growing polymer chain. ${ }^{[153 \mathrm{~b}, \mathrm{c}]}$

With $\alpha$-olefins branched in 3-position such as 3-methyl-1-pentene, ansa-zirconocene catalysts generally have negligible activities. ${ }^{[154]}$ Styrene, formally also an olefin branched in 3-position, has not yet been polymerized at any worthwhile rate by MAOactivated metallocene catalysts. ${ }^{[36]}$ The $\mathrm{CpTiR}_{3} / \mathrm{MAO}$ systems that catalyze this reaction ${ }^{[7 b]}$ appear to polymerize styrene through a 2,1-concatenation, that is, by formation of secondary insertion products. ${ }^{[138 \mathrm{~b}, 155]}$ Apparently, the regioselectivity of ansa-zirconocene-based polymerization catalysts for 1,2-insertions is incompatible with the preference of styrene for 2,1-insertion.

Occasional regioerrors appear to inhibit the polymerization of normal $\alpha$-olefins by MAO-activated metallocene catalysts 
significantly. ${ }^{[14,120,136,156,157]}$ Kashiwa, Tsutsui, and coworkers ${ }^{[156]}$ found that the rates of propene and butene polymerization by (en)(ind) $\mathrm{ZrCl}_{2} / \mathrm{MAO}$ increase in the presence of $\mathrm{H}_{2}$ roughly 10 - and 60 -fold, respectively. These polymers were found to be free of misinserted units; hydrogenolysis apparently eliminates the slowly inserting 2,1-units and allows the start of a new, fast-growing polymer chain.

Busico, Cipullo, and Corradini ${ }^{[157]}$ determined the frequency with which oligomers having primary and secondary end groups are liberated from zirconocene centers by hydrogenolysis in propene hydrooligomerization catalyzed by (en)(ind) ${ }_{2} \mathrm{ZrCl}_{2} /$ $\mathrm{MAO}$. Their data indicate that insertion of propene into a secondary $\mathrm{Zr}$-alkyl unit is about 100 times slower than into a primary one. ${ }^{[158]}$ As a consequence, 2,1-insertions with an incidence frequency of only $1 \%$ are sufficient to tie up about $90 \%$ of the catalyst in secondary $\mathrm{Zr}$-alkyl units when polymerizations are conducted in the absence of $\mathrm{H}_{2}$. Based on Busico's estimate, substantially increased activities can be expected for a catalyst that would be unimpeded by occasional 2,1-misinsertions.

Activities of chiral zirconocene catalysts are also affected by $\mathrm{MAO}$ concentrations. Increasing activation occurs at $\mathrm{Al}: \mathrm{Zr}$ ratios of up to roughly $1-5000: 1$, while inhibition is observed at still higher $\mathrm{Al}: \mathrm{Zr}$ ratios. ${ }^{\text {[75.132a] }}$ For propene polymerization with (en)(thind) $\mathrm{ZrCl}_{2} / \mathrm{MAO},{ }^{[106.116 \mathrm{~b}]} \mathrm{Me}_{2} \mathrm{Si}$ (ind) ${ }_{2} \mathrm{ZrCl}_{2}$ $\mathrm{MAO},{ }^{[116.117 \mathrm{c}]}$ or $\mathrm{Me}_{2} \mathrm{C}(\mathrm{Cp})(9-f]$ orenyl) $\mathrm{ZrCl}_{2} / \mathrm{MAO}$ activity maxima are found at $\mathrm{Al}: \mathrm{Zr}$ ratios between about 1000:1 and 10000:1. ${ }^{[11 \mathrm{id}-\mathrm{f}]}$ Apparently, yet unknown types of equilibria interconnect a diversity of species in these reaction systems.

Puzzling is also the dependence of catalyst activities on the monomer concentration. In several recent studies ${ }^{[69 \mathrm{e}, 120 \mathrm{~d}, 132 \mathrm{c}]}$ polymerization rates have been observed to increase more than linearly with olefin concentrations, for example, as [olefin] ${ }^{1.4-1.7}$. Whether these observations indicate the participation of more than one olefin molecule in the insertion transition state ${ }^{[76]}$ a notion diverging from most of the current thinking about this reaction--or whether they arise from the participation of a second olefin in another reaction step that augments the overall activity of the catalyst, such as reactivation following a 2,1 -insertion, ${ }^{[156,157]}$ remains to be clarified.

\subsection{Polymer Chain Lengths and Crystallinity}

Molecular weight is another property of polyolefins that is strongly influenced by the metallocene catalyst employed. Initial studies with (en)(ind) ${ }_{2} \mathrm{ZrCl}_{2} / \mathrm{MAO}$ and (en)(thind) ${ }_{2} \mathrm{ZrCl}_{2}$ / MAO yielded polypropene with molecular weights ranging from $M_{\mathrm{w}} \approx 50000 \mathrm{~g} \mathrm{~mol}^{-1}$ at ambient polymerization temperatures down to $M_{\mathrm{w}} \approx 10000 \mathrm{~g} \mathrm{~mol}^{-1}$ at $60-70{ }^{\circ} \mathrm{C} .^{[106,112,114,116 \mathrm{c}, 117 \mathrm{~g}]}$ These molecular weights are almost two orders of magnitude higher than those of the atactic polypropene obtained under otherwise identical conditions with $\mathrm{Cp}_{2} \mathrm{ZrCl}_{2} / \mathrm{MAO}$. This effect is probably due, at least in part, to an increased rate of chain propagation $v_{\mathbf{p}}$ for ansa-metallocene catalysts. ${ }^{[17 \mathrm{~g}]}$ In addition to an increased $v_{\mathrm{p}}, \beta$-substituents in these complexes might also cause a decreased rate of chain termination $v_{\mathrm{T}}$, for example by sterically hindering the tertiary $\beta-\mathrm{CH}$ group of the growing chain in its approach to the $\mathrm{Zr}$ center. Bulky $\beta$-tert-butyl sub- stituents as in $\mathrm{Me}_{2} \mathrm{Si}\left(2-\mathrm{Me}-4-t \mathrm{Bu}-\mathrm{C}_{5} \mathrm{H}_{2}\right)_{2} \mathrm{ZrCl}_{2} / \mathrm{MAO}$ lead to rather low molecular weights at elevated temperatures $^{[69 \mathrm{~b} .120 \mathrm{a}-\mathrm{c}]}$ A relatively high fraction of isopropyl end groups indicates that chain growth is frequently terminated here by transfer of the polymer chain to an $\mathrm{Al}$ center, presumably of the trimethylaluminum component of the MAO cocatalyst. ${ }^{[120 \mathrm{c}]}$

The molecular weights initially accessible with metallocenebased catalysts were far lower than those obtained with heterogeneous Ziegler-Natta catalysts. Higher molecular weight polymers were obtained with the analogous hafnium complexes (en)(ind) ${ }_{2} \mathrm{HfCl}_{2} / \mathrm{MAO}$ and (en)(thind) ${ }_{2} \mathrm{HfCl}_{2} / \mathrm{MAO}$, albeit at the expense of substantially decreased catalytic activities. ${ }^{[116 b . c .135]}$ Further studies revealed that additional $\alpha$ methyl substituents at each $C_{5}$ ring ligand increase molecular weights of the polymers produced by factors of 3 to $5 .^{[118,120 a-c]}$ With $\alpha$-methylated complexes such as $\mathrm{Me}_{2} \mathrm{Si}(2-$ Me-ind) ${ }_{2} \mathrm{ZrCl}_{2}$ and $\mathrm{Me}_{2} \mathrm{Si}$ (2-Me-benzind) ${ }_{2} \mathrm{ZrCl}_{2}$, polypropene can be obtained at $T_{\mathrm{P}}=50^{\circ} \mathrm{C}$ with molecular weights of $M_{\mathrm{w}}=100000-400000 \mathrm{~g} \mathrm{~mol}^{-1} .^{[117 \mathrm{f}, \mathrm{h}, 120 \mathrm{~d}]}$ Polypropene with $M_{\mathrm{w}}$ close to $1000000 \mathrm{~g} \mathrm{~mol}^{-1}$ is accessible with the catalyst $\mathrm{Me}_{2} \mathrm{Si}$ (2-methyl-4-naphthyl-1-indenyl) ${ }_{2} \mathrm{ZrCl}_{2} / \mathrm{MAO}$ developed by Spaleck and co-workers. ${ }^{[117 \mathrm{~h}]}$

$\beta$-Hydride transfer from the growing polymer chain directly to a coordinated olefin (see Scheme 8 ) has been implied as a dominant chain termination process by studies on endgroup distributions in ethene-propene copolymers ${ }^{[97]}$ and on hydrooligomer distributions at different olefin concentrations. ${ }^{[157 \mathrm{c}]}$ In ansa-zirconocene catalysts without $\alpha$-methyl substituents, direct $\beta$-H transfer from the growing polymer chain to a coordinated olefin does indeed appear to predominate, as indicated by a near-constancy of molecular weights with increasing olefin concentration. ${ }^{[120 \mathrm{~d} .157 \mathrm{k}]}$ For ansa-metallocene catalysts with $\alpha$-methyl substituents, however, a strong increase of molecular weight almost proportional to olefin concentration ${ }^{[117 \mathrm{~h}, 120 \mathrm{~d}]}$ indicates that the remaining chain termination arises almost exclusively from $\beta-\mathrm{H}$ transfer to the metal. $\alpha$ Methyl substituents thus appear to block a relatively large fraction of chain terminations that would otherwise arise from $\beta-\mathrm{H}$ transfer directly to a coordinated olefin.

Narrow molecular weight distributions, as measured by polydispersity ratios of $M_{\mathrm{w}} / M_{\mathrm{n}} \approx 2,[105,106,112,114,117 \mathrm{~g}, 118,120]$ are as typical for these stereoregular polyolefins as for the atactic polymers produced with $\mathrm{MAO}$-activated $\mathrm{Cp}_{2} \mathrm{ZrCl}_{2} \cdot{ }^{[39 \mathrm{e}, \mathrm{g}]} \mathrm{Sub}$ stituted ansa-zirconocene catalysts thus also appear to induce the growth of their respective polymer products at a single type of active center.

A polydispersity of $M_{\mathrm{w}} / M_{\mathrm{r}} \approx 1$, which indicates a "living" polymerization system (i.e. polymer chains permanently attached to the metal centers on which they simultaneously start to grow),${ }^{[90]}$ are typically observed for ring-opening metathe$\operatorname{sis}^{[159,160]}$ and group-transfer polymerization catalysts, ${ }^{[161 \mathbf{a}, \mathbf{b}]}$ but so far not with either heterogeneous Ziegler--Natta catalysts or with zirconocene-based catalysts for normal $\alpha$-olefin polymerization. Polymerization systems with a finite life span have been obtained with scandium-based metallocene catalysts. ${ }^{[62]}$ Their utilization for the formation of ethene-methacrylate block copolymers as well as partially living polymerizations of cycloolefins with zirconocene-based catalysts will be discussed 
in Sections 4.1 and 4.2, respectively. Development of truly living $\alpha$-olefin polymerization systems remains a challenge. ${ }^{[162]}$

Stereoregularity, regioregularity, and chain length of a polypropene all appear to influence its crystallinity as well as its melting behavior and mechanical properties. Heterogeneously produced isotactic polypropenes normally crystallize in a regular packing of parallel helices, the classical $\alpha$-modification. ${ }^{[163]}$ In contrast, isotactic polypropenes produced by homogeneous, $C_{2}$-symmetric ansa-zirconocene catalysts often crystallize from their melts with sizeable fractions of a heretofore infrequently observed $^{[164]} \gamma$-modification, ${ }^{[114,165-167 b]}$ which was found by Brückner and co-workers to contain alternate layers of helices oriented at an angle of $81^{\circ}$ to each other. ${ }^{[166]}$ For a given polypropene sample, the fraction of this $\gamma$-modification, as measured by wide-angle X-ray diffraction (WAXD), appears to be inversely related to the average length of isotactic chain segments, $n_{\text {iso }}$, if one takes into account that stereoerrors as well as regioinversions and chain ends limit the length of the isotactic segments. ${ }^{[69 b, d, 168]}$

Statistical factor analysis has been used to correlate the melting points of isotactic polypropenes with the substituent patterns of the ansa-zirconocene catalysts used, without differentiating between effects of regio- and stereoerrors and chain lengths variation. ${ }^{[169 a]}$ Melting points and total crystallinity both appear to be directly correlated with the average length of isotactic chain segments in these polyolefins. ${ }^{[69 d]}$ A finite fraction of noncrystalline segments within each polypropene chain appears to augment the toughness of the polymer materials. ${ }^{[117 e, 169 b]}$ These segments apparently function as flexible links between the crystalline polymer domains (Fig. 7).

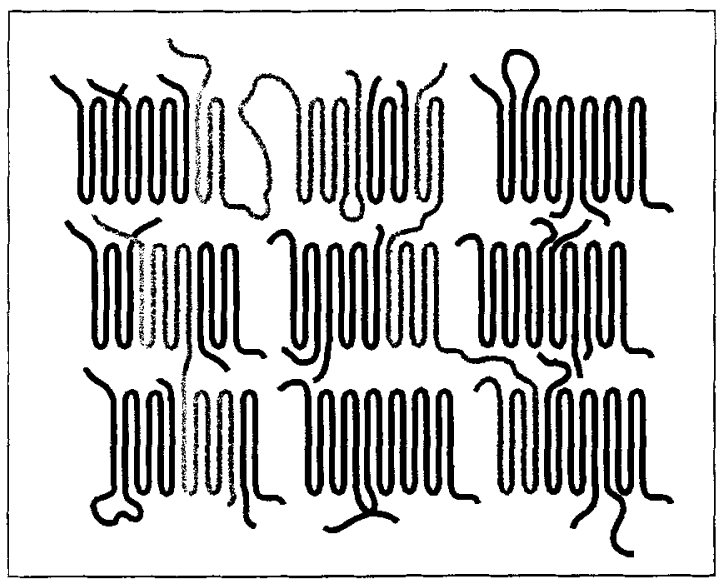

Fig. 7. Noncrystalline segments within longer polymer chains act as flexible links they connect the crystalline polymer domains and render the polymer tougher (less brittle).

Several crystal modifications have now also been characterized for the syndiotactic polypropenes formed with $C_{2}$-symmetric metallocene catalysts. ${ }^{[167 c, 170-173]}$ Their crystallinity appears to correlate again with the length of uninterrupted syndiotactic chain segments $;{ }^{\left[{ }^{74]}\right.}$ a large proportion of an amorphous phase, together with a small crystallite size, appears to cause the high transparency of this material. ${ }^{[169 b]}$ Syndiotactic polypropene can slowly form highly crystalline solids with a melting point of about $160^{\circ} \mathrm{C}$ when kept just slightly below the melting temperature.$^{[171 b]}$ Correlations between the structures of polyolefin materials produced with different homogeneous catalysts and their respective thermal, mechanical, and optical properties are presently being studied in more detail than can be accounted for within the limits of this review. ${ }^{[167.175]}$

\section{Olefin Copolymerization and New Polyolefin Materials}

While the development of homogeneous, chiral metallocene catalysts can be seen mainly as an opportunity for in-depth studies on the fundamental principles of stereoselective $\alpha$-olefin polymerizations, two examples of homogeneously produced polymers encountered already, syndiotactic and hemiisotactic polyolefins, are inaccessible with heterogeneous Ziegler - Natta catalysts. In the following chapter, we summarize additional examples for the formation of polyolefin materials by homogeneous metallocene catalysts which extend beyond the capabilities of classical heterogeneous polymerization catalysts.

\subsection{Copolymers from Ethene and Higher Olefins}

Olefin copolymers, especially those of ethene with propene and/or another $\alpha$-olefin, are of great practical interest; their total production volume is comparable to that of the homopolymers. New possibilities for controlling the properties of olefin copolymers with metallocene-based catalysts have recently caught the interest of industrial chemists and will thus be summarized here.

Linear polyethene with short-chain branches, which has low crystallinity and, hence, low density (linear low-density polyethene, LLDPE) is obtained by copolymerization of ethene with 1-butene, 1-hexene, and/or 1-octene. ${ }^{[176]}$ Its mechanical properties, which differ from those of the long-chain branched LDPE (low-density polyethene) produced by high-pressure radical polymerization, make LLDPE one of the largest volume polyolefin products. Copolymerization of propene with small amounts of ethene gives copolymers of lower crystallinity; ${ }^{[17]}$ increased fractions of ethene lead to amorphous materials with rubber-like elasticity (EP-rubbers). Blending of these EP-rubbers with the stiffer but brittle polypropene yields heterophase materials with balanced toughness-stiffness properties which have opened new ranges of practical applications for these polyolefin blends. ${ }^{[178,179]}$

Mechanical, thermal, and optical properties of these copolymers obviously depend on their comonomer content; however, to a significant degree they also depend on the distribution of the comonomers between and within individual polymer chains. If a catalyst distributes the comonomers randomly along each chain, an amorphous polymer is to be expected, whereas partially crystalline polymers are likely to result when the monomers are collected into separate blocks.

The comonomer selectivity of a given catalyst, in other words its tendency to insert one of two competing monomers into each type of metal-chain-end bonds, is expressed by its copolymerization parameters $r_{1}$ and $r_{2}$ (the subscripts specify the monomer). ${ }^{[176 a, 180]}$ These are defined as $r_{\mathrm{i}}=k_{\mathrm{ii}} / k_{\mathrm{ij}}$, the ratio of 
the rate constant for a homopolymerization step $\left(k_{\mathrm{ii}}\right)$ over that for a copolymerization step $\left(k_{\mathrm{ij}}\right) \cdot{ }^{[181,182]}$ The product $r_{1} r_{2}$ is an indicator for the distribution of two monomers along each chain. ${ }^{[176]}$ Values of $r_{1} r_{2}>1$ indicate that a catalyst tends to collect at least one of the comonomers into separate blocks, while a catalyst with $r_{1} r_{2}<1$ tends to alternate isolated comonomer units along each chain. ${ }^{[183]}$

Values of $r_{1} r_{2}>1$ are typical for ethene-propene copolymers made with heterogeneous polymerization catalysts ${ }^{[177 \mathrm{~b}, 184 \mathrm{~b}]}$ (Table 1) and indicate that these catalysts tend to collect each

Table 1 . Copolynerization parameters $r_{1}$ and $r_{2}$ for ethene and a second $\alpha$-olefin. For heterogeneous catalysts (entries $1-3$ ) values of $r_{1} r_{2}>1$ indicate that the monomers are incorporated in blocks; for metallocene-based catalyst systems (entries $4-9$ ). Fandom or alternating monomer sequences are indicated by values of $r_{1} r_{2} \leq 1$.

\begin{tabular}{|c|c|c|c|c|}
\hline Entry & Catalyst & $r_{1}$ & $r_{2}$ & $r_{1} r_{2}$ \\
\hline 1 & $\delta-\mathrm{TiCl}_{3} \mathrm{AlEt}_{3}[176 \mathrm{c}]$ & 7.3 & $0.76[a]$ & 5.5 \\
\hline 2 & $\mathrm{MgCl}_{2} \mathrm{TiCl}_{4} / \mathrm{AlEt}_{3}[184 \mathrm{a}]$ & - & $-[a]$ & 4 \\
\hline 3 & $\mathrm{SiO}_{2}, \mathrm{MgCl}_{2} / \mathrm{TiCl}_{3} / \mathrm{AlEt}_{3}[184 \mathrm{a}]$ & $5-10$ & $0.2-0.34[\mathrm{a}]$ & 1.9 \\
\hline 4 & $\left(\mathrm{C}_{5} \mathrm{H}_{5}\right)_{2} \mathrm{ZrCl}_{2} / \mathrm{MAO}[190]$ & 48 & $0.015[\mathrm{a}]$ & 0.72 \\
\hline 5 & $\mathrm{C}_{2} \mathrm{H}_{4}$ (ind $)_{2} \mathrm{ZrCl}_{2} ; \mathrm{MAO}$ [194a] & 2.57 & $0.39[\mathrm{a}]$ & 1.0 \\
\hline 6 & $\mathrm{C}_{2} \mathrm{H}_{4}$ (thind $)_{2} \mathrm{ZrCl}_{2} / \mathrm{MAO}[194 \mathrm{a}]$ & 2.90 & $0.28[a]$ & 0.81 \\
\hline 7 & $\mathrm{Me}_{2} \mathrm{Cr}(\mathrm{Cp})(\mathrm{flu}) \mathrm{ZrCl}_{2} / \mathrm{MAO}$ [197] & 1.3 & $0.20[\mathrm{a}]$ & 0.26 \\
\hline 8 & $\mathrm{C}_{2} \mathrm{H}_{4}$ (thind $)_{2} \mathrm{ZrCl}_{2} / \mathrm{MAO}$ [193] & 59 & $0.012[\mathrm{~b}]$ & 0.71 \\
\hline 9 & $\mathrm{Me}_{2} \mathrm{Si}(\mathrm{ind}){ }_{2} \mathrm{ZrCl}_{2} / \mathrm{MAO}[193]$ & 25 & $0.016[\mathrm{~b}]$ & 0.4 \\
\hline
\end{tabular}

[a] Ethene propene. [b] Ethene;1-hexene

type of monomer into separate blocks. In addition, the nonuniform centers of heterogeneous polymerization catalysts have in general different copolymerization characteristics. ${ }^{[6.176 b, 185]}$ Analysis of the copolymer products by temperature-rising elution fractionation (TREF) and cross-fractionation ${ }^{[186]}$ (Fig. 8) shows that the higher $\alpha$-olefin is preferentially incorporated at the centers that produce shorter chains; higher olefins are thus enriched in the low molecular weight fractions of these copolymers. ${ }^{[187]}$ This increases the content of extractables and tends to make these materials sticky, two generally undesirable properties.

In their early studies on chiral, metallocene-based catalysts such as (en)(thind) $\mathrm{ZrCl}_{2} / \mathrm{MAO}$, Kaminsky and co-workers had noticed that these catalysts polymerize propene or 1-butene with only modestly lower rates than ethene. ${ }^{[39 c-h, 188]}$ Accordingly, copolymers obtained with these catalysts contain larger fractions of higher olefins than those obtained with heterogeneous catalysts under comparable conditions. ${ }^{[176,177]}$ These and additional studies, ${ }^{[189-193]}$ particularly by the groups of Zambelli, ${ }^{[122.136 b]}$ Chien, ${ }^{[194]}$ Soga, ${ }^{[195]}$ and Kashiwa, ${ }^{[66,97]}$ showed that copolymers produced by metallocene-based catalysts consist of uniform chains with narrow molecular weight distributions typical of single-site catalysts. The copolymer chains contain the comonomers in nearly random placement ${ }^{[196]}$ as indicated by copolymerization-factor products of $r_{1} r_{2} \approx 1$ (Table 1); their TREF characteristics (Fig. 8) show that comonomer distributions are essentially independent of chain lengths, an important aspect for applications of these copolymers, for instance in films or sealant layers.

The copolymerization characteristics of metallocene-based catalysts vary with the metallocene complex used. ${ }^{[197]}$ Higher

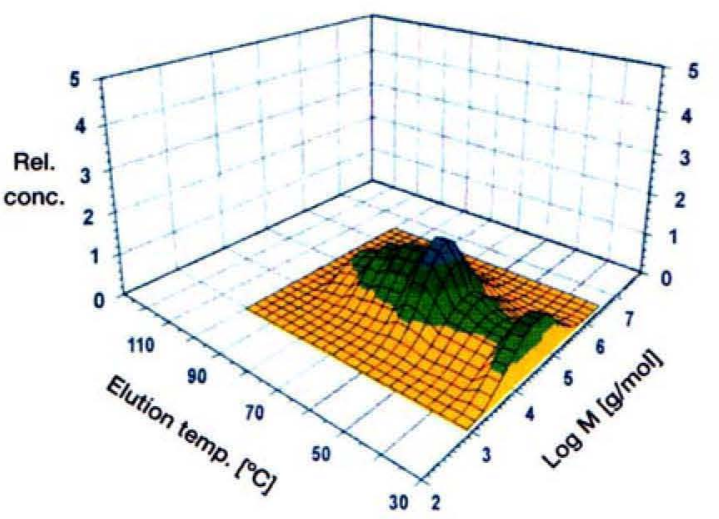

Rel. conc.

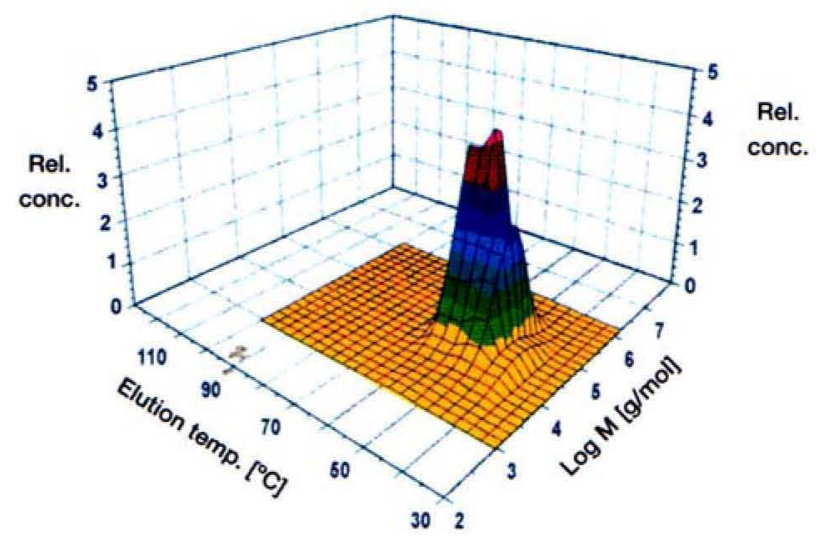

Fig. 8. Holtrup cross-fractionation of a conventional (top) and a metallocenederived (bottom) ethene-butene random copolymer (LLDPE). Whereas LLDPE produced by classical heterogeneous catalysts contains a mixture of polymer chains with different composition and chain lengths, LLDPE produced by metallocene catalysts shows chemical uniformity and a very narrow molecular weight distribution.

$\alpha$-olefins are taken up more readily by isospecific, chiral ansametallocenes than by unbridged complexes. An even greater tendency for the incorporation of higher $\alpha$-olefins is evident for the syndiospecific catalyst $\mathrm{Me}_{2} \mathrm{C}(\mathrm{Cp})\left(\right.$ fluorenyl) $\mathrm{ZrCl}_{2} / \mathrm{MAO}$. This trend reflects the rising activities in this series of catalysts for the homopolymerization of higher $\alpha$-olefins as compared to that of ethene. ${ }^{[132 a]}$ But even monomers that are not homopolymerized by metallocene catalysts, for example isobutene, ${ }^{[188 \mathrm{f}]}$ styrene, and 1,3-dienes, ${ }^{[188 \mathrm{e}, 191]}$ are incorporated, albeit in minor amounts, into various copolymers. ${ }^{39 \mathrm{c}, 188,189 \mathrm{~d}, 191,194 \mathrm{~d}]}$

Even less restricted than the metallocene-based catalysts with regard to comonomer selection are monocyclopentadienyl complexes such as MAO-activated dimethylsilyl-bridged amidocyclopentadienyltitanium complexes. ${ }^{[7 a, 189.198]}$ These catalysts (Fig. 9) incorporate into their polymer products even the vinylic end groups of polymer chains terminated by $\beta$-hydrogen transfer; they can thus generate copolymers with long-chain branches, in contrast to the strictly linear LLDPE copolymers produced by metallocene-based catalysts. ${ }^{[189 c .198 a]}$ These catalysts can also copolymerize styrene with ethene; ${ }^{[7 a]}$ styrene units in these copolymers are mostly isolated and of low regioregularity. Whether styrene-ethene and styrene-1,3-diene copolymers can be obtained also with the unbridged titanium system $\mathrm{CpTiCl}_{3} / \mathrm{MAO}^{[199-201]}$ which catalyzes the syndiotactic homopolymerization of styrene, ${ }^{[7 \mathrm{~b}]}$ needs further clarification. $^{[202]}$ 


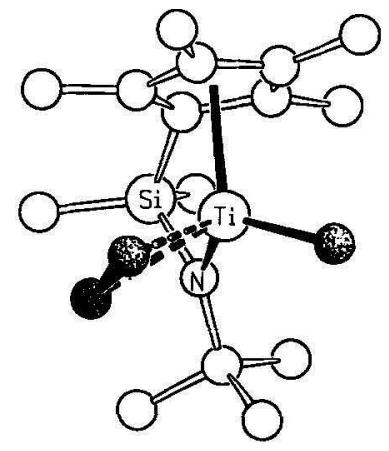

Fig. 9. Monocyclopentadienyltitanium complex with an $\mathrm{Me}_{2}$ Si-bridged alkylamido ligand framework [7 a] which catalyzes, in the presence of MAO, formation of long-chain branched copolymers [198] (ab initio model for the $\mathrm{C}_{2} \mathrm{H}_{4}$ complex of $\left.\mathrm{Me}_{2} \mathrm{Si}\left(\mathrm{Me}_{4} \mathrm{C}_{5}\right)(t \mathrm{BuN}) \mathrm{Ti}-\mathrm{CH}_{3}^{+}\right)$ $[87 \mathrm{~b}, 88 \mathrm{~b}]$.

A long-standing goal in olefin polymerization catalysis is the copolymerization of ethene or propene with olefins bearing polar functional groups such as acrylate esters or vinyl ethers. Copolymers of this type might endow polyolefins with some of the useful properties of polyvinyl esters or ethers such as their adhesiveness. While most metallocene-based polymerization catalysts appear to be as sensitive to oxygen-containing functional groups as their heterogeneous predecessors, advances toward the goal of incorporating olefins with polar functional groups into Ziegler - Natta polymerization systems have recently been made and will be discussed in Section 4.3.

Living polymerizations, briefly mentioned in Section 3.4, would allow the formation of block copolymers, with polar olefins as well as with other alkenes. Advances in this regardcatalyst systems with polymer chains bound to the central metal atom for at least some minutes-have recently been reported. Ethene-propene block copolymers, prepared by Turner and Hlatky with cationic hafnocene catalysts at lower temperatures, indicate that $\mathrm{Hf}$-polymer bonds have a finite lifetime at these temperatures. ${ }^{[203]}$ Yasuda and co-workers ${ }^{[204]}$ utilized the persistence of lanthanide-alkyl bonds ${ }^{[62]}$ to prepare ethene copolymers with polar polyacrylate or polyester blocks. They first polymerized ethene with a samarocene catalyst and used this system then to initiate the polymerization of the polar monomer by group-transfer polymerization or by ring-opening polymerization of a lactone (Scheme 17).

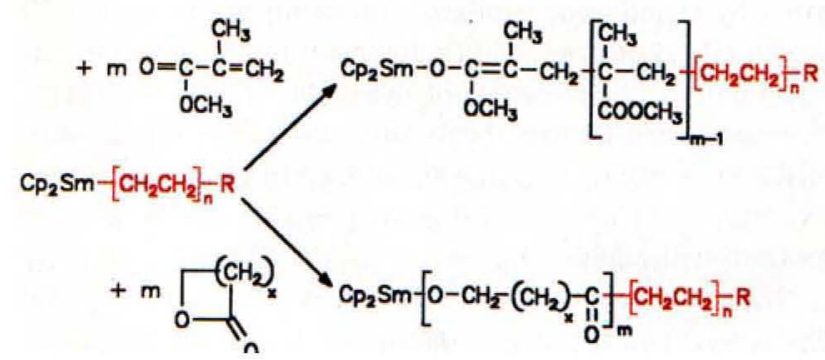

Scheme 17. Block copolymers from ethene and polar monomers obtained by Yasuda and co-workers [204] with a samarocene catalyst. A living Sm-polyethene system is utilized to initiate group-transfer or ring-opening polymerizations of unsaturated or cyclic esters.

Studies on ${ }^{13} \mathrm{C}$ NMR characteristics of ethene-propene copolymers have led to rather complete assignments of their repeat patterns and end group signals. ${ }^{[97,205]}$ Isospecific ansa-zirconocene catalysts generate copolymers with mainly $m$-oriented side chains, as expected from their stereoselectivity. ${ }^{[197]}$ Studies by Zambelli and co-workers on propene copolymers with ${ }^{13} \mathrm{C}$ labeled ethene showed furthermore that the stereoselectivity of the catalyst system is undiminished by incorporation of ethene, thus proving that this stereoselectivity is indeed caused by the chirality of the metallocene centers and not by that of the last inserted monomer unit. ${ }^{[122]}$

End group distributions in ethene-propene copolymers were studied by Kashiwa and co-workers by ${ }^{13} \mathrm{C}$ NMR spectroscopy. ${ }^{[97]}$ The strong prevalence of $n$-propyl ends and the near-absence of ethyl end groups were taken as evidence that chain termination occurs mainly by $\beta-\mathrm{H}$ transfer directly to a coordinated propene molecule rather than to the metal followed by monomer insertion into the $\mathrm{Zr}-\mathrm{H}$ bond, as discussed in Section 2.4.

As with heterogeneous Ziegler-Natta catalysts, ${ }^{[176 b]}$ a distinct comonomer effect is generally observed with MAO-activated zirconocenes. ${ }^{[66,182,188,206]}$ Under otherwise identical conditions, the rate of copolymerization of ethene with higher $\alpha$-olefins often exceeds that of the homopolymerization of ethene. This effect is difficult to reconcile with the fact that homopolymerization rates are higher for ethene than for other $\alpha$-olefins and that ethene is always preferentially incorporated into the copolymer. It remains to be clarified whether these comonomer effects are due to increased rates of ethene insertion into a $\mathrm{Zr}-\mathrm{CH}_{2}-\mathrm{CHR}$ - rather than into a $\mathrm{Zr}-\mathrm{CH}_{2}-\mathrm{CH}_{2}-$ polymer bond (e.g. by destabilization of a $\beta$-agostic resting state of the former ${ }^{[26 i, 63,89,120 a]}$, to cooperative effects of both olefins (e.g. in insertion transition states involving two olefins ${ }^{[76]}$ ), or simply to a higher solubility of a copolymer in the reaction medium ${ }^{[206 \mathrm{~b}]}$ (which might allow for higher rates of diffusion of the monomers to the catalyst centers).

\subsection{Cycloolefin Polymerization and Diolefin Cyclopolymerization}

A distinctive property of homogeneous, metallocene-based polymerization catalysts is their capability to induce the polymerization of cyclic olefins without inducing ring-opening metathesis, which is characteristic of those heterogeneous Ziegler-Natta catalyst systems that polymerize cycloolefins. ${ }^{[4 a]}$ As noted by Kaminsky and co-workers, ${ }^{[207 a]}$ cyclobutene, cyclopentene, norbornene, and dimethanooctahydronaphthalene but not cyclohexene (Scheme 18) are polymerized with remarkably high activities by chiral ansa-zirconocene catalysts such as (en)(ind) ${ }_{2} \mathrm{ZrCl}_{2} / \mathrm{MAO}$ and its $\mathrm{Me}_{2} \mathrm{Si}$-bridged analogue.

The homopolymers obtained from these reactions are highly crystalline with melting points around or above $400^{\circ} \mathrm{C}^{[207]}$ close to their respective decomposition temperatures. Structural assignments for these polymers are rendered difficult by their
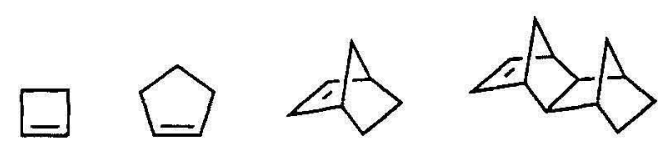

DMON

Scheme 18. Cyclic olefins used by Kaminsky and co-workers [207] in ring-preserving polymerization reactions with $r a c$-(en)(ind $)_{2} \mathrm{ZrCl}_{2} / \mathrm{MAO}$ or $\mathrm{rac}_{-} \mathrm{Me}_{2} \mathrm{Si}$ (ind) ${ }_{2}$ $\mathrm{ZrCl}_{2} / \mathrm{MAO}$. 
insolubility in all common solvents. Instead of a 1,2-enchainment as originally proposed by Kaminsky and co-workers for polymers of cyclopentene, ${ }^{[207 \mathrm{~b}]}$ a 1,3-enchainment was revealed in a recent study by Collins and Kelly ${ }^{[208 a]}$ on the corresponding zirconocene/MAO-catalyzed hydrooligomerization. The mechanism proposed for this enchainment-1,2-insertion followed by $\beta-\mathrm{H}$ elimination, olefin rotation, and reinsertion-is analogous to that assumed to lead to the minor fraction of 1,3-inserted propene units in propene polymerization with these catalysts. ${ }^{[14.136 \mathrm{a}, \mathrm{b}, 208 \mathrm{~b}]}$ Apparently, the intermediate derived from 1.2-insertion of cyclopentene is sterically too demanding to permit insertion of another cyclopentene and has to isomerize before another olefin inserts (Scheme 19). This system is an interesting example for an insertion-isomerization type of polymerization with metallocene-based catalysts. ${ }^{[209]}$

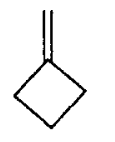

$\left(1,2-\mathrm{Me}_{2} \mathrm{Cp}\right) \mathrm{ZrMe}+\mathrm{MeB}\left(\mathrm{C}_{6} \mathrm{~F}_{5}\right)_{3}^{-}$<smiles>C=C(C)CCCC(=C)CC(C)(C)C</smiles>

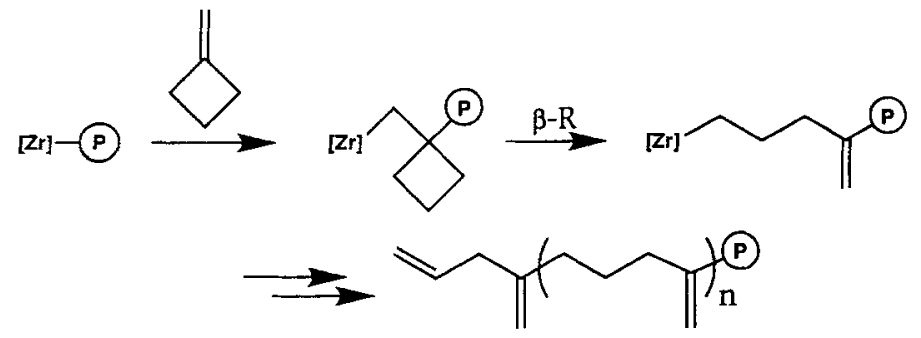

Scheme 20. Ring-opening polymerization of methylenecyclobutane reported by Marks and co-workers [211]. Ring-opening $\not \beta$-alkyl transfer appears to be faster than insertion of methylenecyclobutane into the sterically hindered cyclobutylmethyl-Zr bond.

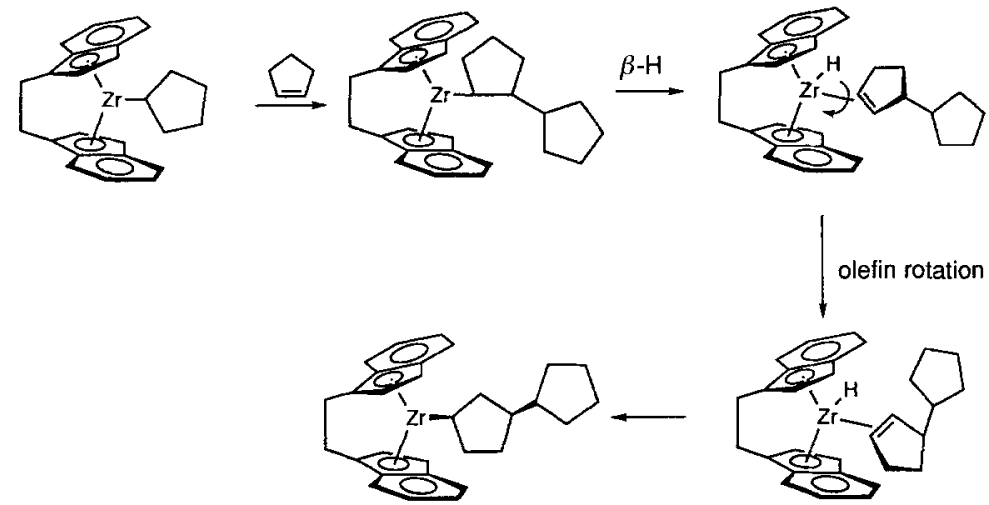

Scheme 19. Mechanism for the formation of 1,3-linked polycyclopentene proposed by Collins and co-workers [208]

The cycloolefin polymers prepared with chiral (en)(ind) ${ }_{2}-$ $\mathrm{ZrCl}_{2} / \mathrm{MAO}$ as catalyst are undoubtedly stereoregular; [208, 209] whether they have an isotactic structure like that of the other olefin polymers produced by this catalyst could not yet be established unequivocally.

Studies on the copolymerization of cyclic monomers with ethene or propene ${ }^{[207,210]}$ showed that all of the cycloolefins mentioned above, as well as cycloheptene and cyclooctene, are incorporated into copolymers. While ethene is vastly more reactive than cyclopentene in the catalyst system (en)(ind) ${ }_{2} \mathrm{ZrCl}_{2} /$ $\mathrm{MAO}$, with a comonomer selectivity factor of $r_{1}=80-300$, norbornene is quite readily incorporated, with $r_{1}=1.5-3.2$, such that a broad range of ethene/norbornene copolymers can be obtained with this system. ${ }^{[207]}$ The cycloolefin copolymers are mostly amorphous (rather than crystalline like the respective homopolymers) and have a relatively high glass transition temperature. A 1,2-enchainment, rather than a 1,3-enchainment has been determined for the copolymers of cyclopentene and ethene. ${ }^{[207]}$ Apparently, insertion of ethene is faster than isomerization of the cyclopentyl group at the zirconium center. In contrast to cyclopentene homopolymers, these copolymers are mostly amorphous; however, they often have relatively high glass transition temperatures.

An interesting ring-opening polymerization, which contrasts the ring-preserving polymerizations of internal cycloolefins dis- cussed above, was recently reported by Marks and co-workers, ${ }^{[21}{ }^{1]}$ who observed that polymerization of exomethylenecyclobutane by $\left[\left(1,2-\mathrm{Me}_{2} \mathrm{C}_{5} \mathrm{H}_{3}\right)_{2}\right.$ $\left.\mathrm{ZrMe}^{+} \cdots \mathrm{MeB}\left(\mathrm{C}_{6} \mathrm{~F}_{5}\right)_{3}^{-}\right]$yields a polymer with mainly ring-opened 2-methylene-1-buten-4-yl rather than the expected 1-methylenecyclobutan-1-yl units (Scheme 20). Apparently, insertion of the disubstituted olefin into a $\mathrm{Zr}$-alkyl unit with a quarternary $\beta$-C atom is so slow that rearrangement of the latter by $\beta$-alkyl transfer to give a secondary $\mathrm{Zr}$-alkyl unit is the preferred process. Kinetic data indicate that insertion of the disubstituted olefin into the latterrather than the $\beta$-alkyl transfer-still limits the overall rate of this process, which has turnover numbers of about $400 \mathrm{~h}^{-1}$ at $25^{\circ} \mathrm{C}$.

Another polymerization process that leads to 1,3cycloalkanediyl units, connected this time by methylene groups, is the cyclopolymerization of nonconjugated dienes..$^{[93,95 b, 212-217]}$ It involves 1,2-insertion of one of the vinyl functions into a metal-carbon bond followed by an intramolecular cyclization (Scheme 21). The microstructure of the resulting polymers concerns the cis/trans stereochemistry of the rings and the relative stereochemistry between rings. The latter, i.e. the tacticity of the polymer, is determined by the enantiofacial selectivity of the metallocene catalyst in the first insertion step; the cis/trans stereochemistry of the rings, on the other hand, arises from the diastereoselectivity of the cyclization step.

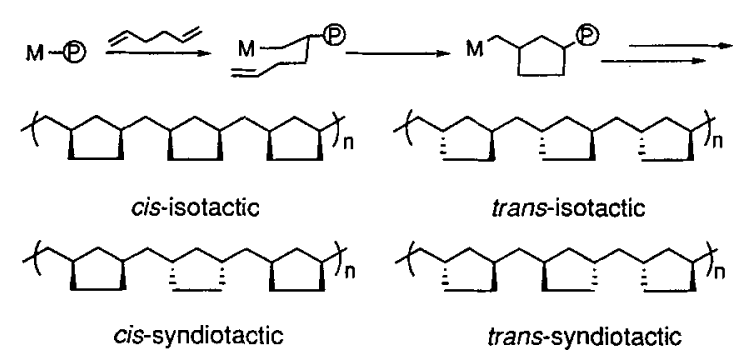

Scheme 21. Cyclopolymerization of nonconjugated dienes studied by Waymouth and co-workers $[93,95,213-217]$. The trans-isolactic form represents an effectively chiral polymer; polymers with substantial molar optical rotations are obtained with $R$ - or $S$-(en)(thind) $\mathrm{ZrCl}_{2} / \mathrm{MAO}$. 
While the cis/trans diastereoselectivity can hardly be controlled with heterogeneous catalysts, ${ }^{[212]}$ it is strongly influenced by substituents at the cyclopentadienyl ligands in metallocene-based catalysts. ${ }^{[93]}$ Cyclopolymerization of 1,5-hexadiene by MAO-activated $\left(\mathrm{C}_{5} \mathrm{H}_{5}\right)_{2} \mathrm{MX}_{2}(\mathrm{M}=\mathrm{Ti}, \mathrm{Zr}, \mathrm{Hf}$; $\mathrm{X}=\mathrm{Cl}, \mathrm{CH}_{3}$ ) leads to polymers containing predominantly trans rings, while cyclopolymerization with the more hindered catalyst $\left(\mathrm{C}_{5} \mathrm{Me}_{5}\right)_{2} \mathrm{MX}_{2} / \mathrm{MAO}$ yields predominantly cis rings.

The melting points of the resulting polymers proved to be quite sensitive to the cis/trans ratio of the carbocycles. ${ }^{[213]}$ trans Polymers are waxes with melting points $\leq 70^{\circ} \mathrm{C}$; polymers containing $>90 \%$ cis rings are crystalline and melt at $189^{\circ} \mathrm{C}$. Cyclopolymerization of unsymmetrical dienes such as 2-methyl1,5-hexadiene with catalysts such as $\mathrm{Cp}_{2}^{*} \mathrm{ZrMe}_{2} / \mathrm{MAO}$ or with $\left[\mathrm{Cp}_{2}^{*} \mathrm{ZrMe}^{+} \cdots \mathrm{X}^{-}\right]\left(\mathrm{X}=\mathrm{B}\left(\mathrm{C}_{6} \mathrm{~F}_{5}\right)_{4}\right.$ or $\left.\mathrm{H}_{3} \mathrm{CB}\left(\mathrm{C}_{6} \mathrm{~F}_{5}\right)_{3}\right)$ affords highly regioregular cyclopolymers. ${ }^{[215]}$ The perfectly alternating head-to-tail microstructure must arise from the regioselective insertion of the less hindered terminus of the diene into the metal-polymer bond, which is sterically encumbered by its quarternary $\beta$-C atom. Cyclization of the disubstituted olefin yields a methylene-1-methylcyclopentan-3-yl intermediate (Scheme 22). This insertion appears to be greatly facilitated by its intramolecular nature; intermolecular insertions of disubstituted olefins into $\mathrm{Zr}$-alkyl bonds are at best quite sluggish.
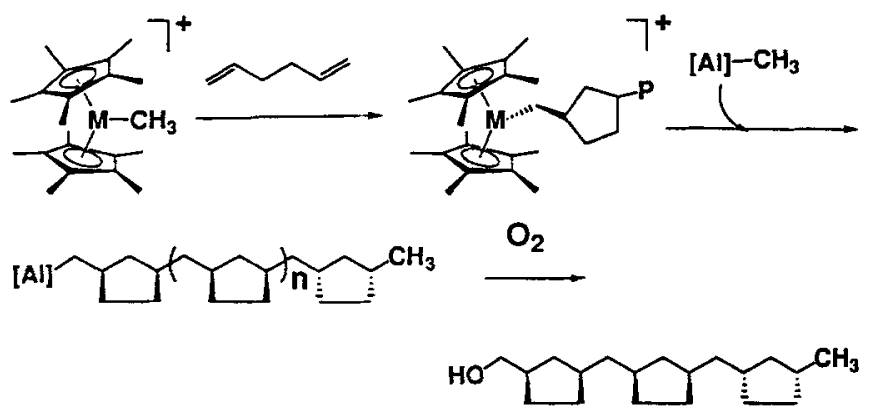

Scheme 22. Hydroxy-terminated cyclopolymers formed by alkyl exchange with a methylaluminum activator [95 b]

Cyclopolymerization of 1,5-hexadiene generates polymers with substantially higher molecular weights than polymerization of 1-hexene with the same catalysts, ${ }^{[93]}$ undoubtedly due to some hindrance of the $\beta-\mathrm{H}$ transfer that normally terminates growth of a polymer chain. For the cyclopolymerization of 1,5hexadiene with a $\mathrm{Cp}_{2}^{*} \mathrm{ZrCl}_{2} / \mathrm{MAO}$ catalyst at $-25^{\circ} \mathrm{C}$, chain transfer to aluminum was found to be the only chain termination process. ${ }^{[95 b]}$ The resulting poly(methylene-cyclopentane) was shown to bear an alkylaluminum end group, which could be oxidized with $\mathrm{O}_{2}$ to give hydroxy-terminated polymers (Scheme 22). Cyclopolymerization of 2-methyl-1,5-hexadiene with the catalysts $\left[\mathrm{Cp}_{2}^{*} \mathrm{ZrMe}^{+} \cdots \mathrm{X}^{-}\right]\left(\mathrm{X}=\mathrm{B}\left(\mathrm{C}_{6} \mathrm{~F}_{5}\right)_{4}\right.$ or $\left.\mathrm{H}_{3} \mathrm{CB}\left(\mathrm{C}_{6} \mathrm{~F}_{5}\right)_{3}\right)$, for which neither $\beta$ - $\mathrm{H}$ transfer nor chain transfer to aluminum are feasible, gave a polymer with end groups derived from a $\beta-\mathrm{CH}_{3}$ transfer process. ${ }^{[95 \mathrm{~b}]}$

Although optically active olefin oligomers of low molecular weight can be obtained with enantiomerically pure ansa-metallocene catalysts, ${ }^{[140,141 b, 143 b]}$ stereoregular polyolefins of high molecular weight contain an effective mirror plane perpendicu- lar to the molecular axis in the middle of the molecule and are thus achiral. ${ }^{[107 \mathrm{c}]}$ Chiral polymers have now become available by metallocene-catalyzed cyclopolymerization of 1,5-hexadiene. Coates and Waymouth recognized that the trans-isotactic form of poly(methylene-1,3-cyclopentane) is chiral. ${ }^{[213,217]}$ Using MAO-activated, resolved $(1 R)$-(en)(thind) ${ }_{2} \mathrm{Zr}$-binaphtholate as a catalyst, they obtained optically active poly(methylene-1,3-cyclopentane) with a molar optical rotation of $[\Phi]_{D}^{20}=+51.0$ $\left(c=0.8\right.$ in $\left.\mathrm{CHCl}_{3}\right)$. Cyclopolymerization with the $(1 S)$ enantiomer of the catalyst gave the enantiomeric polymer. $\mathrm{Cy}$ clopolymers of 1,5-hexadiene obtained with (en)(thind) ${ }_{2} \mathrm{Zr}$ derived catalysts contain a mixture of cis and trans rings. Despite the presence of roughly $32 \%$ cis rings, the molar optical rotation of the polymer $\left([\Phi]_{\mathfrak{D}}^{20}=+22.8\right)$ is considerably higher than that of the model compound trans-(1R,3R)-1,3-dimethylcyclopentane $\left([\Phi]_{\mathrm{D}}^{20}=+3.1\right)$, presumably due to the presence of helical polymer conformations in solution. Interesting insights in this regard might come from $\mathrm{X}$-ray diffraction studies on these chiral polymers. A ${ }^{13} \mathrm{C}$ NMR analysis of the microstructure of the polymer at tetrad resolution provided an estimate of $91 \%$ for the enantiofacial selectivity of this cyclopolymerization reaction..$^{[217]}$

\subsection{Functionalized Polyolefins}

Advances toward the goal of polymerizing polar monomers by Ziegler-Natta catalysis have recently been made with cationic metallocene catalysts. Waymouth and co-workers found that these catalysts are considerably more tolerant of functional groups than either conventional heterogeneous catalysts or homogeneous catalysts activated by MAO. Catalysts of the type $\left[\mathrm{Cp}_{2}^{*} \mathrm{ZrMe}^{+} \cdots \mathrm{X}^{-}\right]\left(\mathrm{X}^{-}=\mathrm{B}\left(\mathrm{C}_{6} \mathrm{~F}_{5}\right)_{4}^{-}\right.$or $\left.\mathrm{H}_{3} \mathrm{CB}\left(\mathrm{C}_{6} \mathrm{~F}_{5}\right)_{3}^{-}\right)$are indeed capable of polymerizing a variety of functionalized $\alpha$ olefins and dienes such as 4-tert-butyldimethylsiloxy-1-pentene, 5- $N, N$-diisopropylamino-1-pentene, and 4-trimethylsiloxy-1,6heptadiene ${ }^{[218]}$ (Scheme 23).
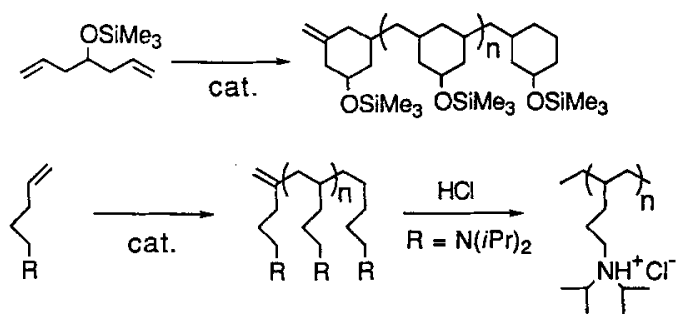

Scheme 23. Formation of polymers with $\mathrm{O}$ - or $\mathrm{N}$-functional groups by use of borane-activated zirconocene catalysts reported by Waymouth and co-workers [218, 219]. $\mathrm{R}=\mathrm{NiPr}_{2}, \mathrm{OTBDMS}$; $\mathrm{cat}=\left[\mathrm{Cp}_{2}^{*} \mathrm{ZrMe}^{+} \mathrm{MeB}\left(\mathrm{C}_{6} \mathrm{~F}_{5}\right)_{3}^{-}\right]$

Activities for the polymerization of 4-tert-butyldimethylsiloxy- and 5-N,N-diisopropylamino-1-pentene by the catalyst $\left[\left(\mathrm{C}_{5} \mathrm{Me}_{5}\right)_{2} \mathrm{ZrMe}^{+} \cdots \mathrm{X}^{-}\right]$were lower than for 1-hexene, with average turnover numbers (at ca. $40-50 \%$ conversion) ranging from $2700 \mathrm{~h}^{-1}$ for 1-hexene to $190 \mathrm{~h}^{-1}$ for 4-tert-butyldimethyl-siloxy-1-pentene and $130 \mathrm{~h}^{-1}$ for 5-N,N-diisopropylamino-1-pentene. Chiral $\left[\mathrm{rac}-(\mathrm{en})(\mathrm{thind})_{2} \mathrm{ZrMe}^{+} \ldots \mathrm{X}^{-}\right]$catalysts are active for the polymerization of 5- $N, N$-diisopropylamino-1-pentene, but not for that of 4-tert-butyldimethyl- 
siloxy-1-pentene. Preliminary ${ }^{13} \mathrm{C}$ NMR analysis of poly-(5$\mathrm{N}, \mathrm{N}$-diisopropylamino-1-pentene) obtained in this manner indicates an isotactic microstructure. ${ }^{[219]}$

Another approach toward functionalized polyolefins is the generation of $\alpha$-olefin polymers capped by polar end groups. Polymers of this kind are principally accessible through living polymerizations. Living polymers of $\alpha$-olefins have been obtained so far only in rare instances, at low temperatures ${ }^{[220,221]}$ (see Section 4.1). Complete transfer of polymer chains to aluminum centers of the cocatalyst, also useful for this purpose, has been observed in only one special case, again at temperatures below ambient. ${ }^{[95 \mathrm{~b}]}$

In contrast to heterogeneous polymerization catalysts, which afford shorter propene oligomers only in the presence of $\mathrm{H}_{2}$, that is, only with saturated chain ends, metallocene catalysts give easy access to propene oligomers with olefinic end groups, which can be converted to various other functional groups. ${ }^{[222,223]}$ Thiol-terminated oligopropenes have been used as chain transfer reagents in methacrylate polymerization to form poly(propene-block-methylmethacrylate). A new class of polymers containing pendant polypropene chains such as polymethylmethacrylate-graft-polypropene is derived from methacrylate-terminated oligopropene macromonomers, which are copolymerized with various acrylic esters, acrylonitrile, or styrene. ${ }^{[224 a]}$

These polypropene block and graft copolymers are efficient blend compatibilizers. By enhancing the dispersion of otherwise incompatible polymers and improving their interfacial adhesion, these copolymers allow the formation of "alloys" of isotactic polypropene, for example, with styrene-acrylonitrile or polyamides. ${ }^{[224 \mathrm{~b}, \mathrm{c}]}$ Polymer blends of this type afford property synergisms such as improved stiffness combined with improved toughness. They are obtained by way of the short isotactic polypropene chains with unsaturated end groups formed by the ansa-metallocene catalyst $\mathrm{Me}_{2} \mathrm{Si}\left(2-\mathrm{Me}-4-t \mathrm{Bu}-\mathrm{C}_{5} \mathrm{H}_{2}\right)_{2} \mathrm{ZrCl}_{2}$ / MAO.

\section{Perspectives}

The most remarkable aspect of metallocene-based catalysts appears to be that they can produce an unprecedented variety of polyolefins. The range of stereo- and regioregularities, molecular weights, and polydispersities of copolymers and cyclopolymers available with these catalysts exceeds that accessible with classical heterogeneous Ziegler-Natta catalysts and opens new possibilities for producing tailored polyolefin materials.

Much of our knowledge in this area has been acquired by application of rational conceptional models to the design of new metallocene structures and catalyst activators. Some traits of these catalysts, in particular their stereoselectivity, are now close to being predictable, based on our understanding of the essential elementary reaction steps in these homogeneous reaction systems. Other traits such as the formation of cyclic or functionalized polyolefins have been and continue to be discovered by testing our understanding of the basic reaction mechanisms of these catalysts against increasingly demanding tasks. This approach derives substantial support from the rapidly advancing methods for modeling even large metallocene reaction systems by ab initio and density functional methods. ${ }^{[84-88]}$ These methods can also provide a calibration for useful molecular mechanics models for these catalysts, ${ }^{[86,139,225]}$ which may eventually allow estimates of steric effects on the course of essential reaction steps, for example on competing insertion and chain termination reactions.

The evolution of advanced catalysts and catalytic processes based on rational model hypotheses is now beginning to carry over to heterogeneous Ziegler-Natta catalysis as well. Practical application of metallocene catalysts requires their preadsorption on solid supports such as alumina or silica gels. ${ }^{[189 c, 200,226-228]}$ Instead of the polymer dust produced by a homogeneously dissolved metallocene catalyst, the solid catalyst particles generate coherent polymer grains. ${ }^{[117 e, 229]}$ As with classical heterogeneous catalysts, these grains appear to be enlarged replicas of the catalyst particles ${ }^{[1170.228]}$ (Fig. 10). Metallocene catalysts that are heterogenized, for example on a silica gel support, can thus be readily used in existing ZieglerNatta production facilities, for instance in solvent-free slurry or gas-phase reaction systems. ${ }^{[227,228]}$
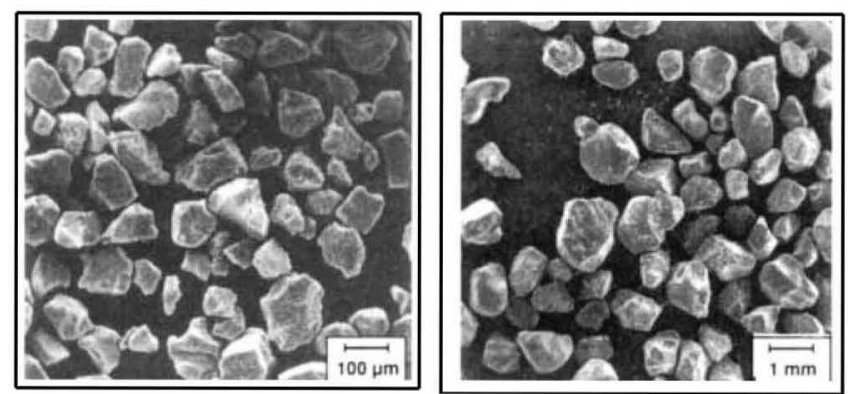

Fig. 10. Catalyst grains containing $\mathrm{Me}_{2} \mathrm{Si}(2-\mathrm{Me} \text {-benz }[e] \text { indenyl })_{2} \mathrm{ZrCl}_{2} / \mathrm{MAO}$ on a silica gel support (left) and polymer grains grown on these in a gas-phase reactor at $70^{\circ} \mathrm{C}$ (right, note different scale) [228].

Detailed guidelines have been developed for the selection of supports with optimal composition, particle size, pore size distribution, and surface $\mathrm{OH}$ group density, and for their treatment with various alkyl aluminum and aluminoxane activators ${ }^{[227,228]}$ prior or subsequent to adsorption of the metallocene complex. The more advanced of these protocols require only limited excess ratios of alkylaluminum activators per zirconocene unit; $\mathrm{Al}: \mathrm{Zr}$ ratios of roughly 100-400:1, much below those used for homogeneous catalyst systems, appear to give entirely satisfactory activities for these surface-supported metallocene catalysts. ${ }^{[28,230]}$ In contrast to modern $\mathrm{MgCl}_{2}$-supported heterogeneous Ziegler-Natta catalysts, silica gel supported metallocene catalysts are practically free of chlorine. This could be an advantage from a ecological standpoint when the chemical or thermal recycling of polymer products reaches a larger scale. $^{[231]}$

Despite the practical advantages of supported catalysts, interactions between support materials and catalyst complexes are only partly understood on a molecular level. Based on the generally close resemblance of the polymer microstructures produced by a metallocene catalyst in homogeneous solutions and on solid supports, even in solvent-free gas phase systems, ${ }^{[228,232]}$ it appears likely that the active catalysts are quite 
similar, in other words that the (presumably cationic) metallocene catalyst is only physisorbed on the alkylaluminum-pretreated (possibly anionic) catalyst surface. Based on this model, "microreactors" might be fabricated by immobilizing different types of single-site metallocene catalysts-or even catalyst cascades $^{[193]}$ _-on suitable supports for in situ production of novel polyolefin biends and other environmentally friendly polyolefin materials.

Polymers with properties distinctly different from those produced in homogeneous solution-with unusually high molecular weights-have recently been obtained by fixing a metallocene catalyst on unpretreated supports ${ }^{[233]}$ and by synthesizing covalently linked ansa-metallocenes directly on a $\mathrm{SiO}_{2}$ support. ${ }^{[234]}$ These observations are probably connected with the site-isolation effects, that is, with the strict suppression of all binuclear reaction intermediates, known to arise from linking catalyst centers covalently to a solid support. ${ }^{[235]}$ If methods become available for a controlled synthesis of such covalently supported metallocenes and for their structural characterization, one could imagine another round of developments toward novel metallocene-based Ziegler-Natta catalysts that are heterogeneous, like their predecessors discovered forty years ago, yet endowed with wider process and product variability and with superior environmental properties.

We thank Dr. A. Reinmuth and Ms. S. Kyncl for checking the text and the references of this article and for help in composing the table and figures. We are grateful to $B A S F A G$ for providing graphs and figures, and for financial support.

[1] K. Ziegler, E. Holzkamp, H. Breil, H. Martin, Angew. Chem. 1955, 67, 541; K. Ziegler, Angew. Chem, 1964, 76, 545.

[2] G. Natta, P. Corradini, Atti Accad, nas. Lincei Mem. Cl. Sci. Fis. Mat. Nat. Sez. II 1955, 5.73; G. Natta, Angew. Chem. 1956, 68. 393; ibid. 1964, 76, 553.

[3] a) History of Polyolefins (Eds.: R. B. Seymour, T. Cheng), Reidel, Dordrecht, 1986; b) J. J. Eisch, J. Chem. Educ. 1983, 60, 1009; c) J. Boor, Ziegler-Natta Catalysts and Polymerizations, Academic Press, New York, 1979.

[4] a) H. Sinn, W. Kaminsky, Adv. Organomet. Chem. 1980, 18, 99: b) P. Pino, R. Mülhaupt, Angew. Chem. 1980, 92,869; Angew. Chem. Int. Ed. Engl. 1980, 19 , 857.

[5] Recent reviews: M. Aulbach, F. Küber, Chem. Unserer Zeit 1994, 28, 197; P. C. Möhring, N. J. Coville, J. Organomet. Chem. 1994, 479, 1; K. B. Sinclair, R. B. Wilson, Chem. Ind. (London) 1994. 857; W. Kaminsky. Catal. Today 1994, 20, 257; J. C. W. Chien in ref. [6 g], p. 199.

[6] Conference proceedings: a) Catalytic Polymerization of Olefins (Eds.: T, Keii, K. Soga), Kodansha Elsevier, Tokyo, 1986; b) Transition Metals and Organometallic's as Catalysts for Olefin Polymerization (Eds.: W. Kaminsky, H. Sinn), Springer, Berlin, 1988; c) Catalysis in Polvmer Sinthesis (Eds.: E. J. Vandenberg. J. C. Salamone) (ACS Symp. Ser. 1992, 496); d) Proc. Int. Conf. Polyolefins VIII, Soc. Plast. Eng., Houston, 1993; e) Advances in Olefin, $\mathrm{Cy}_{y}$ cloolefin and Diolefin Polymerization (Eds.: A. Guyot, R. Spitz) (Makromol. Chem. Macromol. Symp. 1993, 66); f) Catalyst Design for Tailor-Made Polyolefins (Eds.: K. Soga. M. Terano), Kodansha Elsevier, Tokyo, 1994: g) Ziegler Catalysts (Eds.: G. Fink, R. Mülhaupt, H. H. Brintzinger), Springer. Berlin, 1995; h) Sinthedic, Structural and Industriat Aspects of Stereospecific Polymerization (Eds.: I. Tritto. U. Giannini) (Makromol. Chem. Macromol. Symp. 1995.89).

[7] The present review is focused on metallocene-based catalysts for the stereoselective polymerization of $\alpha$-olefins; it will thus not deal in detail with a) recent work on ethene polymerization, e.g. by monocyclopentadienyl (Cp) "constrained-geometry" catalysts (P. J. Shapiro, E. Bunel. W. P. Schaefer, J. E. Bercaw, Organometallics 1990, 9, 867; P. J. Shapiro, W. D. Cotter. W. P. Schaefer. J. A. Labinger, J. E. Bercaw, J. Am. Chem. Soc. 1994, 116, 4623; D. D. Devore, Eur. Pat, Appl. 1991, 514828; J. C. Stevens, F. J. Timmers,
D. R. Wilson, G. F. Schmidt, P. N. Nickias, R. K. Rosen, G. W. Knight, S. Y Lay, ibid. 1990. 416815; J. C. Flores, J. C. W. Chien, M. D. Rausch, Organometallics 1994, $t 3,4140$, and b) on styrene polymerization by $\mathrm{CpT}$ complexes (N. Ishihara, T. Seimiya, M. Kuramoto, M. Uoi, Macromolecules 1986, 19,2464 ; ibid. 1988, 21, 3356; N. Ishihara, N. Kuramoto in ref. [6f], p. $339 ;$ N. Ishihara in ref. $[6 \mathrm{~h}]$, p. $553 ;$ C. Pellecchia, P. Longo, A. Proto, A Zambelli, Makromol. Chem. Rapid Commun. 1992, 13, 265; T. E. Ready, R. O. Day, J. C. W. Chien, M. D. Rausch, Macromolecules 1993, 26, $5822 ;$ R. Quyoum, Q. Wang, M. J. Tudoret, M. C. Baird, D. J. Gillis, J. Am. Chem. Soc 1994, 116, 6435), or c) by Cp-free homogeneous catalysts (T. Miyatake, K. Mizunuma, M. Kakugo. in ref, [6e], p. 203; T. DallOcco. F. Sartori, G. Vecellio. U. Zucchini, A. Maldotti, Makromol. Chem. 1993, 194. 151).

[8] Third-generation Ziegler-Natta catalysts: a) N. Kashiwa, Polymer 1980, 12, 603; N. Kashiwa, J Yoshitake, Makromol. Chem. 1984, 185, 1133; b) B. L. Goodall, J. Chem. Educ. 1986, 63,191; c) P. Galli, P. C. Barbè, L. Noristi. Angew. Makromol. Chem. 1984, 120, 73; P. Galli, J. C. Haylock, Prog. Polym. Sci. 1991, 16, 443; Makromol. Chem. Macromol. Symp. 1992, 63, 19; P. Galli in ref. [6h], p. $13 ;$ d) T. Simonazzi, G. Cecchin, S. Mazzullo, Prog. Pofvm. Sci. 1991, 16, 303; e) J. C. W. Chien in ref. [6c], p. 27; f) U. Zucchini, in ref. [6e] p. 25 ; g) A. Guyot, R. Spitz, C. Journard, O. Eisenstein in ref. [6h], p. 39; h) E. Albizatti. U. Giannini, G. Morini. M. Galimberti, L. Barino, R. Scordamaglia in ref. [6h], p. 73.

[9] a) P. Cossee, Tetrahedron Lett. 1960, 12, 17; J. Catal. 1964, 3, 80; b) E. J. Arlman, ibid. 1964, 3, 89; E. J. Arlman, P. Cossee, ibid. 1964, 3, 99.

[10] cis-Insertion stereochemistry was documented by use of deuterated $x$-olefins G. Natta, M. Farina, M. Peraldo, Chim. Ind. (Paris) 1960, 42, 255; T, Miyazawa. Y. Ideguchi, J. Polym. Sci. Part B 1963, 1. 389; A. Zambelli, M. G. Giongo. G. Natta, Makromol. Chem. 1968, 112, 183.

[11] G. Natta, P. Pino, G. Mazzanti, R. Lanzo, Chim. Ind. (Paris) 1957, 39. 1032 .

[12] a) Experimental evidence for "enantiomorphic-site control" of olefin insertion stereochemistry: A. Zambelli, G. Gatti, C. Sacchi, W. O. Crain, Jr., J. D. Roberts, Macromolecufes 1971, 4, 475; W. O. Crain, Jr., A. Zambelli, J. D Roberts, ibid. 1971, 4, 330; A. Zambelli, C. Tosi, Adv. Polym. Sci. 1974, 15, 31 ibid. 1974, 25, 32. b) Olefin insertion under "chain-segment mediated" enantiomorphic-site control, molecular models: P. Corradini. V. Barone. R. Fusco, G. Guerra, Eur. Polym. J. 1979. 15. 1133; P. Corradini. G. Guerra, R. Fusco, V. Barone, ibid. 1980, 16. 835; P. Corradini. V. Barone, R. Fusco. G. Guerra, J. Catal 1982, 77, 32; P. Corradini, V. Barone, G. Guerra, Macromolecules 1982, 15, 1242. c) Evidence from ${ }^{13} \mathrm{C}$ NMR spectroscopy: A. Zambelli, M. C. Sacchi, P. Locatelli, G. Zannoni, ibid. 1982, 15, 211 ; A. Zambelli, P. Locatelli, M. C. Sacchi, I. Tritio, ibid. 1982, 15,831; A. Zambelii, P. Ammendola, M. C. Sacchi, P. Locatelli, NMR and Macromolecules (Ed.: J. C Randall) (ACS Symp. Ser. 1984, 247, p. 223).

[13] F. Patat. H. Sinn, Angew, Chem. 1958, 70.496.

[14] D. S. Breslow, US Pat. Appl. 1955, 537039; D. S. Breslow, N. R. Newburg, $J$. Am. Chem. Soc. 1957, 79, 5072.

[15] G. Natta, P. Pino, G. Mazzanti, U. Giannini, E. Mantica, M. Peraldo, Chim Ind. (Paris) 1957, 39, 19; G. Natta. P. Pino, G. Mazzanti, U. Giannini, J. Am. Chem. Soc. 1957, 79, 2975.

[16] a) B. A. Krentsel', L. A. Nekhaeva. Russ. Chem. Rev. (Engl. Transl.) 1990, 59 1193; b) J. Skupinska, Chem. Rev. 1991, 91, 613.

[17] D. S. Breslow, N. R. Newburg, J. Am. Chem. Soc. 1959, 81, 81; W. P. Long, itid. 1959. 81, 5312: W. P. Long. D. S. Breslow, ibid. 1960, 82. 1953.

[18] J. C. W. Chien. J. Am. Chem. Soc. 1959, $81,86$.

[19] G. Natta, G. Mazzanti, Tetrahedron 1960, $8,86$.

[20] H. Sinn, F. Patat, Angew. Chem. 1963, 75, 805

[21] a) K. H. Reichert, E. Schubert, Makromol. Chem. 1969, 123, 58; b) K. H Reichert. J. Berthold, V. Dornow, ibid. 1969, 121, 258; c) K. Meyer, K. H. Reichert. Angew. Makromol. Chem. 1970, 12, 175; d) K. H. Reichert, ibid 1970. $13,177$.

[22] G. Henrici-Olivé, S. Olivé, Angew. Chem. 1967. 79, 764; Angew. Chem. Int Ed. Engl. 1967, 6, 790; Kolloid Z. Z. Polym. 1968, 228, 43; J. Organomet. Chem. 1969, 16, 339; Polymerization, Verlag Chemie, Weinheim, 1969.

[23] A. K. Zefirova, A. E. Shilov, Dokl. Akad. Nauk SSSR 1961, 136. 599; Dokl Chem. (Engt. Transt.) 1961, t36, 77; F. S. Dyachkovskii, A. K. Shilova, A. E. Shilov, J. Polym. Sci. Purt C 1967, 16, 2333.

[24] G. Natta, P. Corradini, I. W. Bassi, J. Am. Chem. Soc. 1958, 80, 755.

[25] W. Kaminsky. J. Kopf. H. Sinn, H. J. Vollmer, Angew. Chem. 1976, 88, 688: Angew. Chem. Int. Ed. Engl. 1976, 15, 629, and references therein.

[26] a) R. F. Jordan, W. E. Dasher, S. F. Echols, J. Am. Chem. Soc. 1986, 108, 1718; b) R. F. Jordan. C. S. Bajgur, R. Willett, B. Scott. ibid. 1986, 108, 7410; c) R. F. Jordan, R. E. LaPointe, C. S. Bajgur, S. F. Echols, R. Willett, ibid. 1987, 109. 4111 ; d) R. F. Jordan. C. S. Bajgur, W. E. Dasher, A. L. Rheingold, Organometallics 1987,6,1041; e) R. F. Jordan, $J$ Chem. Educ 1988, 65, 285 f) R. F. Jordan, R. E. LaPointe, P. K. Bradley, N. Baenziger, Organometallics 1989, 8, 2892; g) R. F. Jordan, P. K. Bradley. R. E. LaPointe, D. F. Taylor, New J. Chem. 1990, 14, 505; h) R. F. Jordan, P. K. Bradley, N. C. Baenziger, R. E. LaPointe. J. Am. Chem. Soc. 1990, 112, 1289; i) R. F. Jordan, R. E. LaPointe, N. Baenziger, G. D. Hinch, Organometallics 1990, 9.1539; j) R. F. Jordan, Ady. Organomet. Chem, 1991, 32, 325; k) D. J. Crowther, S. L. 
Borkowsky, D. Swenson. T. Y. Meyer, R. F. Jordan, Organometallics 1993. 12,2897 .

[27] M. Bochmann, L. M. Wilson, J. Chem. Soc. Chem. Commun. 1986, 1610; M. Bochmann. L. M. Wilson. M. B. Hursthouse, R. L. Short, Organometallics 1987. 6. 2556; M. Bochmann, L. M. Wilson, M. B. Hursthouse, M. Motevalli, ibid. 1988, 7, 1148; M. Bochmann, A. J. Jaggar, J. C. Nicholls, Angew Chem. 1990. 102. 830; Anger. Chem. Int. Ed. Engl 1990, 29, 780; M. Bochmann. A. J. Jaggar. J. Organomet Chem. 1992, 424, C5; M. Bochmann, S. J Lancaster, itid. 1992. 434. C1.

[28] J. J. W. Eshuis, Y. Y. Tan, J. H. Teuben. J. Mol. Catal. 1990, 62, 277: b) J. J. W. Eshuis, Y. Y. Tan, A. Meetsma, J. H. Teuben, J. Renkema, G. G. Evens, Organome'tallics 1992, 11, 362.

[29] R. Taube, L. Krukowka, J. Organomet. Chem. 1988, 347, C9.

[30] G. G. Hlatky, H. W. Turner, R. R. Eckman, J. Am. Chem. Soc. 1989, 111, 2728: H. W. Turner, Elat. Pat. Appt 1988, 277004; Chem. Abstr. 1989, 1to, 58290a: H. W. Turner, G. G. Hlatky. Eur. Pat. Appl. 1988, 277003; Chem. Ahstr. 1989. 110. 58291b; G. G. Hlatky, R. R. Eckman. H. W. Turner, Organometallics 1992, 11, 1413.

[31] D. Schnell, G. Fink, Angew. Makromol. Chem. 1974, 39, 131; G. Fink, R. Rottler, ihid. 1981, 94, 25; G. Fink, R. Rottler, C. G. Kreiter, ibid. 1981, 96, 1; G. Fink. D. Schnell, ibid. 1982, 105, 15, 31, 39; G. Fink, W. Zoller, Makromol. Chem. 1981, 182,3265; G. Fink, W. Fenzl, R. Mynott, Z. Naturforsch. B 1985. 40, 158: R. Mynott. G. Fink, W. Fenzl, Angew. Makromol. Chem. 1987, 1.54. 1.

[32] J. J. Eisch. A. M. Piotrowski. S. K. Brownstein, E. J. Gabe. F. L. Lee, J. Am. Chem. Soc, 1985, 107, 7219; J. J. Eisch. M. P. Boleslawski, A. M. Piotrowski in ref. [6 b]. p. 371; J. J. Eisch, K. R. Caldwell, S. Werner, C. Krüger, Organometallic's 1991, 10, 3417; J. J. Eisch, S. 1. Pombrik, G. X. Zheng in ref [6e], p. 109; Organometallics 1993, 12, 3856; J. J. Eisch, S. I. Pombrik, S. Gürtzgen, R. Rieger, W. Uzick in ref. [6f], p. 221 ; J. J. Eisch, S. I. Pombrik, X. Shi, S.-C. Wu in rel. [6h], p. 221

[33] Since an olefin complex of the type $\left[\mathrm{Cp}_{2} \mathrm{MR} \text { (olefin) }\right]^{+}(\mathrm{M}=\mathrm{Ti}, \mathrm{Zr}$ ) has not been observed by spectroscopic or kinetic means so far [32], it is doubtful whether it should be regarded as a reaction intermediate.

[34] These "dormant" species might still be quite reactive, however, with regard to other important transformations, such as chain termination or catalyst deactivation reactions.

[35] Reagents stch as ${ }^{131} \mathrm{I}_{2},{ }^{14} \mathrm{CO}$ or $\mathrm{CH}_{3} \mathrm{OT}$, which are used to determine the number of active sites in a given reaction system [18], react also with these "dormant" sites; these methods will thus count all transition metal alkyl species as "active": P. J. T. Tait, B. L. Booth, M. O. Jejelowo. Makromol. Chem. Rapid Commun. 1988, 9, 393: P. J. T. Tait in ref. [6 b], p. 309.

[36] Besides ethene. styrene has been reported to be polymerized by $\mathrm{Cp}_{2} \mathrm{TiCl}_{2}$ $\mathrm{AlEt}_{2} \mathrm{Cl}$ cattalyst systems (C. G. Overberger. F. S. Diachkovsky, P. A. Jarovitzsky, J. Polym. Sci. 1964, A 2. 4113; C. G. Overberger. P. A. Jarovitzsky, ibid. 1965. A3.1483); it cannot be excluded that the presence of minor amounts of mono- $\mathrm{Cp}$ titanium compounds in these reaction systems are responsible for this catalysis (cf. ref. [7 b]). Recently, polymerization of styrene has been found to occur also with $\mathrm{CH}_{2}\left(\mathrm{C}_{5} \mathrm{H}_{4}\right)_{2} \mathrm{TiCl}_{2} / \mathrm{MAO}$ : A. Miyashita. M. Nabika, T. Suzuki, Abstr. Int. Symp. Synthetic, Structural and Industrial Aspects of Stereoselective Polymerization (Ed.: L. Porri), Milan, 1994. p. 8s:

[37] K. H. Reichert, K. R. Meyer, Makromol. Chem. 1973, 169, 163.

[38] W. P. Long. D. S. Breslow, Liebigs Ann. Chem, 1975. 463.

[39] a) A. Andresen, H. G. Cordes, J. Herwig, W. Kaminsky, A. Merck, R. Mottweiler. J. Pein, H. Sinn, H. J. Vollmer, Angew. Chem. 1976, 88, 689; Angew. Chem. Int. Ed. Engl. 1976, 15, 630; b) H. Sinn, W. Kaminsky, H. J. Vollmer, R. Woldt, ibid. 1980, 92, 396 and 1980, 19, 396; c) W. Kaminsky, Nachr. Chem. Tech. Lab. 1981, 29, 373; d) W. Kaminsky, MMI Press Sump. Sor. 1983, 4, 225; e) J. Herwig. W. Kaminsky, Polym. Bull. (Berlin) 1983, 9. 464; O) W. Kaminsky, M. Miri, H. Sinn, R. Woldt, Makromol. Chem. Rapid (ommmm. 1983, 4, 417:g) W. Kaminsky, Naturwissenschaften 1984, 71.93; h) W. Kaminsky, Angew. Makromol. Chem. 1986, 145/146, 149; i) W. Kaminsky, R. Steiger. Polyhedron 1988, 7, 2375; R. Steiger, Dissertation, Universität Hamburg. 1990; W. Kaminsky, A. Bark, R. Steiger, J. Mol. Catal. 1992, 74. 109; j) H. Sinn, J. Bliemeister, D. Clausnitzer, L. Tikwe, H. Winter, O. Zarncke in rel. [6 b], p. 257: J. Bliemeister. W. Hagendorf. A. Harder, B. Heitmanı. I. Schimmel. E. Schmedt. W. Schnuchel. H. Sinn. L. Tikwe, N. von Thienen, K. Urlass, H. Winter. O. Zarncke in ref. [6g]. p. 57: O. Zarncke, Disscrtation. Universität Hamburg. 1991.

[40] Similar but less pronounced reductions to the $\mathrm{Zr}^{.111}$ stage have been reported also for $\mathrm{Cp}_{2} \mathrm{ZrCl}_{2} / \mathrm{MAO}$ catalyst systems, especially in the presence of ethene: D. Cam. F. Sartori. A. Maldotti, Macromol. Chem. Phys. 1994, 195, 2817.

[41] E. J. Vandenberg. J. Pol.m. Sci. 1960. 47, 486.

[42] a) N. Piccolrovazzi, P. Pino, G. Consiglio. A. Sironi, M. Moret, Organometallicr 1990. 9. 3098; b) N. Piccolrovazzi, Dissertation. Eidgenössische Technische Hochschule Zürich. 1989.

[43] L. Resconi, S. Bossi, L. Abis, Macromolecules 1990, $23,4489$.

[44] a) D. Cam. E. Albizzati, P. Cinquina, Makromol. Chem. 1990, 191, 1641; b) D. Cam, U. Giannini, ibid. 1992. 193, 1049.

[45] S. Pasynkiewicz, Polyhedron 1990, 9, 429
[46] E. Giannetti, G. M. Nicoletti, R. Mazzocchi, J. Polym. Sci. Polym. Chem. Ed. 1985, 23, 2117.

[47] S. Lasserre, J. Derouault, Nouv. J. Chim. 1983, 7, 659.

[48] a) M. R. Mason, J. M. Smith, S. G. Bott, A. R. Barron, J. Am. Chem. Soc. 1993, 115, 4971; C. J. Harlan, M. R. Mason, A. R. Barron. Organometallics 1994, 13,2957 ; b) C. J. Harlan, S. G. Bott, A. R. Barron. J. Am. Chem. Soc. 1995,117 , in press.

[49] L. A. Nekhaeva, G. N. Bondarenko, S. V. Rykov, A. I. Nekhaev, B. A. Krentsel. V. P. Mar'in, L. I. Vyshinskaya. I. M. Khrapova, A. V. Polonskii, N. N. Korneev, J. Organomet. Chem. 1991, 406. 139.

[50] a) A. R. Siedle, R. A. Newmark, W. M. Lamanna, J. N. Schroepfer, Polyhe dron 1990, 9, 301; b) A. R. Siedle, W. M. Lamanna, J. M. Olofson. B. A. Nerad, R. A. Newmark, Selectivity in Catalysis (Eds.: M. E. Davis, S. L. Suib) (ACS Symp. Ser. 1993, 517, 156); c) A. R. Siedle, W. M. Lamanna, R. A. Newmark, J. Stevens, D. E. Richardson. M. Ryan in ref. \{6e\}, p. 215; d) A. R. Siedle, R. A. Newmark, D. E. Richardson. M. F. Ryan, C. R. Landis, J. Wright. D. Root, M. G. Hill, K. R. Mann, Proc. MetCon, Houston 1993. 351 ; e) A. R. Siedle. R. A. Newmark. J. Organomet. Chem. 1995, in press; A. R. Siedle. B. Hanggi, R. A. Newmark, K. R. Mann. T. Wilson, in ref. $[6 \mathrm{~h}]$, p. 299.

[51] Catalytic activities of titanocene and zirconocene complexes for the polymerization of propene, comparable to those attainable with $\mathrm{MAO}$, have also been induced by mixtures of $\mathrm{AlMe}_{3}$ and $\mathrm{AlMe}_{2} \mathrm{~F}$ : A. Zambelli, P. Longo, A. Grassi, Macromolecules 1989, 22, 2186; P. Longo, L. Oliva, A. Grassi. C. Pellecchid, Makromol. Chem. 1989, 190, 2357.

[52] P. G. Gassman. M. R. Callstrom, J. Am. Chem. Soc, 1987, 109, 7875.

[53] a) C. Sishta, R. M. Hathorn, T. J. Marks. J. Am. Chem. Soc, 1992, 114, 1112 ; b) X. Yang, C. L. Stern, T. J. Marks, Organometallics 1991, $10,840$.

[54] G. G. Hlatky, D. J. Upton. H. W. Turner, US Pat. Appl. 1990, 459921; Chent. Abstr. 1991, 115, 256897v.

[55] J. A. Ewen, M. J. Elder, Eur. Pat. Appl. 1991, 426637, 426638; Chem. Abstr. $1991,115,136987 \mathrm{c}, 136988 \mathrm{~d}$; in ref. [6e], p. 179.

[56] J. C. W. Chien, W. M. Tsai, M. D. Rausch, J. Am. Chem. Soc. 1991, 113,8570; J. C. W. Chien, W. M. Tsai in ref. [6e], p. 141.

[57] a) M. Bochmann. S. J. Lancaster. Organometallics 1993. 12,633; b) M. Bochmann. Nachr. Chem. Tech. Lab. 1993, 41, 1220; c) M. Bochmann. S. J. Lancaster, M. B. Hursthouse. K. I. M. Abdul Malik, Organometallics 1994, 13. 2235; d) M. Bochmann, S. I. Lancaster, Angesw. Chem. 1994, 106, 1715; Angew. Chem. Int. Ed. Engl. 1994, 33, 1634.

[58] a) A. D. Horton, J. H. G. Frijns, Angew. Chem. 1991, 103, 1181; Angew. Chem. Int. Ed. Engl. 1991, 30, 1152; b) A. D. Horton, A. G. Orpen, Organometallics 1991, 10, 3910; c) A. D. Horton, J. Chem. Soc. Chem. Commun. 1992. 185

[59] J. A. Ewen. M. J. Elder, US Pat. Appl. 1989, 419017; Chcm. Abstr. 1991, 115, $136998 \mathrm{~g}$.

[60] a) X. Yang, C. L. Stern, T. I. Marks, J. Am. Chem. Soc. 1991, /13, 3623: isid. 1994. 116,$10015 ;$ b) related permethyl zirconocene hydride complexes: $X$. Yang. C. L. Stern, T. J. Marks, Angew. Chem. 1992, 104, 1406; Angew: Chem. Int. Ed. Engl. 1992, 31, 1375.

[61] D. G. H. Ballard, A. Courtis, J. Holton, J. McMeeking, R. Pearce, J. Chem. Soc. Chem. Commun. 1978, 994.

[62] P. L. Watson. J. Am. Chem. Soc. 1982, 104, 337; P. L. Watson, D. C. Roe, ibid 1982, 104. 6471; P. L. Watson, G. W. Parshall, Acc. Chem. Res. 1985, 18.51.

[63] G. Parkin. E. Bunel, B. J. Burger. M. S. Trimmer, A. van Asselt. J. E. Bercaw, J. Mol. Catal. 1987, 41.21: B. J. Burger. M. E. Thompson, W. D. Cotter, J. E. Bercaw, I. Am. Chem. Soc. 1990, 112, 1566.

[64] G. Jeske, H. Lauke, H. Mauermann, P. N. Swepston. H. Schumann, T. J. Marks, J. Am. Chem. Soc. 1985, 107, 8091.

[65] a) D. T. Mallin, M. D. Rausch, J. C. W. Chien, Polym. Bull. (Berlin) 1988, 20 , 421 ; b) J. C. W. Chien, A. Razavi, J. Polym. Sci. Part A 1988, 26, 2369 ; J. C. W. Chien, B. P. Wang, ihid. 1988, 26, 3089; ibid. 1989. 27, 1539; c) ibid. 1990, 28, 15.

[66] T. Tsutsui, N. Kashiwa, Polym. Commun. 1988, 29, 180.

[67] P. J. T. Tait, B. L. Booth, M. O. Jejelowo in ref. [6c], p. 78.

[68] B. W. S. Kolthammer, D. J. Mangold, D. R. Gifford, J. Polym. Sci. Purt A 1992, 30, 1017 .

[69] a) D. Fischer. R. Mülhaupt, J. Organomet. Chem. 1991, 417, C7; b) D. Fischer. Dissertation, Universität Freiburg, 1992 ; c) D. Fischer, S. Jüngling, R. Mülhaupt in ref. [6e], p. 191; d) D. Fischer. R. Mülhaupt, Makromol. Chem. 1994, 195, 1433; e) S. Jüngling. Dissertation. Universität Freiburg. 1995.

[70] Such an equilibrium explains that increasing MAO concentrations cause further increases in activity even though ${ }^{14} \mathrm{CO}$ or $\mathrm{CH}_{3}$ OT radio-tagging methods represent most of the $\mathrm{Zr}$ centers as "active", i.e. as carrying a polymer chain, even in homogeneous catalyst systems with moderate MAO concentrations $[18,35,65,67]$.

[71] A. D. Horton, A. G. Orpen, Organometalics 1992, 11, 8: Angew. Chem. 1992. 104. 912; Angew: Chem. Int. Ed. Engl. 1992, 31, 876: A. D. Horton, Organometallics 1992, 11, 3271.

[72] Added $\mathrm{AlMe}_{3}$ increases the steady-state activities in reaction systems of this kind: S. Srinivasa Reddy, G. Shashidhar. S. Sivaram, Macromolecules 1993, 
26,$1180 ; \mathrm{I}_{1}$ might thus be reconverted to $\mathrm{C}$ by alkyl exchange with the $\mathrm{AlMe}_{3}$ content of MAO.

[73] a) M. Bochmann, S. J. Lancaster, J. Organomet. Chem. 1992, 434. C1; b) Angew. Chem. 1994, 106, 1715; Angew. Chem. Int. Ed. Engl. 1994. 33, 1634.

[74] Formation of a zirconocene allyl cation from $\left[\mathrm{Cp}_{2} \mathrm{ZrMe}^{+}\right.$and $\mathrm{C}_{2} \mathrm{H}_{4}$ has been observed in the gas phase: C. S. Christ, J. R. Eyler, D. E. Richardson, J. Am. Chem. Soc. 1988, 110, 4038.

[75] A decrease of activities with increasing MAO concentrations is occasionally observed at very high Al:Zr ratios: I. C. W. Chien, R. Sugimoto. J. Polym. Sci. Part $A$ 1991, 29, 459; and ref. [132a].

[76] M. Ystenes, J. Catal. 1991, 129,383 ; in ref. [6e], p. 71.

[77] D. T. Laverty, J. J. Rooney, J. Chem. Soc. Faraday Trans. 1 1983, 79 , 869.

[78] M. Brookhart, M. L. H. Green, J. Organomet. Chem. 1983, 250, 395; M. Brookhart, M. L. H. Green, L. Wong, Prog. Inorg. Chem. 1988, 36,1 .

[79] Experimental and theoretical investigations on agostic interactions: a) R. B Calvert, J. R. Shapley, J. Am. Chem. Soc. 1978, 100, 7726; b) S. Obara, N. Koga, K. Morokuma, J. Organomet. Chem. 1984, 270, C33: N. Koga. S. Obara, K. Morokuma, J. Am. Chem. Soc. 1984, 106, 4625; c) O. Eisenstein, Y. Jean, ibid. 1985, 107, 1177; d) M. J. Calhorda, J. A. M. Simoes, Organometallics 1987, 6, 1188; e) K. Tatsumi, A. Nakamura, J. Am. Chem. Soc. 1987, 109, 3195; Organotnetallics 1987, 6, 427; K. Mashima, A. Nakamura, J. Organomet. Chem. 1992, 428, 49; f) A. Shiga, J. Kojima, T. Sasaki, Y. Kikuzono, ibid. 1988, 345, 275; g) R. F. Jordan, P. K. Bradley, N. C. Baenziger, R. E. LaPointe, J. Am. Chem. Soc. 1990, 112, 1289; Z. Guo, D. C. Svenson, R. F. Jordan, Organometallics 1994, 13, 1424.

[80] H. Krauledat, H. H. Brintzinger, Angew. Chem. 1990, 102, 1459; Angew. Chem. Int. Ed. Engl. 1990, 29, 1412.

[81] L. Clawson, J. Soto, S. L. Buchwald, M. L. Steigerwald, R. H. Grubbs, J. Am. Chem. Soc. 1985, 107, 3377

[82] W. E. Piers, J. E. Bercaw, J. Am. Chem. Soc. 1990, 112, 9406.

[83] While hydrocyclization of $1,6-\left[D_{2}\right]-1,5$-hexadiene with a scandocene catalyst gave a stereokinetic isotope effect of $k_{\mathrm{H}} / k_{\mathrm{D}} \approx 1.25[82,144]$, the analogous reaction with $\mathrm{Cp}_{2} \mathrm{ZrCl}_{2} / \mathrm{MAO}$ did not [80].

[84] a) D. R. Armstrong, P. G. Perkins, J. J. P. Steward, J. Chem. Soc. Dalton Trans. 1972, 1972; b) J. W. Lauher, R. Hoffmann, J. Am. Chem. Soc. 1976, 98. 1729 ; c) D. L. Thorn, R. Hoffmann, ibid. 1978, 100, 2079; d) O. Novaro, E. Blaisten-Barojas. E. Clementi, G. Giunchi, M. E. Ruiz-Vizcaya, J. Chem Phys. 1978, 68, 2337; e) H. Fujimoto, T. Yamasaki, H. Mizutani, N. Koga, $J$ Am. Chem. Soc. 1985, 107, 6157; f) A. Shiga, H. Kawamura, T. Ebara, T Sasaki, Y. Kikuzono, J. Organomer. Chem. 1989, 366, 95; g) C. A. Jolly, D. S. Marynick, J. Am. Chem. Sor. 1989, 111, 7968.

[85] H. Kawamura-Kuribayashi, N. Koga. K. Morokuma, J. Am. Chem. Soc 1992, 114, 8687; Chem. Rev. 1991, 91, 823; T. Yoshida. N. Koga, K. Morokuma, Organometallics 1995, 14,746; N. Koga. T. Yoshida, K. Marokumá in ref. [6g], p. 275.

[86] a) L. A. Castonguay, A. K. Rappé, J. Am. Chem. Soc. 1992, 114, 5832; b) J. R. Hart, A. K. Rappé, ibid. 1993, 115,6159

[87] a) T. K. Woo, L. Fan, T. Ziegler, Organometallics 1994, 13, 432, 2252; in ref. [6g], p. 291 ; b) L. Fan, D. Harrison, T. K. Woo, T. Ziegler, ibid., 1995. 14, 2018.

[88] a) H. Weiss, M. Ehrig, R. Ahlrichs. J. Am. Chem. Soc. 1994, 116, 4919; b) H. Weiss, private communication; c) R. J. Meier, G. H. J. van Doremaele. S. Iarlori, F. Buda, J. Am. Chem. Soc. 1994, 116, 7274; S. Iarlori, F. Buda. G. van Doremaele, R. J. Meier in ref. [6 h], p. 369.

[89] M. H. Prosenc, C. Janiak, H. H. Brintzinger, Organometallics 1992, 11, 4036. This study yields a - probably exaggerated - estimate of ca. $20 \mathrm{~kJ} \mathrm{~mol}^{-1}$ for the agostic stabilization of the insertion transition state.

[90] P. J. Flory, Principles of Polymer Chemistry. Cornell University Press, Ithaca, 1986, p. 317.

[91] Other end groups, which arise from $\beta$-alkyl transfer to the $\mathrm{Zr}$ centers [58, 92-94], from $\sigma$-bond metathesis with the olefin substrate [ $50 \mathrm{~b}, \mathrm{c}]$, or from alkyl exchange between $\mathrm{Zr}$ and $\mathrm{Al}$ centers [43,65e, 95], are occasionally observed, in particular with sterically strongly hindered (e.g. permethyl) metallocene catalysts (cf. G. Sini, S. A. Macgregor, O. Eisenstein. J. H Teuben, Organometallics 1994, 13. 1049). These reactions do not appear to contribute significantly to chain termination in propene polymerization by $\mathrm{MAO}$-activated $\mathrm{Cp}_{2} \mathrm{ZrCl}_{2}$ systems.

[92] E. Bunel, B. J. Burger, J. E. Bercaw, J. Am. Chem. Soc. 1988, 110, 976; S. Hajela, J. E. Bercaw, Organometallics 1994, 13, 1147

[93] L. Resconi, R. M. Waymouth, J. Am. Chem. Soc. 1990, 112.4953; L. Resconi, U. Giannini, E. Albizzati, F. Piemontesi, T. Fiorani, Polym. Prepr. (Am. Chem. Soc, Div. Polym. Chem.) 1991, 32. 463; L. Resconi, F. Piemontesi, G. Franciscono, L. Abis. T. Fiorani, J. Am. Chem. Soc. 1992, 114, 1025.

[94] T. Mise, A. Kageyama, S. Miya, H. Yamazaki, Chem. Letr. 1991, 1525.

[95] a) A. L. Mogstad. L. Resconi, R. M. Waymouth, Polym. Prepr. \{Am. Chem. Soc, Div. Polym. Chem.) 1991, 32, 160; b) A. L. Mogstad, R. M. Waymouth. Macromolecules 1992, 25, 2282.
[96] Such an n-propyl unit is observed at the head of most polypropene chains, except for a small fraction, which is initially formed by propene insertion into the $\mathrm{Zr}-\mathrm{CH}_{3}$ units generated during activation of $\mathrm{Cp}_{2} \mathrm{ZrCl}_{2}$ by the $\mathrm{MAO}$ cocatalyst [97]

[97] T. Tsutsui, A. Mizuno, N. Kashiwa, Polymer 1989, 30, 428.

[98] W. Kaminsky, K. Külper, S. Niedoba, Makromol. Chem. Macromol. Symp. 1986, 3, 377.

[99] This would imply that $v_{\mathrm{T}}$ is not significantly affected by MAO concentrations, i.e. that chain terminations arise predominantly) from "dormant" (i.e. associated) zirconocene ion pairs. Facile olefin isomerizations with Schwartz's hydrozirconation reagent $\mathrm{Cp}_{2} \mathrm{ZrHCl}$ indicate that olefin extrusion from neutral zirconocene alkyl species is fairly fast: J. Schwartz, J. A. Labinger, Angew. Chem. 1976, 88, 402; Angew. Chem. Int. Ed. Engl. 1976, 15, 333.

[100] Previously prepared chiral titanocene and zirconocene complexes: H. Brunner, H. D. Schindler, J. Organomet. Chem. 1973, 55, C71; J. Tirouflet, A Dormond, J. C. Leblanc, F. Le Moigne, Tetrahedron Lett. 1973, 257; J. Besancon, F. Huq, M. Colette, J. Organomet. Chem. 1975, 96, 63; P. Renaut, G. Tainturier, B. Gautheron, ibid. 1978, 148, 43; J. C. Leblanc, C. Moise, J. Tirouflet, ibid. 1978, 148, 171; S. Couturier, B. Gautheron, ibid. 1978 157. C61; E. Cesarotti, H. B. Kagan, R. Goddard, C. Krüger, ihid. 1978, 162, 297.

[101] Studies on metallocene-based polymerization catalysts in Kaminsky's group [39 a, b] as well as syntheses of chiral ansa-metallocenes in Brintzinger's group (H. Schnutenhaus, H. H. Brintzinger, Angew. Chem. 1979, 91, 837; Angew' Chem. Int. Ed. Engl. 1979, 18, 777) were supported from 1973 to 1978 by Deutsche Forschungsgemeinschaft through a special program for research in homogeneous catalysis.

[102] Fixation of ligand geometries by an ethanediyl bridge had been found to be beneficial for other types of stereoselective homogeneous catalysts, see e.g.: M. D. Fryzuk, B. Bosnich, J. Am. Chem. Soc. 1978, 100, 5491; B. Bosnich, M. D. Fryzuk. Top. Stereochem. 1981, 12,119.

[103] a) F. R. W. P. Wild, L. Zsolnai, G. Huttner, H. H. Brintzinger, J. Organomet Chem. 1982, 232, 233; F. R. W. P. Wild, M. Wasiucionek, G. Huttner, H. H. Brintzinger, ibid. 1985, 288, 63; b) more recent syntheses and structural studies: J. A. Ewen. L. Haspeslagh, J. L. Atwood, H. Zhang, J. Am. Chem. Soc 1987, 109, 6544; R. M. Waymouth, F. Bangerter, P. Pino, Inorg. Chem. 1988, 27, 758; S. Collins, B. A. Kuntz. N. J. Taylor, D. G. Ward, J. Organomet Chem. 1988, 342, 21; S. Collins, W. J. Gauthier, D. A. Holden, B. A. Kuntz, N. J. Taylor, D. G. Ward, Organometallics 1991, 10, 2061; R. B. Grossman, R. A. Doyle, S. L. Buchwald, ibid. 1991, 10,1501; G. M. Diamond, S. Rodewald, R. F. Jordan, ibid. 1995, 14, 5; F. Piemontesi. I. Camurati, L. Resconi, D. Balboni, A. Sironi, M. Moret, R. Zeigler, N. Piccolrovazzi, ibid. 1995, 14, 1256

[104] The prefix unsa (lat. ansa $=$ bent, handle), first used for compounds with an alkane bridge across an arene ring (A. Lüttringhaus, H. Gralheer, Justus Liebigs Ann. Chem. 1942, 550, 67), was adopted as a short notation for metallocene derivatives with an interannular bridge (J. A. Smith, J. von Seyerl, G. Huttner, H. H. Brintzinger, J. Organomet. Chem. 1979, 173, 175).

[105] J. A. Ewen, J. Am. Chem. Soc. 1984, 106, 6355.

[106] W. Kaminsky, K. Külper, H. H. Brintzinger, F. R. W. P. Wild, Angew. Chem 1985, 97, 507; Angew. Chem. Int. Ed. Engl. 1985, 24, 507.

[107] a) F. A. Bovey, High Resolution NMR of Macromolecules, Academic Press, New York. 1972; A. Zambelli, P. Locatelli, G. Bajo, F. A. Bovey, Macromolecules 1975, 8, 687; F. A. Bovey, Chain Structure and Conformation of Macromolecules. Academic Press, New York, 1982: b) J. C. Randall, Polymer Sequence Determination by the Carbon 13 NMR Method, Academic Press, New York, 1977 ; in Polymer Characterization by NMR and ESR (Eds.: A. E. Woodward, F. A. Bovey) (ACS Symp. Ser.; 1980, 142); c) M. Farina, Top. Stereochem. 1987, 17, 1; d) A. E. Tonelli, NMR Spectroscopy and Polymer Microstructure, VCH, Weinheim, 1989 ; e) J. L. Koenig, Spectroscopy of Polymers, American Chemical Society, Washington, 1991.

[108] Today, polymer NMR spectra can be analyzed at even higher resolution levels: A. E. Tonelli, F. C. Schilling, Acc. Chem. Res. 1981, 14, 233; T. Hayashi, Y. Inoue, R. Chujo, T. Asakura, Polymer 1988, 29, 138; A. De Marco, P. Sozzani, G. Di Silvestro, M. Farina, Macromolecules 1989, 22, 2154; M. Farina, G. Di Silvestro, P. Sozzani, Prog. Polym. Sci. 1991, 16, 219.

[109] The mmrm and $r m r r$ pentad signals have identical chemical shifts.

[110] Essentially atactic polypropylene was first obtained with a homogeneous catalyst containing $\mathrm{VCl}_{4}$ and $\mathrm{AlClEt}_{2}$ at $-78^{\circ} \mathrm{C}$ (G. Natta, A. Zambelli, G. Lanzi, I. Pasquon. E. R. Mognaschi, A. L. Segre, P. Cantola, Makromol. Chem. 1965, 81, 161). Strictly atactic polypropene is obtained from isotactic polypropene by epimerization with Pd catalysts at elevated temperatures U. W. Suter, P. Neuenschwander, Macromolecules 1981, 14, 528

[111] Alternative measures for polyolefin stereoregularity are the relative triad probabilities $[\mathrm{mm}]=[\mathrm{mmmm}]+[\mathrm{mmmr}]+[\mathrm{rmmr}],[\mathrm{mr}]=[\mathrm{mm} r \mathrm{r}]+$ $[\mathrm{mmrm}]+[\mathrm{rmrr}]+[\mathrm{rmrm}]$ and $[\mathrm{rr}]=[\mathrm{rrrr}]+[\mathrm{rrrm}]+[\mathrm{mrrm}]$, and the average lengths of isotactic and syndiotactic sequences, $n_{\mathrm{iso}}=2[\mathrm{~mm}] /[\mathrm{mr}]+1$ and $n_{w}=2[r r][[m r]+1$ [107]. For typical isotactic polymers with $[\mathrm{mmmm}] \approx 0.95$, the mean length of an isotactic sequence is $n_{\mathrm{i}: \mathrm{p}} \approx 100$ units.

[112] T. Tsutsui. N. Ishimaru, A. Mizuno, A. Toyota, N. Kashiwa, Polymer 1989, 30,1350 
[113] Since [ $m m m m]>0.9$ corresponds to a diastereomer excess of $>95 \%$ for each insertion step. these homogeneous polymerization catalysts are roughly comparable to the most highly stereoselective organometallic catalysts employed for other $C-C$ coupling reactions: $\mathrm{H}$. Brunner, Top. Stereochem. 1988, $t 8$, 129; Sinthesis 1988, 645; D. Seebach, Angen'. Chem. 1990, 102, 1363; Angew. Chem. Int. Ed. Engl. 1990, 29, 1320.

[114] a) B. Rieger. J. C. W. Chien, Polym. Bull. (Berlin) 1989, 21, 159; B. Rieger, X. Mu, D. T. Mallin, M. D. Rausch. I. C. W. Chien, Macromolec ustes 1990, 23 , 3559 ; b) Y. X. Chen. M. D. Rausch, J. C. W. Chien. Organometallics 1994, 13. 748.

[115] a) H. N. Cheng, M. A. Bennett, Makromol. Chem. 1987, 188, 135: H. N. Cheng. J. A. Ewen, ibid. 1989, 190, 1931; H. N. Cheng, G. N. Babu, R. A. Newmark, J. C. W. Chien, Macromolecules 1992, 25, 6980; H. N. Cheng, Makromol. Chem. Theory Simul. 1993, 2, 561. b) Recently, the term "catalyt ic-site control". which is applicable also to metal centers of $C_{\text {s }}$ symmetry appears to be used more frequently instead of the previously used term "enantiomorphic-site control

[116] a) J. A. Ewen. in ref. [6a], p. 271; b) J. A. Ewen, L. Haspeslagh. J. L. Atwood. H. Zhang. J. Am. Chem. Soc, 1987, 109, 6544: c) J. A. Ewen. L. Haspeslagh. M. J. Elder. J. L. Atwood, H. Zhang, H. N. Cheng, in ref. [6 b], p. 281; d) J. A Ewen. R. L. Jones. A. Razavi, J. D. Ferrara. J. Am. Chem. Soc. 1988, 110 6255 ; e) J. A. Ewen, M. J. Elder, R. L. Jones, S. Curtis, H. N. Cheng, Stud. Stwi Sci. ('atal. 1990, 56, 439; f) J. A. Ewen, M. J. Elder, R. L. Jones, L. Haspeslagh, J. L. Atwood, S. G. Bott, K. Robinson, Makromol. Chem Macromol. Simp. 1991, 48/49, 253; g) J. A. Ewen, M. J. Elder in ref. [6e] p. $179 ;$ h) J. A. Ewen. M. J. Elder. Eur. Pat. Appl. 1993. EP-A 0537130; in ref. $[6 \mathrm{~g}]$, p. $99 ;$ J. A. Ewen in ref. $[6 \mathrm{~h}]$, p. 181 .

[117] a) M. Antberg. L. L. Böhm, V. Dolle, H. Lüker, J. Rohrmann, W. Spaleck, A. Winter, 44th Southw'est Reg. Meet. Am. Chem. Soc. 1988, Abstr. No. 48; b) W. A. Herrmann, J. Rohrmann, E. Herdtweck, W. Spaleck, A. Winter, Angew Chem. 1989, t01, 1536; Angew'. Chem. Int. Ed. Engl. 1989, 28, 1511; c) W Spaleck, M. Antberg, V. Dolle, R. Klein, J. Rohrmann, A. Winter, New $J$. Chem. 1990, 14, 499; d) M. Antberg, V. Dolle, R. Klein, J. Rohrmann, W. Spaleck, A. Winter, Stud. Surf. Sir. Catal. 1990, 56, 501; e) M. Antberg. V. Dolle, S. Haftka, J. Rohrmann. W. Spaleck, A. Winter, H. J. Zimmermann, Makromol. Chem. Macromol. Symp. 1991, 48/49. 333; f) W. Spaleck. M. Antberg. J. Rohrmann, A. Winter, B. Bachmann, P. Kiprof, J. Behm, W. A. Herrmann, Angew. Chem. 1992, 104.1373; Angew: Chem. Int, Ed. Engl, 1992 3), 1347; g) W. Kaminsky, R. Engehausen, K. Zoumis, W. Spaleck, J. Rohrmann, Makromol. Chem. 1992, 193, 1643; h) W. Spaleck, F. Küber, A. Winter, J. Rohrmann, B. Bachmann, M. Antberg, V. Dolle, E. F. Paulus, Organomefalics 1994, 13, 954; i) W. Spaleck, M. Antberg, M. Aulbach, B. Bachmann, V. Dolle, S. Haftka, F. Küber, J. Rohrmann, A. Winter in ref. [6g], p. 83: W. Spaleck, M. Aulbach, B. Bachmann, F. Küber. A. Winter in ref. $[6 \mathrm{~h}]$, p. 237

[118] S. Miya. T. Yoshimura. T, Mise, H. Yamazaki, Polym. Prepr. Jpn. 1988, 37 285: T. Mise, S. Miya, H. Yamazaki, Chem. Lett. 1989, 1853; S. Miya, T. Mise, H. Yamazaki, Stud. Surf. Sci. Catal. 1990, 56, 531

[119] a) S. Collins, W. J. Gauthier, D. A. Holden, B. A. Kuntz, N. J. Taylor, D. G. Ward, Organometallies 1991, 10, 2061; b) I. M. Lee, W. J. Gauthier, J. M. Ball, B. Jyengar, S. Collins, ibid. 1992, $11,2115$.

[120] a) W. Röll. H. H. Brintzinger. B. Rieger, R. Zolk, Angew. Chem. 1990, 102, 339; Angt't. Chom. Int. Ed. Engl. 1990, 29, 279; b) B. Rieger. A. Reinmuth. W. Röll. H. H. Brintzinger. J. Mol. Catal. 1993, 82, 67; c) A. Reinmuth, Dissertation, Universität Konstanz, 1992; d) U. Stehling, J. Diebold, R. Kirsten, W. Röll, H. H. Brintzinger, S. Jüngling, R. Mülhaupt, F. Langhauser, Organometalics 1994, 13,964; e) T. Haselwander, S. Beck, H. H. Brintzinger in ref. $[6 \mathrm{~g}]$, p. 181

[121] Comparison of results from different laboratories is difficult not only because of variations in $T_{\mathrm{p}}$ and other catalysis parameters, but also because of inexplicit corrections of signal intensities for contributions from various end group and regio-irregularity signals and by use of different stereoregularity measures [111].

[122] A. Zambelli. P. Ammendola, A. Grassi, P. Longo, A. Proto, Macromolecules 1986, 19. 2703; A. Zambelli, P. Longo, P. Ammendola, A. Grassi, Gazz. Chim. Ihal 1986, 116, 731: A. Zambelli, P. Ammendola in ref. [6 b], p. 329.

[123] G. Erker, R. Nolte, Y. H. Tsay, C. Krüger, Angew'. Chem. 1989, 101, 642; Angews. Chenz. Int. Ed. Engl. 1989, 28, 628; G. Erker, R. Nolte, R. Aul, S. Wilker, C. Krüger, R. Noe, J. Am. Chem. Soc. 1991, 113, 7594; G. Erker, C. Fritze. Angew. Chem. 1992, 104, 204: Angew. Chem. Int. Ed. Engl. 1992. 31, 199; G. Erker, B. Temme, J. Am. Chem. Soc. 1992, 114, 4004; G. Erker, M. Aulbach, C. Krüger, S. Werner, I. Organomet. Chem. 1993, 450, 1; G. Erker, M. Aulbach. M. Knickmeier, D. Wingbermühle, C. Krüger, M. Nolte, S. Werner, J. Am. Chem. Soc. 1993. 115, 4590; G. Erker, C. Mollenkopf, J. Organomet. Chem. 1994, 483,173.

[124] a) A. Razavi, J. L. Atwood, J. Am. Chem. Soc. 1993, 115. 7529; b) A. Razavi, U. Thewalt, J. Organomet. Chem. 1993, 445, 111: c)A. Razavi, J. Ferrara, ibid. 1992, 435, 299; A. Razawi, D. Vereecke, L. Peters, K. Den Dauw, L. Nafpliotis, J. L. Atwood in ref. [6g]. p. 111; A. Razawi, L. Peters, L. Nafpliotis. D. Vereecke. K. Den Dauw, J. L. Atwood. U. Thewald in ref. [6h], p. 345 .
[125] G. W. Coates, R. M. Waymouth, Science 1995, 267, 217

[126] a) A. Schäfer, E. Karl, L. Zsolnai, G. Huttner, H. H. Brintzinger, $J$ Organomet. Chem. 1987, 328, 87; b) P. Burger, J. Diebold. S. Gutmann, H. U. Hund, H. H. Brintzinger, Organometallics 1992, 11,1319 .

[127] B. Rieger, J. Organomet. Chem. 1992, 428, C33.

[128] Predominantly syndiotactic polypropene was first obtained with vanadiumbased catalyst systems at low temperatures: G. Natta, J. Pasquon, A. Zambelli, J. Am. Chem. Soc. 1962, 84. 1488; Y. Doi, J. Kinoshita, A. Morinaga, T. Keii, J. Polym. Sci. 1975, 13, 2491. There, it arises from a 2.1 olefin insertion, which is stereocontrolled by the configuration of the secondary chain end: A. Zambelli, G. Allegra, Macromolecules 1980, 13, 42.

[129] a) Previously prepared by host-guest inclusion polymerization of 2-methyl1,3-pentadiene and subsequent hydrogenation: M. Farina, G. Di Silvestro P. Sozzani, Macromolecules 1982, 15, 1451; M. Farina. G. Di Silvestro, P. Sozzani, B. Savaré, ibid. 1985, 18,923 ; G. Silvestro. P. Sozzani, B. Savaré, M. Farina, ibid. 1985, 18, 928; b) stereoerror statistics: M. Farina, G. Di Silvestro, P. Sozzani, ibid. 1993, 26, 946; c) M. Farina. G. Di Silvestro, A. Terragni, Macromol. Chem. Phys. 1995, 196, 353.

[130] Polymers with microstructures intermediate between isotactic and atactic structures, which resemble the hemiisotactic structures discussed above in being sensitive to monomer concentrations, have also been obtained with other ansa-metallocene catalysts lacking $C_{2}$ or $C_{8}$ symmetry: D. T. Mallin, M. D. Rausch, Y. G. Lin, S. Dong. I. C. W. Chien, J. Am. Chem. Soc 1990. 112, 2030; G. Hidalgo Llinas, S. H. Dong, D. T. Mallin, M. D. Rausch, Y. G. Lin, H. H. Winter, J. C. W. Chien, Macromolecules 1992, 25, 1242; J. C. W. Chien. G. Hildago Llinas, M. D. Rausch. Y. G. Lin. H. H. Winter, J. L. Atwood, S. G. Bott, J. Polym. Sct. Part A 1992, 30, 2601; M. A Giardello, M. S. Eisen, C. L. Stern. T. J. Marks, J. Am. Chem. Soc. 1993, 115, 3326; B. Rieger, R. Fawzi, M. Steimann, Chem. Ber. 1992, 125, 2373; B. Rieger, G. Jani, R. Fawzi, M. Steinmann, Organometallics 1994, 13, 647.

[131] Decreased stereoregularities have recently been observed for polypropylene obtained at low olefin concentrations even with $\mathrm{rac}$-(en)(thind) $\mathrm{ZrCl}_{2} / \mathrm{MAO}$ and other $C_{2}$-symmetric catalysts [69 e]: a) V. Busico, R. Cipullo, J. Am. Chem. Soc. 1994, 116, 9329; V. Busico in ref. [6 h], p. 277; b) G. Balbontin, A. Fait, F. Piemontesi, L. Resconi, H. Rychlicki in Abstr. Internat. Symp. Synthetic, Structural and Industrial Aspects of Stereoselective Polymerization (Ed.: L. Porri), Milan 1994, p. 205; L. Resconi, A. Fait, F. Piemontesi. M. Colonnesi. H. Rychlicki, R. Zeigler, J Am. Chem. Soc. 1995, 117 , in press.

[132] a) N. Herfert, G. Fink, Makromol. Chem. 1992, 193, 1359; b) Makromol Chem. Rapid Commun. 1993, 14, 91; in ref. $[6 \mathrm{e}]$, p. 157 ; c) G. Fink, N. Herferth, P. Montag in ref. [6g], p. 159.

[133] Exchange of a $\mathrm{CH}_{3}$ ligand between the coordination sites of a zirconocene methyl cation: NMR spectroscopic studies $[50 \mathrm{a}, \mathrm{d}, \mathrm{e}]$; calculations by EHMO $[84 \mathrm{~b}]$ and ab initio methods $[85,86,134]$.

[134] E. P. Bierwagen, J. E. Bercaw, W. A. Goddard III, J. Am. Chem. Soc. 1994. II6, 1481.

[135] ansa-Hafnocene catalysts, such as $\mathrm{MAO}$-activated (en)(ind) ${ }_{2} \mathrm{HfCl}_{2}$ and (en)(thind) ${ }_{2} \mathrm{HfCl}_{2}$ have similar stereoselectivities as their $\mathrm{Zr}$ analogues [118 a, b, $119 \mathrm{~g}]$ : A. Toyota, T. Tsutsui, N. Kashiwa, J. Mol. Catal. 1989, 56 , 237; M. Kioka, T. Tsutsui, T. Ueda, N. Kashiwa, Stud. Surf. Sci. Calal. 1990, 56,483 .

[136] a) K. Soga, T. Shiono, S. Takemura, W. Kaminsky. Makromol. Chem. Rapid Commun. 1987, 8. 305; b) A. Grassi, A. Zambelli, L. Resconi, E. Albizzati, R. Mazzocchi, Macromolecules 1988, 21, 617; A. Grassi, P. Ammendola, P. Longo, E. Albizzati, L. Resconi, R. Mazzocchi, Gazz. Chim. Ital. 1988, 118, 539 ; c) T. Tsutsui, A. Mizuno, N. Kashiwa, Makrontol. Chem. 1989, 190. 1177; d) T. Asakura, N. Nakayama, M. Demura, A. Asano, Macromolecules 1992. 25,4876 .

[137] a) K. Hortmann, H. H. Brintzinger, New J. Chem. 1992. 16, 51: b) P. Burger, K. Hortmann, H. H. Brintzinger, Makromol. Chem. Macromol. Symp. 1993 , 66. 127.

[138] a) P. Longo, A. Grassi. C. Pellecchia, A. Zambelli, Macromolecules 1987, 20 1015; b) A. Zambelli, C. Pellecchia, L. Oliva, Makromol. Chem. Macromol. Symp. 1991, 48/49, 297; c) A. Zambelli, C. Pellecchia in ref. [6e], p. 1.

[139] a) P. Corradini, G. Guerra, M. Vacatello, V. Villani, Gazz. Chim. Ital. 1988 118,173 ; P. Corradini, V. Busico, G. Guerra in ref. [6 b] p. 337; b) L. Cavallo G. Guerra, L. Oliva, M. Vacatello, P. Corradini, Polym. Commun. 1989, 30. 16: c) V. Venditto, G. Guerra, P. Corradini, R. Fusco, Polymer 1990. 31, 530; d) L. Cavallo, P. Corradini, G. Guerra, M. Vacatello, ibid. 1991, 32, 1329; e) Macromolecules 1991. 24. 1784; f) L. Cavallo, G. Guerra. M. Vacatello, P. Corradini, Chirality 1991, 3, 299; g) P. Corradini, G. Guerra, Prog. Polym. Sci. 1991, 16, 239; h) P. Corradini, V. Busico, L. Cavallo, G. Guerra, M. Vacatello, V. Venditto, J. Mol. Catal. 1992, 74, 433; i) P. Corradini in ref. [6e]. p. 11; j) G. Guerra, L. Cavallo, V. Venditto, M. Vacatello, P. Corradini. Makromol. Chem. Macromol. Symp. 1993.69, 237; k) (j. Guerra, L. Cavallo, G. Moscardi, M. Vacatello, P. Corradini, J. Am. Chem, Soc. 1994, /16, 2988 ; 1) P. Corradini, G. Guerra, L. Cavallo, G. Moscardi, M Vacatello in ref. [6g] p. $237 ; \mathrm{m}) \mathrm{G}$. Guerra, P. Corradini, L. Cavallo, M. Vacatello in ref. $[6 \mathrm{~h}]$, p. 307 .

[140] T. Asanuma, Y. Nishimori. M. Ito, T. Shiomura, Mokromol. Chem. Rapid Commun. 1993, 14, 315: ibid. 1994, 15, 723 . 
[141] Weak direct interactions between the olefin substituent and the chiral ligand framework appear to reinforce this olefin orientation for an isospecific ansametallocene catalyst. while opposing it for a syndiospecific catalyst: P. Longo, A. Proto, A. Grassi, P. Ammendola, Macromolecules 1991, 24, 4624.

[142] P. Pino, P. Cioni, J. Wei, J. Am. Chem. Soc. 1987, 109.6189: P. Pino, P. Cioni. M. Galimberti, J. Wei, N. Piccolrovazzi in ref. [6b] , p. 269.

[143] a) W. Kaminsky. H. Lüker, Makromol. Chem. Rapid Commun. 1984, 5, 225 b) W. Kaminsky, A. Ahlers, N. Möller-Lindenhof, Angew. Chem. 1989, 101, 1304; Angew. Chem. Int. Ed. Engl. 1989, 28, 1216; W. Kaminsky, A. Ahlers, O. Rabe. W. König in Proc. 4. Symp. Organic Synthesis via Organometallics 1992 (Eds.: D. Enders, H. J. Gais, W. Keim), Vieweg, Braunschweig, 1993 p. 151 .

[144] a) E. B. Coughlin, J. E. Bercaw. J. Am. Chem. Soc. 1992. 114. 7606; b) B. J. Burger, W. D. Cotter, E. B. Coughlin. S. T. Chacon, S. Hajela, T. A. Herzog. R. O. Köhn, J. P. Mitchell, W. E. Piers, P. J. Shapiro, J. E. Bercaw in ref. [6 g] p. 317.

[145] M. Leclere, H. H. Brintzinger, J. Am. Chem. Soc. 1995, 117, 1651

[146] Appropriate corrections have to be made for the stereoselectivity of the first olefin insertion into the $\mathrm{Zr}-\mathrm{H}$ bond [147], which affects the resulting diastereomer ratios in a sense opposite for cis- and trans-deuterated olefins.

[147] P. Pino, M. Galimberti, J. Organomet. Chem. 1989, 370, 1; P. Pino, M. Galimberti. P. Prada, G. Consiglio, Makromol. Chem. 1990, 191, 1677; R. Waymouth. P. Pino. J. Am. Chem. Soc. 1990. 112, 4911

[148] W. Röll, L. Zsolnai, G. Huttner, H. H. Brintzinger, J. Organomet. Chem. 1987. 322,$65 ; \mathrm{J}$. A. Ewen, personal communication.

[149] J. A. Vol.y, M. L. H. Green, I. M. Gardiner, K. Prout, J. Chem. Soc. Dalton Trans. 1991, 2207

[150] a) M. E. Huttenloch, J. Diebold, U. Rief, H. H. Brintzinger, A. M. Gilbert, T. J. Katz, Organometallics 1992, 11,$3600 ;$ M. E. Huttenloch. Dissertation, Universität Konstanz, 1994; b) W. Mengele, J. Diebold, C. Troll, W. Röll, H. H. Brintzinger. Organometallics 1993, 12.1931: W. Mengele, Dissertation. Universität Konstanz. 1993

[151] a) J. C. W. Chien. J. C. Vizzini, W. Kaminsky, Makromol Chem. Rapid Commun. 1992, 13, 479; b) J. C. Vizzini, J. C. W. Chien, G. N. Babu, R. A. Newmark, J. Polvm. Sci. Parl A 1994, 32, 2049 ; c) J. C. W. Chien. W. Song, M. D. Rausch, ibid. 1994, 32, 2387

[152] H. J. R. de Boer, B. W. Royan, J. Mol. Catal. 1994, 90, 171

[153] a) G. Natta, P. Pino, G. Mazzanti, P. Corradini. U. Giannini, Rend. Accad. naz, Lincei Cl. Sci. Fis. Mat. Nat. Rend. (VIII) 1955. 19. 397: P. Pino, F. Ciardelli, G. P. Lorenzi, G. Natta, J. Am. Chem. Soc. 1962, 84. 1487; P. Pino, F. Ciardelli, G. Montagnoli, J. Polvm. Sci. Part C 1969, 16, 3256: C. G. Overberger, G. Khattab, J. Polym. Sci. Polym. Chem. Ed. 1969, 7, 217; Y Atarashi, ibid. 1970, 8. 3359; F. Ciardelli, C. Carlini, G. Montagnoli, Macromolecules 1969, 2, 296; C. Carlini, R. Nocci. F. Ciardelli, J. Polym. Sci. Polym Chem. Ed. 1977, 15, 767; A. Zambelli, P. Ammendola, M. C. Sacchi, P. Locatelli, G. Zannoni, Macromotecules 1983, 16, 341: A. Zambelli, P. Ammendola. A. J. Sivak, ibid. 1984, 17,461: A. Zambelli. P. Ammendola, P. Locatelli, M. C. Sacchi, ibid. 1984, 17, 977: P. Ammendola, G. Guerra, V. Villani. Makromol. Chem. 1984, 185, 2599; P. Corradini, G. Guerra, V. Villani, Macromolecules 1985, 18,1401; A. Zambelli, P. Ammendola, P. Longo, A Grassi, Gazz. Chim. Ital. 1987, 117, 579; A. Zambelli, A. Proto, P. Longo in ref. $[6 \mathrm{~g}]$, p. $217 ;$ b) for the stereochemistry of the polymers obtained from 4-methyl-1-hexene with the syndiospecific catalyst $\mathrm{Me}, \mathrm{C}(\mathrm{Cp})$ (9-fluorenyl) $\mathrm{ZrCl}_{2} / \mathrm{MAO}[116 \mathrm{~d}-\mathrm{g}]$ cf. A. Zambelli, A. Grassi, M. Galimberti, G. Perego, Makromol. Chem. Rapid Commun. 1992, 13,269, 467; c) a polymerization in which one of the olefin enantiomers is incorporated into a polymer at a higher rate than its antipode has been termed "stereo-elective": P. Pino, F. Crardelli, G. P. Lorenzi, J. Polvm. Sci. Part C 1962, 4. 21; F. Ciardelli, C. Carlini, A. Altomare in ref. [3c], p. 448.

[154] Polymerization of 3-methyl-1-butene by the syndiospecific catalyst $\mathrm{Me}_{2} \mathrm{C}(\mathrm{Cp})(9-$ fluorenyl $) \mathrm{ZrCl}_{2} / \mathrm{MAO}[116 \mathrm{~d}-\mathrm{g}]$ has been reported by $\mathrm{Kashiwa}$ and co-workers (Jap. Pat. Appl. 338220 to Mitsui Toatsu Chem. Inc.); low activities for the polymerization of 3-methyl-1-butene and 3-methyl-1-pentene have been observed with the catalyst $\mathrm{Me}_{2} \mathrm{Si}$ (benzind) ${ }_{2} \mathrm{ZrCl}_{2} / \mathrm{MAO}$ $[120 \mathrm{~d}]$.

155] C. Pellecchia, P Longo, A Grassi, P. Ammendola, A Zambelli, Makromol. Chem. Rapid Commun. 1987, 8, 277; P. Longo, A. Grassi, A. Proto, P. Ammendola, Macromolecules 1988, 21, 24; A. Zambelli, C. Pellecchia, L. Oliva, ibid. 1989, 22, 2129; A. Zambelli, C. Pellecchia, L. Oliva, P. Longo, A. Grassi, Makromol. Chem. 1991. 192. 223.

[156] T. Tsutsui, N. Kashiwa. A. Mizuno, Makromol. Chem. Rapid Commun. 1990, 11, 565: M. Kashiwa, M. Kioka, Polym. Mat. Sci, Eng, 1991 64, 43; M. Kioka, A. Mizuno, T. Tsutsui, N. Kashiwa in ref. [6c], p. 72 .

[157] a) V. Busico. R. Cipullo. P. Corradini, Makromol. Chem. Rapid Commun. 1992, 13, 15; b) ibid. 1992, 13, 21; c) ibid. 1993, 14, 97.

[158] A recent molecular modeling study finds that an agostic $\mathrm{Zr}-\mathrm{C}-\mathrm{H}(\mathrm{x})$ interaction is impossible in the transition state for the insertion of propene into a secondary $\mathrm{Zr}-\mathrm{alkyl}$ unit $[139 \mathrm{k}, \mathrm{l}]$; this might be an explanation for the low rate of this reaction.
[159] B. M. Novak, R. H. Grubbs, J. Am. Chem. Soc. 1988, 110, 960, 7542; H. Grubbs in Proceedings 3. Symposium on Organic Syntheses via Organometallics 1990 (Eds. : K. H. Dötz, R. W. Hoffmann), Vieweg, Braunschweig, 1991 p. 1.

[160] K. Knoll, R. R. Schrock. J. Am. Chem. Soc. 1989, 111, 7989: R. S. Saunders, R. E. Cohen. R. R. Schrock, Macromolecules 1991, 24, 5599; H. H. Fox. R. R. Schrock. Organometallics 1992, 11, 2763.

[161] a) O. W. Webster, W. R. Hertler, D. Y. Sogah. W. B. Farnham, T. V. RajanBabu, J. Am. Chem. Soc. 1983, 105, 5706; O. W. Webster, Science 1991, 251 887 ; b) S. Collins, D. G. Ward, J. Am. Chem. Soc. 1992, 114, 5460

[162] Polyethenes with $M_{\mathrm{w}} / M_{\mathrm{n}}$ values of ca. 1.1 have been obtained at temperatures between -20 and $-60^{\circ} \mathrm{C}$ with reaction systems containing $\mathrm{CpTa}$ (butadiene) $\mathrm{Me}_{2}$ or its heptamethyl analogue in the presence of $\mathrm{MAO}: \mathrm{K}$. Mashima. S. Fujikawa, A. Nakamura, J. Am. Chem. Soc. 1993, 115, 10990; J. Chem. Soc. Chem. Commun, 1994, 1623.

[163] G. Natta, P. Corradini, M. Cesari, Rend. Accad. naz. Lincei Cl. Sci, Fis. Mat. Nat. 1956, 21, 365

[164] E. J. Addink, J. Beintema, Polymer 1961, 2, 185; A. Turner-Jones, J. M. Aizlewood, D. R. Beckett, Makromol. Chem. 1964, 75, 134; D. R. Morrow, J. Macromol. Sci. Part B 1969, 3, 53; A. Turner-Jones, Polymer 1971, 12, 487 G. P. Giuidetti, P. Busi, 1. Giulianelli, R. Zannetti, Eur. Polym. J. 1983, 19 757; V. Busico, P. Corradini, C. De Rosa, E. Di Benedetto, ibid. 1985, 21, 239; M. Avella, E. Martuscelli, G. Della Volpe, A. Segre, E. Rossi, T. Simonazzi, Makromol. Chem. 1986, 187, 1927.

[165] a) B. Lotz, S. Graff, J. C. Wittmann, J. Polym. Sci. Part B 1986, 24, 2017; b) B. Lotz, S. Graff, C. Straupé. J. C. Wittmann, Polymer 1991, 32, 2902.

[166] a) S. Brückner. S. V. Meille, Nature (London) 1989, 340,455; b) S. V. Meille S. Brückner, W. Porzio, Macromolecules 1990, 23, 4114; c) S. Brückner, S. V Meille, P. Sozzani, G. Torri, Makromol. Chem. Rapid Commun. 1990, 11, 55; d) S. Brückner, S. V. Meille, V. Petraccone, B. Pirozzi, Prog. Polym. Sri. 1991 , 16, 361 ; S. V. Meille. D. R. Ferro, S. Brückner, Polym. Pepr. (Am. Chem. Soc. Dir. Polym. Chem.) 1992, 33, 268; S. V. Meille. D. R. Ferro, S. Brückner in ref. $[6 \mathrm{~h}]$, p. 499 ; e) structure of the $\beta$-modification: S. V. Meille, D. R Ferro, S. Brückner, A. J. Lovinger, F. J. Padden, Macromolecules 1994, 27, 2615

[167] a) A. Marigo, C. Marega, R. Zannetti, G. Paganetto, E. Canossa, F. Coletta F. Gottardi, Makromol. Chem. 1989, 190, 2805; b) A. Marigo, C. Marega, R Zannetti. G. Paganetto, S. Schmidt, H. G. Zachmann, ibid. 1990, 191, 1967 c) A. Marigo, C. Marega, R. Zannetti, A. Celli, G. Paganetto, Macromol Rapid Commun. 1994, 15, 225.

[168] As the mean length of isotactic sequences approaches a value of $n_{\text {iso }} \approx 100$ polypropene tends to crystallize predominantly in the $x$-modification $[69 \mathrm{~b}$, d]

[169] a) T. J. Burkhardt, M. Murata, R. J. Vaz in ref. [6h], p. 321; b) K. B. Sinclair, in ref. [6d]

[170] a) G. Natta, M. Peraldo, G. Allegra, Makromol Chem. 1964, 75, 215; b) P. Corradini, G. Natta, P. Ganis, P. A. Temussi, J. Polym. Sci. 1967, C-16, 2477

[171] a) B. Lotz. A. J. Lovinger, R. E. Cais, Macromolecules 1988, 2f, 2375; A. J Lovinger, B. Lotz, D. D. Davis, Polymer 1990, 31, 2253; A. J. Lovinger, D. D. Davis, B. Lotz, Macromolecules 1991, 24, 552; A. J. Lovinger, B. Lotz, D. D. Davis, Polym. Preprints 1992, 33, 270; A. J. Lovinger, B. Lotz, D. D. Davis, F. J. Padden Jr., Macromolecules 1993, 26, 3494; G. Balbontin, D. Dainelli. M. Galimberti, G. Paganetto, Makromol. Chem. 1992, 193, 693; P. Sozzani. R. Simonutti, M. Galimberti, Macromolecules 1993, 26, 5782; b) J. RodriguezArnold, A. Zhang, S. Z. D. Cheng, A. J. Lovinger, E. T. Hsieh, P. Chu, T. W Johnson, K. G. Honell, R. G. Geerts, S. J. Palackal, G. R. Hawley, M. B Welch, Polvmer 1994, 35, 1884; A. J. Lovinger, B. Lotz, D. D. Davis, M Schumacher, Macromolecules 1994, 27, 6603; W. Stocker, M. Schumacher, S. Graff, J. Lang, J. C. Wittmann, A. J. Lovinger, B. Lotz, ibid. 1994, 27, 6948; M. Schumacher, A. J. Lovinger, P. Agarwal, J. C. Wittmann. B. Lotz, ibid. 1994, 27, 6956; R. Thomann, C. Wang, J. Kressier, S. Jüngling, R. Mülhaupt, Polymer 1995, in press.

[172] Y. Chatani, H. Maruyama, K. Noguchi, T. Asanuma, T. Shiomura, J. Polym Sci. Part C: Polym. Lett. 1990. 28. 393.

[173] a) C. De Rosa, P. Corradini, Macromolecules 1993, 26, 5711; b) F. Auriemma C. De Rosa, P. Corradini. ibid. 1993, 26, 5719.

[174] Since these syndiotactic polypropenes show no regioirregularities and rather high molecular weights $[69 \mathrm{~b}, \mathrm{~d}, 116 \mathrm{e}-\mathrm{f}, 132 \mathrm{~b}, \mathrm{c}]$, the length of stereoregular chain segments, $n_{\mathrm{syn}}$, is primarily limited here by $m m$ triad and single- $m$ dyad stereoerrors.

[175] F. de Candia. R. Russo, V. Vittoria, Makromol. Chem, 1988, 189, 815; S Haftka, K. Könnecke, J. Macromol. Sci. Part B 1991, 30, 319; A. Galambos, M. Wolkowicz, R. Zeigler, M. Galimberti, Polym. Mat. Sci. Eng. 1991, 64, 45 A. Galambos, M. Wolkowicz, R. Zeigler in ref. [6c], p. 104; G. Balbontin, D. Dainelli, M. Galimberti, G. Paganetto, Makromol. Chem. 1992, 193, 693; P. Sozzani, R. Simonutti, M. Galimberti, Macromolecules 1993, 26, 5782

[176] a) P. J. T. Tait, 1. G. Berry in Comprehensive Polymer Science, Vol. 4 (Eds G. C. Eastmond, A. Ledwith. S. Russo, P. Sigwalt), Vol. 4, Pergamon Press, Oxford, 1989, p. 575; b) Encyclopedia of Polymer Science and Engineering (Eds.: H. F. Mark, N. B. Bikales, C. G. Overberger, G. Menges, J. I. Kroschwitz). Vol. 6, John Wiley \& Sons, New York 1986, p. 429 (LLDPE) p. 522 (EPDM); c) ibid., Vol. 13, 1988. p. 500 
[177] a) C. P. Guidetti, P. Busi, I. Giulianelli. R. Zannetti, Eur, Polym. J. 1983, 19 757; b) V. Busico, P. Corradini, C. De Rosa, E. Di Benedetto, ibid. 1985, 21 239: c) M. Avella. E. Martuscelli, G. D. Volpe, A. Segre. E. Rossi, T. Simonazzi. Makromol. Chem. 1986, 187, 1927: d) D. S. Davis. Proc. Annu. Tech Conf. Reint. Plast. Compos. Inst. Soc. Plast. Ind. 1992, 50, 628; e) J. Zimmermann. J. Macromol. Sci. 1993, B32, 141

[178] a) F. M. Mirabella, Jr., Polym. Mater. Sci. Eng. 1992, 67. 303; b) Polymer 1993, $34.1729 ;$ c) H. Schwager, Kunststoffe 1992, 82, 499; d) L. D'Orazio, C. Mancarella. E. Martuscelli. G. Sticotti. P. Massari. Polymer 1993, 34 3671 .

[179] Elastomers are also available by terpolymerization of ethene, propene, and small amounts of a diene (EPDM); residual double bonds remaining in the Ziegler - Natta polmyerization products are used for their subsequent vulcanization [176].

[180] a) F. R. Mayo, C. Walling. Chem. Rev. 1950, 46, 191; b) A. E. Hamielec J. F. Macgregor, A. Penlidis in Comprehensive Polymer Science, Vol 3 (Eds. G. C. Eastmond. A. Ledwith, S. Russo, P. Sigwalt), Pergamon, Oxford, 1989 p. 17.

[181] Equation $r_{1}=k_{11} k_{12}$ thus pertains to a catalyst center which had previously inserted monomer $1, r_{2}=k_{22} / k_{21}$ to one with monomer 2 as the last inserted unit.

[182] For the metallocene-catalyzed copolymerization of ethene and 1-hexene Fink and Herfert observed deviations from this "terminal model"; these author report that the probabilities of inserting either one of the comonomers depend on the last two previously inserted units ("penultimate effect"), ref. [132d] N. Herfert, G. Fink. Poltm. Mater. Sci. Eng. 1992. 67, 31: N. Herfert, P. Montag, G. Fink, Makromol. Chem. 1993. 194, 3167; N. Herfert, Dissertation. Universität Düsseldorf, 1992; cf. also ref. [69e]

[183] In the case of $r_{1} r_{2}=1$, the probability of inserting either monomer is independent of the last inserted unit; the comonomer distribution along each chain will then correspond to a Bernoullian random distribution.

[184] a) S. van der Ven, Studies in Polymer Science, Vol. 7, Dekker. New York, 1989 221: b) Y. V. Kissin in Handhook of Polymer Science and Technology (Ed. N. P. Cheremisinoff), Marcel Dekker. New York. 1989, 1, p. 103.

[185] a) H. N. Cheng, Polm. Mater. Sci. Eng. 1992. 67. 61; b) Y. V. Kissin. T. E. Nowlin. R. 1. Mink, Macromolecules 1993, 26, 2151: Y. V. Kissin in ref. [6h] p. $113 ;$ c) M. W. van der Burg. J. C. Chadwick, O. Sudmeijer. H. J. A. F Tulleken. Makromol. Chem. Theory Simul. 1993, 2, 399.

[186] L. Wild, C. Blatz, Polym. Mater. Sci. Eng. 1992, 67, 153; M. G. Pigeon, A. Rudin, I. Appl. Polym. Sci. 1994, 5t, 303.

[187] a) T. Usami. Y. Gotoh, S. Takayama, Macromolecules 1986, 19, 2722; b) F. Defoor, G. Groeninckx, P. Schouterden, B. van der Heijden, Polymer 1992. 33. 3878: c) A. A. Montagna, J. C. Floyd, Proc. MetCon Houston 1993. 172 .

[188] a) W. Kaminsky, M. Miri, J. Polym. Sci. Polym. Chem. Ed. 1985, 23, 2151: b) M. Miri. Dissertation. Universität Hamburg. 1985; c) W. Kaminsky, Stud. Surf. Sci. Catal. 1986, 25, 293; d) W. Kaminsky, M. Miri, Proc. Int. Symp Relat. Heterog. Homog. Calal.. VNU Science, Novosibirsk, 1986; e) W. Kaminsky, M. Schlobohm, Makromol. Chem. Macromol. Symp. 1986. 4, 103 ; f) W. Kaminsky, A. Bark. R. Spiehs, N. Möller-Lindenhof, S. Niedboda in ref. [6 b]. p. 291 : g) H. Drögemüller, K. Heiland. W. Kaminsky, ibid., p. 303 h) W. Kaminsky, H. Drögemüller, Makromol. Chem. Rapid Commun. 1990 11, 89: i) K. Heiland. W. Kaminsky, Makromol. Chem. 1992, 193, 601.

[189] a) D. van der Sanden, R. W. Halle, Proc. Anmu. Tech. Cont Reinf. Plast. Compos. Inst. Soc. Plast. Ind. 1992, 50, 154; b) B. C. Trudell, C. S. Speed, F. C Stehling. ihid. 1992,50,613; c) G. W. Knight, S. Lai in ref. [6d], p. $226 ;$ d) A. B. Furtek, Proc. MetCon Houston 1993, 126; e) J. Koivumäki. J. V. Seppälä, Polym. Commun. 1993, 34, 1958.

190] I. A. Ewen, Stud. Surf. Sci. Catal. 1986, 25, 271.

[191] M. Galimberti, E. Albizatti. L. Abis, G. Bacchilega, Makromol. Chem. 1991, 192. 2591.

[192] R. Mani, C. M. Burns, Polvmer 1993, 34. 1941.

[193] Formation of LLDPE by simultaneous oligomerization of ethene with a nickel catalyst and polymerization by an ansa-metallocene catalyst: $\mathrm{Ch}$ Denger, U. Haase, G. Fink, Makromol. Chem. Rapid Commun. 1991, 12, 697.

[194] a) J. C. W. Chien. D. He, J. Polym. Sci. Part A 1991, 29.1585; b) ibid. 1991 29, 1595: c) ibid. 1991, 29.1603; d) ibid. 1991, 29.1609; e) J. C. W. Chien, T. Nozaki, J. Polm. Sci. Part A: Polym. Chem. 1993, 31, 227; f) J. C. W. Chien. B. Xu, Makromol. Chem. Rapid Commun. 1993, 14, 109.

$195]$ T. Uozumi. K. Soga, Makromol. Chem. 1992, 193, 823.

[196] Ethene-olefin copolymers prepared with catalysts of this type have been commercialized by Dow Chemicals ("Insite"-LLDPE) and by Exxon ("Exxact"-LLDPE): R. D. Leaversuch, Modern Plastics International November 1993, 12; ibid. October 1993, 8: Plastics Week March 22. 1993, 3; G. Lancaster, Eur. Chem. New's 1993, 35; Eur. Plast. New's 1993, 19 Modern Plasics International October 1993, 99: Plastic Week November 8. 1993. 6 .

[197] V. Busico, L. Mevo, G. Palumbo, A. Zambelli, Makromol. Chem. 1983, 184 , 2193: A. Zambelli. A. Grassi, M. Galimberti, R. Mazzocchi, F. Piemontesi, Makromol. Chem. Rapid Commun. 1991, 12.523.
[198] a) S.-Y. Lai, J. R. Wilson. G. W. Knight, J. C. Stevens. WO-93;08221, 1992; b) J. Stevens, Proc. MetCon Houston 1993, 157; in ref. [6f], p. 277; c) K. W Swogger, Che-I Kao in ref. [6d], p. 13; K. W. Swogger. G. M. Lancaster in ref. [6 h], p. 285; d) B. Story, Proc. MetCon Houston 1993, 111

[199] a)L. Oliva, P. Longo, A. Grassi, P. Ammendola. C. Pellecchia. Makromol. Chem. Rapid Commun. 1990, 11, 519; b) P. Longo. A. Grassi, L. Oliva, Makromol. Chem. 1990, 191, 2387; c) G. Ricci, S. Italia, A. Giarrusso, L. Porri. J. Organomet. Chem. 1993, 451, 67; d) L. Porri. A. Giarrusso. G. Ricci in ref. [6e], p. 231.

[200] K. Soga, J. R. Park. T. Shiono. Polym. Commun. 1991, 10, 310

[201] C. Pellecchia, A. Proto, A. Zambelli, Macromolecules 1992. 25, 4450; A Zambelli, C. Pellecchia, Proc. MetCon Houston 1993. 378

[202] P. Aaltonen, J. Seppälä, Eur. Polym. J. 1994, 30.683.

[203] H. Turner, G. Hlatky WO-9 //12285, 1991

[204] H. Yasuda, H. Yamamoto, K. Yokota, S. Miyake. A. Nakamura, J. Am Chom Sac 1992 114,4908-b) H Yasuda, N Furo, H Yamamoto A Nakamura, S. Miyake, N. Kibino, Macromolecules 1992, 25, 5115; H. Yasuda, H. Yamamoto, M. Yamashita, K. Yokota, A. Nakamura. S. Miyake, Y. Kai, N. Tanehisa, ibid. 1993, 26, 7134: H. Yasuda. E. Ihara. S. Yoshioka, M. Nodono, M. Morimoto, M. Yamashita in ref. [6f], p. 237

[205] H. N. Cheng, D. A. Smith. Macromolecules 1986, 19. 2065.

[206] a) J. V. Seppälä, J. Koivumäki, X. Liu, J. Polym. Sci. Part A : Polvm. Chem. 1993, 31, 3447; b) J. Koivumäki, J. V. Seppälä, Macromolecules 1993, 26. 5535.

[207] a) W. Kaminsky. A. Bark, M. Arndt. Makromol. Chem. Macromol. Symp. 1991, 47. 83; b) W. Kaminsky, A. Bark. I. Däke in ref. [6a], p. 425; c) W Kaminsky, R. Spiehl, Makromol. Chem. 1989, 190. 515; W. Kaminsky, Shokubai 1991, 33, 536; W. Kaminsky, A. Noll in ref. [6g], p. 149.

[208] a) S. Collins, W. M. Kelly, Macromolecules 1992, 25, 233; W. M. Kelly, N. J. Taylor, S. Collins, ibid. 1994, 27, 4477; Proc. MelCon Houston 1994, 1. b) The rans-connection of part of the 1,3-cyclopentandiyl units observed in these hydroligomers is not in accord with the stereochemistry of normal olefin insertions: its mechanism deserves further study.

[209] A strictly alternating insertion-isomerization mechanism has been determined for nickel-based olefin polymerization catalysts: V. M. Möhring, G. Fink, Anger. Chem. 1985, 97, 982: Angew. Chem. Int. Ed. Engl. 1985, 24, 1001; G. Fink, V. Möhring. A. Heinrichs, C. Denger in ref. [6c], p. 88.

[210] M. Brekner. F. Osan, J. Rohrmann. M. Antberg. Eur. Pat. Appl. 1992 485893.

[211] X. Yang. L. Jia, T. J. Marks, J. Am. Chem. Soc. 1993. 115, 3392.

[212] Cyclopolymerization of 1,5-hexadiene with heterogeneous Ziegler catalysts: C. S. Marvel, J. K. Stille, J. Am. Chem. Soc. 1958, 80, 1740; H. S. Makowski B. K. Shim. Z. W. Wilchinsky, J. Polym. Sci. Part A 1964, 2. 5149; H. N. Cheng. N. P. Khasat, J. Appl. Polvm. Sci. 1988, 35, 825.

[213] L. Resconi, G. W. Coates, A. Mogstad, R. M. Waymouth, J. Macromol. Sci. Chem. Ed. 1991, A 28, 1225.

[214] G. W. Coates, R. M. Waymouth, J. Am. Chem. Soc: 1991, 113, 6270; J. Mol. Catal. 1992, 76, 189

[215] M. R. Kesti, R. M. Waymouth, J. Am. Chem Soc. 1992. 114, 3565

[216] L. Cavallo, G. Guerra, P. Corradini, L. Resconi, R. M. Waymouth, Macromolecules 1993, 26, 260.

[217] G. W. Coates, R. M. Waymouth, J. Am. Chem. Soc. 1993, 115, 91; S. H Miller. R. M. Waymouth in ref. [6g], p. 441; G. Ruiz de Ballesteros, F. Auriemma, L. Cavallo, V. Venditto, G. Guerra, L. Resconi. R. M. Waymouth in Abstr. Internat. Symp. Stereoselective Polymerization, (Ed.: L. Porri), Milan, 1994 , p. 282.

[218] M. R. Kesti. G. W. Coates, R. M. Waymouth. J. Am. Chem. Soc. 1992, 114 9679

[219] K. Stein, R. M. Waymouth, unpublished results

[220] Y. Doi, T. Keii, Adv. Polvm. Sci. 1986, 73/74, 201: Y. Doi. S. Suzuki, F. Nozawa, K. Soga, Stud. Surf. Sci. Catal. 1986, 25, 257; Y. Doi. S. Suzuki. G Hizal, K. Soga, Transition Metal Catalyzed Polymerizations (Ed.: R. P. Quirk), Cambridge University Press, Cambridge, 1988, p. 182; Y. Doi, N Tokuhiro, M. Nunomura, H. Miyake, S. Suzuki, K. Soga in ref. [6 b], p. 379

[221] T. Shiono, K. Yoshida. K. Soga, Makromol. Chem. Rapid Commun. 1990. 1t 169.

[222] R. Mülhaupt. T. Duschek, B. Rieger, Makromol. Chem. Macromol. Symp $1991,48 / 49,317$

[223] T. Shiono, K. Soga, Mukromol. Chem. Rapid Commun. 1992, 13, 371

[224] a) T. Duschek. R. Mülh:supt, Polym. Prepr. 1992.33,170: T. Duschek, Dissertation, Universität Freiburg, 1993; b) R. Mülhaupt, T. Duschek, D. Fischer. S. Setz. Polym. Adv' Technol. 1993, 4, 439; R. Mülhaupt. T. Duschek. J. Rösch. ibid. 1993, 4, 465

[225] a) T. N. Doman, C. R. Landis, B. Bosnich, J. Am. Chem. Soc, 1992, 114, 7264 T. K. Hollis, J. K. Burdett, B. Bosnich, Organometallics 1993, 12, 3385: B Bosnich. Chem. Soc. Rev. 1994. 387; T. N. Doman, K. T. Hollis, B. Bosnich J. Am. Chem. Soc. 1995, 17, 1352; b) K. Angermund, A. Hanuschik, M. Nolte in ref. $[6 \mathrm{~g}]$, p. 251 ; c) U. Höweler, R. Mohr, M. Knickmeier, G. Erker, Organometallics 1994, 13,2380.

[226] M. Kaminaka, K. Soga. Makromol. Chem. Rapid Commun. 1991, 12. 367; K Soga, M. Kaminaka, ibid. 1992, 13, 221; ibid. 1994, 15, 593. 
[227] H. F. Herrmann, B. Bachmann, B. Hierholzer, W. Spaleck, Eur. Pal. Appl. 1993. 563917 A 1; T. J. Burkhardt, M. Murata, W. B. Brandley, WO-93/23439. 1993.

[228] K. D. Hungenberg, J. Kerth, F. Langhauser, P. Müller in ref. [6f], p. 373; K D. Hungenberg, J. Kerth, F. Langhauser, B. Marczinke, R. Schlund in ref. $[6 \mathrm{~g}]$, p. 363 .

[229] Particle forming kinetics for homogeneous and heterogeneous polymerization catalysts: H. F. Herrmann, L. L. Böhm, Polym. Commun. 1991, 32, 58.

[230] The overall productivities of these heterogenized metallocene catalysts, per $g$ of support and catalyst, are about $50 \%$ of those of recent heterogeneous, $\mathrm{MgCl}_{2}$-supported catalysts [228].
[231] a) E. Otto, Kunststoffe 1993,83, 188; b) K. Wagemann, Nachr. Chem. Tech. Lab. 1994, 42. 28

[232] T. Tsutsui, N. Kashiwa, Polymer 1991, 32, 2671.

[233] W. Kaminsky, F. Renner, Makromol. Chem. Rapid Commun. 1993, 14, $239 ;$ W. Kaminsky in ref. [6h], p. 203.

[234] K. Soga, H. J. Kim, T. Shiono, Makromol. Chem. Rapid Commun. 1994, 15, 139; Makromol. Chem. Phys. 1994, 195, 3347; K. Soga in ref. [6f], p. 307; K. Soga, M. Kaminaka, H. J. Kim, T. Shiono in ref. $[6 \mathrm{~g}]$, p. 333; K. Soga in ref. [6h], p. 249.

[235] R. Grubbs, C. P. Lau, R. Cukier, C. Brubaker, Jr., J. Am. Chem. Soc. 1977, 99, 4517; C. U. Pittman, Jr., Polymer-supported Reactions in Organic Synthesis (Eds.: P. Hodge, D. C. Sherrington), Wiley, New York, 1980, p. 24. 